\title{
IMPACTO AMBIENTAL NA ÁREA DO ATERRO SANITÁRIO E INCINERADOR DE RESÍDUOS SÓLIDOS DE RIBEIRÃO PRETO, SP: Avaliação dos níveis de metais pesados.
}

Tese apresentada à Escola de Enfermagem de Ribeirão Preto da Universidade de São Paulo, para concorrer ao Título de Doutor, pelo Programa de PósGraduação de Enfermagem em Saúde Pública - Linha de Pesquisa: Saúde Ambiental.

Ribeirão Preto 2002 


\title{
IMPACTO AMBIENTAL NA ÁREA DO ATERRO SANITÁRIO E INCINERADOR DE RESÍDUOS SÓLIDOS DE RIBEIRÃO PRETO, SP: Avaliação dos níveis de metais pesados.
}

Susana Inés Segura Muñoz

\begin{abstract}
Tese apresentada à Escola de Enfermagem de Ribeirão Preto da Universidade de São Paulo, para concorrer ao Título de Doutor, pelo Programa de PósGraduação de Enfermagem em Saúde Pública - Linha de Pesquisa: Saúde Ambiental.
\end{abstract}

Orientadora: Profa. Dra. Angela Maria Magosso Takayanagui

Ribeirão Preto 


\section{FICHA CATALOGRÁFICA}

Preparada pela Biblioteca Central do Campus Administrativo de Ribeirão Preto / USP

Segura Muñoz, Susana Inés

Impacto ambiental na área do Aterro Sanitário e Incinerador de Resíduos Sólidos de Ribeirão Preto, SP: avaliação dos níveis de metais pesados. 131 p. : il. ; $30 \mathrm{~cm}$

Tese de Doutorado, apresentada à Escola de Enfermagem de Ribeirão Preto/USP - Depto de Enfermagem Materno-Infantil e Saúde Pública.

Linha de Pesquisa: Saúde Ambiental

Orientadora: Takayanagui, Angela Maria Magosso

1. Metais Pesados. 2. Resíduos Sólidos. 3. Aterro Sanitário.

4. Incinerador de Resíduos de Serviços de Saúde.

5. Meio Ambiente 
Data de defesa:

Banca Examinadora

Prof. Dr.

Julgamento:

Assinatura:

Prof. Dr.

Julgamento:

Assinatura:

Prof. Dr.

Julgamento:

Assinatura:

Prof. Dr.

Julgamento:

Assinatura:

Prof. Dr.

Julgamento:

Assinatura: 
Ao meu esposo, Victor Hugo, pela compreensão e carinho...

Às minhas filhas, Alicia e Camila, pela alegria, ternura e inocência....

A memória dos meus pais, Alicia e Alfonso, pelo amor, coragem, dedicação e saudade...

Aos meus irmãos...Henry, Lupe e Suli, pelo apoio e complicidade...

Com todo meu amor, é a vocês que dedico este trabalho. 
Trabalho realizado com o apoio de:

- Fundação de Amparo à Pesquisa do Estado de São Paulo - FAPESP, pelo Auxilio à Pesquisa (Processo: $N^{o}$ 99/11064).

- Coordenação de Aperfeiçoamento de Pessoal de Nível Superior - CAPES, pela Bolsa de Demanda Social. 


\section{AGRADECIMENTOS}

À Prof. Dra. Angela Maria Magosso Takayanagui, pela sabia orientação, amizade e confiança incutida para que conduzisse este trabalho. Por ter acreditado nas minhas possibilidades e por ter tantas vezes entendido minhas limitações.

À Profa. Dra. Sylvia Hering, do Setor de Metais do Laboratório de Pediatria do Hospital das Clínicas da Faculdade de Medicina de Ribeirão Preto, pelas brilhantes sugestões oferecidas, além do carinho e amizade, que me foram de fundamental importância.

À Dra Palmira Cupo, do Setor de Metais do Laboratório de Pediatria do Hospital das Clínicas da Faculdade de Medicina de Ribeirão Preto, pela disponibilidade e apoio sempre presentes.

À Biomédica Tânia Maria Beltramini Trevilato, do Setor de Metais do Laboratório de Pediatria do Hospital das Clínicas da Faculdade de Medicina de Ribeirão Preto, por ter acreditado na importância deste trabalho e por ter sido uma colaboradora direta no desenvolvimento analítico deste estudo. Pessoa que revelouse uma extraordinária amiga, pela qual sempre guardarei um amor de irmã.

A Profa. Dra. Cláudia Benedita dos Santos, da Área de Estatística do Departamento de Enfermagem Materno Infantil e Saúde Pública da EERP-USP, pela valiosa assessoria nas análises estatísticas dos dados obtidos neste trabalho.

Ao Engenheiro Mauro Pereira Júnior, Diretor do Aterro Sanitário e Incinerador de Resíduos de Serviços de Saúde do Departamento de Água e Esgoto DAERP, da Prefeitura Municipal de Ribeirão Preto, pela confiança e apoio para o desenvolvimento deste estudo, desde o projeto original.

Ao Engo. Paulo Grecco, pelas valiosas contribuições num momento importante deste estudo.

Ao Engo. Paulo Mano pela colaboração na demarcação geográfica dos ponstos de coleta do material analisado.

Ao Engo. Otávio Cano, pelas importantes contribuições. 
Ao Engo. Luiz Vizaio, da VARIAN INC de São Paulo, pela pronta disposição na colaboração para realização de análises de metais com equipamentos de ultima geração.

Ao Dr Graemer Waller, da Quality Control Technologies Inc. de Queensland, Austrália, pela autorização de nossa participação no controle de certificação interlaboratorial.

Aos alunos, Susan, Ricardo, Vinicius e Ana Carolina, do Curso de Graduação em Enfermagem, pela colaboração na coleta de amostras.

Ás funcionárias Alessandra e Márcia, do Setor de Metais do HCFMRP/USP e às aprimorandas da FUNDAP, Milena, Andresa e Aline, pela colaboração e amizade.

Aos demais funcionários do Laboratório de Pediatria, pela inestimável colaboração em diversas etapas deste estudo, particularmente a acolhida a Isa, Adelina, Betty, Sylvia, Pedro, Helena, Lúcia e Ivonne.

Ao biomédico Carlos Cambrea, do Laboratório de Gastroenterologia do HCFMRP/USP, pelo apoio para a realização de uma etapa da análise de metais em amostras de solo.

Ao Prof. João Alvarez da Costa e à Eng. Cristina Filomena P. R. Pazholato, da Universidade de Ribeirão Preto - UNAERP, pela valiosa colaboração na coleta de amostras de água subterrânea.

Aos professores da EERP/USP, particularmente a todos os docentes do Departamento de Enfermagem Materno-Infantil e Saúde Pública, pelo conhecimento compartilhado.

À Olânia, Adriana, Andréa e Augusto, do Departamento MISP da EERP/USP por toda a colaboração e apoio.

Às funcionárias da Seção de Pós-Graduação da EERP/USP pela colaboração e apoio.

À Deolinda e Maria de Lourdes, da Sala de Leitura Glete de Alcântara, da EERP/USP pelo pronto atendimento às muitas solicitações de minha parte.

Aos funcionários das Seções de Informática e Audiovisual, que muitas vezes auxiliaram na realização deste trabalho, particularmente ao Rogelio, pela presteza e competência. 
Ao pessoal da Seção de Zeladoria da EERP/USP, pela amizade e apoio.

Às bolsistas do Laboratório de Saúde Ambiental de EERP/USP, pela amizade e carinho.

Às pós-graduandas Aparecida, Leila, Maria Isabel, Sueli e Fabiana pelos valiosos momentos compartilhados, pela amizade e apoio.

À Prof. Dra. Yvone Vicente, que teve a sensibilidade de me ajudar num momento decisivo da minha vida, acreditando em mim e me estimulando para o Doutorado. Agradeço a ela e a seus familiares pelas felizes noites de Natal que compartilharam com minha família durante estes anos.

Ao pessoal da Creche Carochinha, que se constituiu na segunda família de minhas filhas, significando um importantíssimo apoio para que eu pudesse me dedicar integralmente ao curso de doutoramento. Meus eternos agradecimentos, pela felicidade propiciada às minhas filhas Alicia e Camila, nessa etapa de sua infância.

À Maria, minha irmã brasileira, sempre presente, pelos cuidados esmerados com minhas filhas e com minha casa durante minhas ausências. Meus extensivos agradecimentos a sua filha Marilene, pela doçura de coração.

Aos meus amigos estrangeiros, pelos momentos compartilhados. Principalmente meu abraço à Orfa, Jorge e Jorgito.

Para todas as pessoas que estiveram comigo durante essa etapa da vida que Deus me permitiu viver... Um beijo no coração. 


\section{SUMÁRIO}

LISTA DE FIGURAS

LISTA DE TABELAS

LISTA DE ABREVIATURAS

RESUMO

SUMMARY

RESUMEN

APRESENTAÇÃO

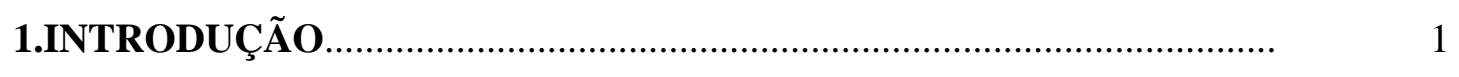

1.1 Resíduos sólidos, definição e classificação................................................... 4

1.2 Sistemas de disposição e tratamento dos resíduos sólidos........................... 7

1.3 Resíduos sólidos urbanos e a contaminação por metais pesados.................. 13

1.4 Efeito toxicológico dos metais pesados no ser humano............................... 16

1.5 Avaliação de risco e os resíduos sólidos........................................................ 21

1.6 Problemática dos resíduos...................................................................... 25

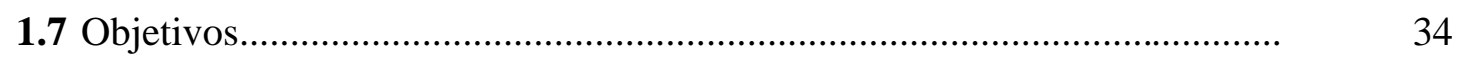

2. MATERIAL E MÉTODOS................................................................ 35

2.1 Delineamento da Pesquisa..................................................................... 35

2.2 Procedimento Metodológico................................................................... $\quad 35$

3. RESULTADOS E DISCUSSÃO ......................................................... 55

3.1 Níveis de metais no solo, raiz e folha....................................................... 55

3.2 Possíveis fatores determinantes da distribuição espacial dos metais............ $\quad 90$

3.3 Variabilidade dos níveis de metais em vegetais......................................... 94

3.4 Metais pesados no líquido percolado........................................................ 98

3.5 Metais pesados em água subterrânea...................................................... 102

3.6 Importância dos valores de referência........................................................... 105 
4. CONCLUSÕES

5. CONSIDERAÇÕES FINAIS.

6. REFERÊNCIAS BIBLIOGRÁFICAS

\section{ANEXOS}

Anexo A - Informe de Situação do Aterro Sanitário, emitido pelo DURSARP, em 1999

Anexo B - Relatórios de Ações de Controle no Incinerador de Resíduos de Serviços de Saúde no Município de Ribeirão Preto

Anexo C - Projeto Topográfico apresentando a localização dos pontos para coleta das amostras

Anexo D - Registro de chuvas do Núcleo de Agronomia da Alta Mogiana, RP/SP (Janeiro-Junho/2000)

Anexo E - Método de extração de metais e metaloides do solo por água regiamétodo de digestão em placa aquecida da Australian Standard Association

Anexo F - Condições analíticas para cada metal

Anexo G - Certificados de participação no controle inter-laboratorial emitido por Quality Control Technologies Pty Ltd., Queensland, Australia.

Anexo H - Banco de dados elaborado a partir dos resultados obtidos das análises laboratoriais

Anexo I - Valores orientadores para solos e águas subterrâneas no Estado de São Paulo (CETESB, 2001) 


\section{LISTA DE FIGURAS}

Fig. 1 Propagação dos efeitos da poluição no meio físico e na biota.

Fig. 2 Esquema de um lixão a céu aberto, com a presença de catadores e animais no local de descarga dos caminhões e acúmulo de chorume na superfície do solo, bem como sua absorção pelas camadas subterrâneas

Fig. 3 Esquema das características de construção de um Aterro Sanitário, mostrando a operacionalização em condições ideais de funcionamento.

Fig.4 Representação simplificada da estrutura de um incinerador mostrando a operacionalização em condições ideais de funcionamento.

Fig. 5 Dinâmica dos metais pesados no solo.

Fig. 6 Mapa de localização do Aterro Sanitário e Incinerador de Ribeirão Preto

Fig. 7 Foto Aérea do Aterro Sanitário e Incinerador de Resíduos Sólidos Urbanos do município de Ribeirão Preto-SP..

Fig. 8 Momento de determinação dos pontos de coleta de amostras de solo e vegetais na área do Aterro Sanitário de Ribeirão PretoSP.

Fig.9 Canaviais limítrofes no sentido Sul do Aterro Sanitário da Cidade de Ribeirão Preto-SP.

Fig.10 Pontos de coleta delimitados para cada matriz segundo sua distribuição espacial.

Fig.11 Materiais utilizados para a coleta de amostras de solo, vegetais, água e chorume no local.

Fig.12 Espectrofotômetro de Absorção Atômica com Forno de Grafite (EAA-FG), Setor de Metais, Laboratório de pediatria e Puericultura do HCRP-FMRP/USP.

Fig.13 Espectrofotômetro de Absorção Atômica com Gerador de Hidretos (EAA-VGA), Setor de Metais, Laboratório de pediatria e Puericultura do HCRP-FMRP/USP.

Fig.14 Espectrofotômetro de Absorção Atômica com Chama (EAAChama), Setor de Metais, Laboratório de Pediatria e Puericultura do HCRP-FMRP/USP.

Fig.15 Padrões certificantes provenientes do laboratório Quality Control Technologies Pty Ltd. Queensland, Austrália.

Fig.16 Distribuição das matrizes que apresentaram diferença estatisticamente significante para Cádmio (Cd), segundo os pontos de coleta (S: solo; R: raiz; F:folha). 
Fig.17 Distribuição das matrizes que apresentaram diferença estatisticamente significante para Cromo $(\mathrm{Cr})$, segundo os pontos de coleta (S: solo; R: raiz; F:folha).....

Fig.18 Distribuição das matrizes que apresentaram diferença estatisticamente significante para Chumbo $(\mathrm{Pb})$, segundo os pontos de coleta (S: solo; R: raiz; F:folha)

Fig.19 Distribuição das matrizes que apresentaram diferença estatisticamente significante para Manganês (Mn), segundo os pontos de coleta (S: solo; R: raiz; F: folha)

Fig.20 Distribuição das matrizes que apresentaram diferença estatisticamente significante para Zinco (Zn), segundo os pontos de coleta (S: solo; R: raiz; F: folha).

Fig.21 Distribuição das matrizes que apresentaram diferença estatisticamente significante para Cobre $(\mathrm{Cu})$, segundo os pontos de coleta (S: solo; R: raiz; F: folha).

Fig.22 Distribuição das matrizes que apresentaram diferença estatisticamente significante para os metais avaliados, segundo os pontos de coleta (S: solo; R: raiz; F: folha)

Fig.23 Mapa dos perfis topográficos da área do Aterro Sanitário e Incinerador de Resíduos Sólidos de Ribeirão Preto, delimitados entre os paralelos $21^{\circ} 10^{\prime}-21^{\circ}{ }^{\circ} 15^{\prime} \mathrm{S}$ e $47^{\circ} 50^{\prime}-47^{\circ} 55^{\prime} \mathrm{W}$, obtidos a partir do mapa do IBGE- folha 23-V-C-I-1 de 1979, escala $1: 50000$.

Fig.24 Declividade da área do Aterro sanitário e Incinerador de Resíduos Sólidos de Ribeirão Preto, a partir dos perfis topográficos da figura anterior

Fig.25 Correlação dos níveis de $\mathrm{Cd}, \mathrm{Cr}$ e $\mathrm{Pb}$ em amostras de raiz e folha e suas correspondentes amostras de solo.

Fig.26 Correlação dos níveis de $\mathrm{Mn}, \mathrm{Zn}$ e $\mathrm{Cu}$ em amostras de raiz e folha e suas correspondentes amostras de solo. 


\section{LISTA DE TABELAS}

Tab. 1 Distribuição das amostras coletadas na área do Aterro sanitário Municipal e da Mata Santa Tereza de Ribeirão Preto...

Tab. 2 Métodos e limites de detecção de metais do Setor de Metais do Laboratório de Pediatria e Puericultura, FMRP/USP. distribuição espacial, expressado em $\mathrm{mg} / \mathrm{Kg}$ para cada matriz......

Tab. 4 Valores críticos de $q$ obtidos na comparação dos valores de cádmio do grupo controle com os valores obtidos das amostras coletadas no limite 0 do Aterro Sanitário.

Tab. 5 Valores críticos de $q$ obtidos na comparação dos valores de cádmio do grupo controle com os valores obtidos das amostras coletadas no limite 50 do Aterro Sanitário.

Tab. 6 Valores críticos de $q$ obtidos na comparação dos valores de cádmio do grupo controle como os valores obtidos das amostras coletadas no limite 100 do Aterro Sanitário.

Tab. 7 Valores críticos de $q$ obtidos na comparação dos valores de cádmio do grupo controle como os valores obtidos das amostras coletadas no limite 200 do Aterro Sanitário.

Tab. 8 Nível de cromo nas amostras de solo, raiz e folha segundo a sua distribuição espacial, expressado em $\mathrm{mg} / \mathrm{Kg}$ para cada matriz......

Tab. 9 Valores críticos de $q$ obtidos na comparação dos valores de cromo do grupo controle com os valores obtidos das amostras coletadas no limite 0 do Aterro Sanitário.

Tab. 10 Valores críticos de $q$ obtidos na comparação dos valores de cromo do grupo controle com os valores obtidos das amostras coletadas no limite 50 do Aterro Sanitário.

Tab. 11 Valores críticos de $q$ obtidos na comparação dos valores de cromo do grupo controle com os valores obtidos das amostras coletadas no limite 100 do Aterro Sanitário.

Tab. 12 Valores críticos de $q$ obtidos na comparação dos valores de cromo do grupo controle com os valores obtidos das amostras coletadas no limite 200 do Aterro Sanitário.

Tab. 13 Nível de chumbo nas amostras de solo, raiz e folha segundo a sua distribuição espacial, expressado em $\mathrm{mg} / \mathrm{Kg}$ para cada matriz.

Tab. 14 Valores críticos de $q$ obtidos na comparação dos valores de chumbo do grupo controle com os valores obtidos das amostras coletadas no limite 0 do Aterro Sanitário.

Tab. 15 Valores críticos de $q$ obtidos na comparação dos valores de chumbo do grupo controle com os valores obtidos das amostras 
Tab.16 Valores críticos de $q$ obtidos na comparação dos valores de chumbo do grupo controle com os valores obtidos das amostras coletadas no limite 100 do Aterro Sanitário.

Tab.17 Valores críticos de $q$ obtidos na comparação dos valores de chumbo do grupo controle com os valores obtidos das amostras coletadas no limite 200 do Aterro Sanitário.

Tab.18 Nível de manganês nas amostras de solo, raiz e folha segundo a sua distribuição espacial, expressado em $\mathrm{mg} / \mathrm{Kg}$ para cada matriz.

Tab. 19 Valores críticos de $q$ obtidos na comparação dos valores de manganês do grupo controle com os valores obtidos das amostras coletadas no limite 0 do Aterro Sanitário.

Tab. 20 Valores críticos de $q$ obtidos na comparação dos valores de manganês do grupo controle como os valores obtidos das amostras coletadas no limite 50 do Aterro Sanitário.

Tab. 21 Valores críticos de $q$ obtidos na comparação dos valores de manganês do grupo controle com os valores obtidos das amostras coletadas no limite 100 do Aterro Sanitário.

Tab. 22 Valores críticos de $q$ obtidos na comparação dos valores de manganês do grupo controle com os valores obtidos das amostras coletadas no limite 200 do Aterro Sanitário.

Tab. 23 Nível de zinco nas amostras de solo, raiz e folha segundo a sua distribuição espacial, expressado em $\mathrm{mg} / \mathrm{Kg}$ para cada matriz.

Tab. 24 Valores críticos de $q$ obtidos na comparação dos valores de zinco do grupo controle com os valores obtidos das amostras coletadas no limite 0 do Aterro Sanitário.

Tab. 25 Valores críticos de $q$ obtidos na comparação dos valores de zinco do grupo controle com os valores obtidos das amostras coletadas no limite 50 do Aterro Sanitário

Tab. 26 Valores críticos de $q$ obtidos na comparação dos valores de zinco do grupo controle com os valores obtidos das amostras coletadas no limite 100 do Aterro Sanitário.

Tab. 27 Valores críticos de $q$ obtidos na comparação dos valores de zinco do grupo controle com os valores obtidos das amostras coletadas no limite 200 do Aterro Sanitário.

Tab. 28 Nível de cobre nas amostras de solo, raiz e folha segundo a sua distribuição espacial, expressado em $\mathrm{mg} / \mathrm{Kg}$ para cada matriz.

Tab. 29 Valores críticos de $q$ obtidos na comparação dos valores de cobre do grupo controle com os valores obtidos das amostras coletadas no limite 0 do Aterro Sanitário.

Tab. 30 Valores críticos de $q$ obtidos na comparação dos valores de cobre 
do grupo controle com os valores obtidos das amostras coletadas no limite 50 do Aterro Sanitário.

Tab. 31 Valores críticos de $q$ obtidos na comparação dos valores de cobre do grupo controle com os valores obtidos das amostras coletadas no limite 100 do Aterro Sanitário.

Tab. 32 Valores críticos de $q$ obtidos na comparação dos valores de cobre do grupo controle com os valores obtidos das amostras coletadas no limite 200 do Aterro Sanitário

Tab. 33 Níveis de metais pesados detectados nas amostras de chorume, segundo sua distribuição espacial, expressado em $\mathrm{mg} / \mathrm{L}$

Tab. 34 Níveis de metais pesados detectados nas amostras de água subterrânea, segundo sua distribuição espacial, expressado em $\mathrm{mg} / \mathrm{L}$ 


\section{LISTA DE ABREVIATURAS}

ABNT

$\operatorname{ALFA}(\alpha)$

ASQ

$\mathrm{C}^{\mathrm{o}}$

$\mathrm{Cd}$

CETESB

CONAMA

$\mathrm{Cr}$

$\mathrm{Cu}$

DAERP

EAA-FG

EAA-VGA

EAA-Chama

EERP

EIA-RIMA

EPA

F

FMRP

HCFMRP

$\mathrm{Hg}$

$\mathrm{HNO}_{3}$

IBGE

L/

$\mathrm{Mn}$

N/

$\mathrm{O} /$

OMS

$\mathrm{Pb}$

PGRSS

$q$

$\mathrm{R}$
-Associação Brasileira de Normas Técnicas

-Nível de Significância Alfa

-Amplitude Semi-Quartílica

-Graus Celsius

-Cádmio

-Companhia de Tecnologia de Saneamento Ambiental

-Conselho Nacional de Meio Ambiente

-Cromo

-Cobre

-Departamento de Água e Esgoto de Ribeirão Preto

-Espectrofotômetro de Absorção Atómica-Forno de Grafite

-Espectrofotômetro de Absorção Atómica-Gerador de Hidretos

-Espectrofotômetro de Absorção Atómica-Chama

-Escola de Enfermagem de Ribeirão Preto

-Estudo de Impacto Ambiental-Relatório de Impacto no Meio Ambiente

-Environmental Protection Agency

-Folha

-Faculdade de Medicina de Ribeirão Preto

-Hospital das Clínicas da Faculdade de Medicina de Ribeirão Preto

-Mercúrio

-Ácido Nítrico

-Fundação Instituto Brasileiro de Geografia e Estatística

-Leste/ distância em metros dos limites do Aterro Sanitário

-Manganês

-Norte/ distância em metros dos limites do Aterro Sanitário

-Oeste/ distância em metros dos limites do Aterro Sanitário

-Organização Mundial da Saúde

-Chumbo

-Plano de Gerenciamento de Resíduos de Serviços de Saúde

-Valor crítico de $q$

-Raiz 


$\begin{array}{ll}\text { RP } & \text {-Ribeirão Preto } \\ \text { RS } & \text {-Resíduos Sólidos } \\ \text { RSS } & \text {-Resíduos de Serviços de Saúde } \\ \text { S/ } & \text {-Sul/ distância em metros dos limites do Aterro Sanitário } \\ \text { So } & - \text { Solo } \\ \text { SP } & \text {-São Paulo } \\ \text { SPSS } & \text {-Statistical Program for Social Sciences } \\ \text { USP } & \text {-Universidade de São Paulo } \\ \text { Zn } & - \text { Zinco }\end{array}$




\section{RESUMO}

Segura-Muñoz, S.I. Impacto ambiental na área do Aterro Sanitário e Incinerador de Resíduos Sólidos de Ribeirão Preto, SP: Avaliação dos níveis de metais pesados. 2002. 131p. Teses Doutorado - Escola de Enfermagem de Ribeirão Preto, Universidade de São Paulo, Ribeirão Preto.

Os resíduos sólidos podem conter substâncias químicas com características tóxicas, dentre elas os metais pesados presentes em diversos materiais provenientes de indústrias, funilarias, atividades agrícolas, laboratórios, hospitais e residências. A contaminação por metais pesados apresenta um amplo espectro de toxicidade que inclui efeitos neurotóxicos, hepatotóxicos, nefrotóxicos, teratogênicos, carcinogênicos ou mutagênicos. Em Ribeirão Preto - SP há em funcionamento desde 1989, um aterro sanitário (AS) para resíduos domiciliares e um incinerador de resíduos de serviços de saúde (IRSS). Este estudo teve como objetivo fazer um diagnóstico dos níveis de metais pesados na área do AS e IRSS de Ribeirão Preto, entre 2000 e 2001. Foram realizadas análises de amostras de solo, água, chorume e vegetais, em pontos previamente demarcados na área, tendo sido avaliada a presença de mercúrio $(\mathrm{Hg})$, cobre $(\mathrm{Cu})$, chumbo $(\mathrm{Pb})$, cádmio $(\mathrm{Cd})$, manganês $(\mathrm{Mn})$, zinco $(\mathrm{Zn})$ e cromo $(\mathrm{Cr})$ por Espectrofotometria de Absorção Atômica. Visando a obtenção de parâmetros locais, foram também analisadas amostras coletadas na Estação Ecológica na mata Santa Teresa, zona de preservação permanente do município, para comparação de valores. Pela análise dos resultados verificou-se, de um modo geral, que os níveis de metais pesados presentes nas amostras de solo e vegetais na área apresentaram concentrações significativamente superiores às detectadas nas amostras coletadas na mata Santa Teresa, evidenciando-se uma tendência de maiores concentrações no sentido Norte, fato que pode estar associado com a declividade geográfica da área, com a direção dos ventos e com a localização do incinerador. Destacam-se neste estudo os níveis de $\mathrm{Cd}, \mathrm{Mn}$ e $\mathrm{Cu}$ presentes em amostras de solo em níveis que superaram os valores máximos estabelecidos para solos de uso agrícola no Estado de São Paulo pela CETESB, órgão estadual ambiental. O chorume também apresentou níveis de $\mathrm{Cd}, \mathrm{Pb}, \mathrm{Mn}, \mathrm{Cu}$ em concentrações superiores às normatizadas para efluentes líquidos, segundo o Decreto 8486/76 do estado de São Paulo. A água subterrânea da área estudada não apresentou níveis de metais acima dos valores máximos permitidos, de acordo com a Portaria 1469/2000 do Ministério da Saúde. Considerando a carência de pesquisas dessa natureza no Brasil, este estudo tem gerado informações que podem constituir-se em ferramenta para a tomada de decisões políticoadministrativas pelas autoridades responsáveis pelo gerenciamento de resíduos sólidos, não apenas do Município de Ribeirão Preto e região, mas, também, podendo servir de parâmetro para realidades similares no país.

Palavras-chave: Metais pesados, resíduos sólidos, resíduos de serviços de saúde, aterro sanitário, incinerador, meio ambiente. 


\section{SUMMARY}

Segura-Muñoz, S.I. Environmental impact in the Municipal Landfill Site and Medical Waste Incinerator area in Ribeirao Preto, São Paulo: Evaluation of heavy metals levels. 2002. 131 p. Doctoral Tesis - School of Nursing of Ribeirão Preto, São Paulo University, Ribeirão Preto.

Solid waste may content toxic chemical substances such as heavy metals that are present in materials generated by industries, agricultural activities, laboratories, hospitals and houses. The contamination with heavy metals has a wide spectrum of toxicity that includes neurotoxic, hepatotoxic, nephrotoxic, teratogenic, carcinogenic or mutagenic effects. Since 1989, a municipal landfill site (MLS) for urban waste disposal has been in operation in Ribeirao Preto (Sao Paulo, Brazil) integrated with a medical waste incinerator plant (MWIP). This study aimed to do a diagnostic of the heavy metal levels in MLS and MWIP area, in 2000 and 2001. The total cadmiun (Cd), chromium (Cr), lead $(\mathrm{Pb})$, manganese $(\mathrm{Mn})$, zinc $(\mathrm{Zn})$, cooper $(\mathrm{Cu})$ and mercury $(\mathrm{Hg})$ levels were analysed by Atomic Absortion Spectrophotometry in soil, water, percolated liquid and vegetables, in previously delimitated points. Samples from Santa Teresa Forest Ecological Station of Ribeirao Preto were collected as control samples. The results showed that, in general terms, the heavy metals detected in soil and vegetal samples in that area showed significant higher concentrations when compared with Santa Teresa Forest samples. The highest concentrations were detected to the North direction, these results can be associated with the topographic gradient in the area, the prevailing winds and the Incinerator localization. Special atention should be given to $\mathrm{Cd}, \mathrm{Mn}$ and $\mathrm{Cu}$ levels detected in soil samples, that showed higher concentrations that those recomended for agricultural soil in Sao Paulo State by the Environmental Sanitation Company (CETESB). The percolated liquid also showed $\mathrm{Cd}, \mathrm{Pb}, \mathrm{Mn}$ and $\mathrm{Cu}$ levels higher than the maximum recomended levels according to the Sao Paulo State Law (Decreto 8486/76). The water samples showed levels according to the Brasilian Health Ministry Law (Portaria 1469/2000). Taking into account that few researches had been developed on this thematic in Brasil, the obtained results constituted an instrument for the decision makers and public managers, not only for Ribeirao Preto and region but for other cities around the country.

Key words: Heavy metals, solid waste, medical service waste, sanitary landfill site, incinerator, environment. 


\section{RESUMEN}

Segura-Muñoz, S.I. Impacto ambiental en el área del Relleno Sanitario e Incinerador de Residuos Sólidos de Ribeirão Preto, SP: Evaluación de los niveles de metales pesados. 2002. 131 p. Tesis de Doctorado - Escuela de Enfermería de Ribeirão Preto, Universidad de São Paulo, Ribeirão Preto.

Los residuos sólidos pueden contener sustancias químicas con características tóxicas, entre las cuales se encuentran los metales pesados presentes en diversos materiales de industrias, actividades agrícolas, laboratorios, hospitales e residencias. La contaminación con metales pesados presenta un amplio espectro de toxicidad que incluye efectos neurotóxicos, hepatotoxicos, nefrotóxicos, teratogénicos, carcinogénicos o mutagénicos. En Ribeirão Preto, SP, se encuentra en funcionamiento desde 1989 un relleno sanitario (RS) para residuos domiciliares y un incinerador para residuos de servicios de salud (IRSS). Este estudio tuvo como objetivo realizar un diagnóstico de la concentración de metales pesados en el área del RS e IRSS de Ribeirão Preto, entre 2000 y 2001. Fueron realizados análisis de suelo, vegetales, líquido percolado y agua en puntos delimitados en esa área, evaluando la presencia de mercurio $(\mathrm{Hg})$, cobre $(\mathrm{Cu})$, plomo $(\mathrm{Pb})$, cadmio $(\mathrm{Cd})$, manganeso $(\mathrm{Mn})$, zinc $(\mathrm{Zn})$ y cromo $(\mathrm{Cr})$ por Espectrofotometría de Absorción Atómica. También fueron analizadas muestras colectadas en la Estación Ecológica Bosque Santa Teresa, zona de preservación permanente del municipio, para comparación de los valores. Mediante el análisis de resultados se verificó, de modo general, que los niveles de metales pesados presentes en las muestras de suelo y vegetales en el área estudiada presentaron concentraciones significativamente superiores a las detectadas en las muestras colectadas en el bosque Santa Teresa, evidenciándose un aumento de las concentraciones en el sentido Norte, hecho que puede ser asociado con la declividad geográfica del área, la dirección de los vientos y con la localización del incinerador. Se destacan en este estudio los niveles de $\mathrm{Cd}, \mathrm{Mn}$ y $\mathrm{Cu}$ presentes en muestras de suelo en concentraciones superiores a los valores máximos recomendados para suelos de uso agrícola en el estado de São Paulo por la CETESB, órgano ambiental estatal. El liquido percolado también presentó niveles de $\mathrm{Cd}, \mathrm{Mn}$ y $\mathrm{Cu}$ superiores a las normalizadas para efluentes líquidos en el Decreto del Estado de São Paulo 8486/76. La concentración de metales en el agua subterránea no sobrepasó los valores máximos permitidos en la Portaría 1469/2000 del Ministerio de Salud. Debido a la carencia de investigaciones de esta naturaleza en Brasil, se considera el presente estudio de significativa importancia para la generación de informaciones que pueden constituirse en importante herramienta para la tomada de decisiones político-administrativas de las autoridades responsables por el gerenciamiento de residuos sólidos, no solo del municipio de Ribeirão Preto, sino también, para realidades similares en el país.

Palabras-clave: Metales pesados, residuos sólidos, residuos de servicios de salud, relleno sanitario, incinerador, medio ambiente. 


\section{APRESENTAÇÃO}

O Departamento de Enfermagem Materno-Infantil e Saúde Pública da Escola de Enfermagem de Ribeirão Preto-USP, desde a sua criação em 1986, engloba diferentes áreas de conhecimento, tendo como fio condutor a Saúde Coletiva, o que dá sustentação ao caráter dos seus estudos e investigações acadêmicas. Dentre suas linhas de pesquisa, a Linha de Saúde Ambiental vem conquistando, cada vez mais, um importante espaço na busca de estratégias para uma melhor qualidade de vida.

A Saúde Ambiental, segundo a definição da Organização Mundial da Saúde (OMS), é a parte da saúde pública que se ocupa das formas de vida, das substâncias e das condições em torno do homem que podem exercer alguma influência sobre a saúde e o bem-estar. O trabalho em saúde ambiental na sua dimensão interdisciplinar, contempla a participação de uma equipe multiprofessional, que tem como objetivo gerar e difundir conhecimentos nas áreas relacionadas ao meio ambiente, dando ênfase ao saneamento ambiental, ao saneamento básico, a saúde do trabalhador e a qualidade de vida da população.

Frente às inúmeras inquietações, referente à situação ambiental em todo o planeta, destaca-se, para o presente trabalho, a questão dos contaminantes químicos, tais como os pesticidas, agrotóxicos, dioxinas, furanos e metais pesados, principalmente no que se refere à associação de seus efeitos na saúde pública, dado aos processos de adsorção, volatilização, complexação, precipitação, acumulação, mobilização e biotransformação que os caracterizam e, os disponibilizam na ampla "teia da vida". 
O presente estudo trata da contaminação ambiental por metais pesados decorrente das atividades permanentes de disposição e tratamento dos resíduos sólidos urbanos, tanto domiciliares quanto de Serviços de Saúde, no Município de Ribeirão Preto, SP. A idéia de realização do mesmo, nasceu do encontro de minhas inquietações aliadas aos estudos da Linha de Pesquisa em Saúde Ambiental, liderada pela Profa. Dra. Angela Maria Magosso Takayanagui.

Otrabalho foi estruturado em seis partes, ou seja, introdução material e métodos, resultados, discussão e conclusão.

$\mathrm{Na}$ introdução é apresentada a fundamentação teórica do tema, abordando aspectos relacionados aos resíduos sólidos, aos sistemas de disposição e tratamento de resíduos sólidos e à contaminação por metais pesados e agravos à saúde, decorrentes da exposição a elementos químicos e seus compostos. No final da introdução é abordada a situação do gerenciamento de resíduos sólidos no Brasil, com particular ênfase na realidade do Município de Ribeirão Preto, trazendo uma descrição da sua evolução histórica e da situação atual. Logo após, são apresentados os objetivos que nortearam o trabalho.

Em seguida é feita a descrição do percurso metodológico utilizado para a análise dos níveis de metais pesados no solo, no chorume, na água e nos vegetais das áreas circunvizinhas ao Aterro Sanitário e Incinerador de Resíduos de Serviços de Saúde.

Posteriormente, são apresentados os resultados obtidos da análise dos metais presentes nas amostras de solo e de vegetais, complementados por análise estatística, verificando a significância das diferenças encontradas na área em estudo, quando comparados os resultados com os valores obtidos nas amostras procedentes da mata Santa Teresa, definida como local controle. São também 
apresentados os resultados das análises das amostras de água subterrânea e chorume coletadas na área do Aterro Sanitário.

Dando continuidade, é apresentada a discussão baseada nos resultados obtidos, buscando possíveis explicações para dar sustentação aos achados, tomando como referência a literatura existente nessa área, no nível mundial. A discussão também foi realizada à luz de padrões já normatizados para as condições de contaminação ambiental do Estado de São Paulo.

Nas considerações finais, é apresentada uma avaliação do estudo no conjunto, levando em conta suas repercussões e as questões levantadas a partir desse trabalho, de forma a poder representar ferramentas na tomada de decisões políticas pelas autoridades locais, com a finalidade de estabelecer programas que melhorem a qualidade de vida e a saúde pública no município e região.

É importante destacar que a realização deste projeto tem permitido nosso aprofundamento acerca do conhecimento referente à problemática dos metais pesados, bem como a repercussão das diferentes práticas de tratamento e destinação dos rejeitos resultantes das atividades humanas.

A realização desta pesquisa, também permitiu a conformação de um importante intercâmbio com o Setor de Metais do Laboratório de Pediatria e Puericultura do Hospital das Clínicas da Faculdade de Medicina de Ribeirão Preto/USP. É importante salientar que, além disso, tem sido possível estabelecer importantes intercâmbios com outros serviços e profissionais ligados à temática, a exemplo do Laboratório Quality Technologies em Queensland, Austrália.

Foi de inestimável valor o apoio recebido da Fundação de Apoio à Pesquisa do Estado de São Paulo (FAPESP), através do auxilio à pesquisa recebido no início do ano 2000, para o desenvolvimento do projeto, possibilitando a aquisição de 
alguns equipamentos para o Laboratório de Saúde Ambiental da Escola de Enfermagem de Ribeirão Preto, bem como dos materiais necessários para a coleta das amostras e análises laboratoriais realizadas junto ao Setor de Metais, aquisições estas que, com certeza, contribuirão também para o desenvolvimento de futuros estudos.

A partir deste estudo e de trabalhos relacionados que foram realizados paralelamente a esta investigação, foi gerada a oportunidade de uma maior participação em diversos eventos científicos, apresentando resultados de alguns trabalhos oriundos dessa linha de investigação, tais como os abaixo citados:

Segura-Muñoz S.I. \& Takayanagui A.M.M. "Estudo sobre a relação entre exposição prolongada a metais pesados e agravos à saúde”. Apresentado no $12^{\circ}$ Encontro Regional de Química. Sociedade Brasileira de Química. Ribeirão Preto, São Paulo. 10 a 12 de outubro de 1999. In: Livro de resumos A contribuição das instituições da região para o desenvolvimento da química brasileira. p.70, 1999.

Segura-Muñoz S.I.; Takayanagui A.M.M.; Trevilato B.T.M.; Hering E.S.. "Revisão Sistemática sobre o efeito neurotóxico da exposição ocupacional ao mercúrio, chumbo e manganês" Apresentado no VI Congresso Brasileiro de Saúde Coletiva. Salvador, Bahia. 28 de agosto a 01 de setembro de 2000.In: Livro de resumos Ciência e saúde Coletiva. v. 5, p. 49, 2000.

Segura-Muñoz S.I.; Trevilato B.T.M.; Hering E.S.;Takayanagui A.M.M. "Heavy metals content in the water of drinking fountains localized in the University of São Paulo in Ribeirão Preto, Brazil" Apresentado na III Brazilian Meeting on Chemistry of Food and Beverages. Realizado no Instituto de Química de São Carlos da Universidade de São Paulo. São Carlos, São Paulo. 01-03 de setembro de 2000. In: Book of Abstracts do referido evento. p. 11, 2000.

Segura-Muñoz S.I.; Trevilato B.T.M.;Takayanagui A.M.M.; Hering E.S.; Cupo P. "Metais pesados em água potável" Apresentado no XII Congresso Brasileiro de Toxicologia, VII Encontro Nacional de Professores de Toxicologia, III Encontro Nacional de Toxicologia Forense. Reunião Nacional de Centros Informações Toxicologicas. Realizado em Porto Alegre, Rio Grande do Sul. 11-15 de novembro de 2001.In: Revista Brasileira de Toxicologia, v.4, n.2, p. 33, 2001 (Suplemento).

Segura-Muñoz S.I.; Trevilato B.T.M.;Takayanagui A.M.M.; Hering E.S.. "Metais Pesados em áreas circunvizinhas a um Aterro Sanitário e Incinerador de Resíduos Sólidos" Apresentado no XII Congresso Brasileiro de Toxicologia, VII Encontro Nacional de Professores de Toxicologia, III Encontro Nacional de Toxicologia Forense. Reunião Nacional de Centros Informações Toxicologicas. 
Realizado em Porto Alegre, Rio Grande do Sul. 11-15 de novembro de 2001. In: Revista Brasileira de Toxicologia, v.4, n.2, p.145, 2001 (Suplemento).

Segura-Muñoz S.I.; Takayanagui A.M.M.; Trevilato B.T.M.;Hering E.S. "Condições de saúde dos trabalhadores de um Incinerador de Resíduos de Serviços de Saúde" Apresentado no II Seminário Nacional de Saúde e Ambiente. Realizado em Rio de Janeiro. 3 a 13 de junho de 2002.

Trevilato B.T.M; Segura-Muñoz S.I.; Turati A.; Souza, A.M.; Menezes C.; Hering E.S.; Cupo P. "Chumbo em sangue de trabalhadores de indústria química na região de Ribeirão Preto". Apresentado no $5^{\circ}$ Encontro Regional de Biomedicina. Realizado em Botucatu, SP. 18 a 21 de outubro de 2002.

Além dessa participação em eventos, alguns trabalhos foram encaminhados para publicação e outros estão em fase de preparação, descritos a seguir:

Segura-Muñoz S.I.; Trevilato B.T.M.;Takayanagui A.M.M.; Hering E.S.; Cupo P. Metales pesados em água de bebederos de presión. No prelo. Archivos Latinoamericanos de Nutrición. v. 52, 2002.

Segura-Muñoz S.I.; Takayanagui A.A.M.; Santos C.B.; Sanchez-Sweatman O. Revisão Sistemática de Literatura e Metanálise: Noções básicas sobre seu desenho, interpretação e aplicação na área da saúde. No prelo. Livro $8^{\circ}$ Simposio Brasileiro de Comunicação em Enfermagem, 2002.

Segura-Muñoz S.I.; Takayanagui A.M.M.; Trevilato B.T.M.; Santos C.B.; Hering E.S. Spatial distribution of metals in surface soil around a municipal solid waste landfill and a medical waste incinerator. Encaminhado para publicação em The Science of the Total Environment.

Segura-Muñoz S.I.; Takayanagui A.M.M.; Lopes T.; Trevilato B.T.M.; Hering E.S. Estudo de efeito neurotóxico da exposição ocupacional ao mercúrio, chumbo e manganês utilizando como ferramenta metodológica a Revisão Sistemática de Literatura. Encaminhado para publicação em Cadernos de Saúde Pública.

Segura-Muñoz S.I.; Takayanagui A.M.M.; Trevilato B.T.M.; Hering E.S.; Cupo P. "Condições de saúde dos trabalhadores de um incinerador de Resíduos de Serviços de Saúde”. Em fase de preparação.

Segura-Muñoz S.I.; Takayanagui A.M.M.; Trevilato B.T.M.; Santos C.B.; Hering E.S. "Heavy metals in vegetation and surface soil in a Municipal Landfill Site and a Medical waste Incinerator Plant area”. Em fase de preparação.

Segura-Muñoz S.I.; Takayanagui A.M.M.; Trevilato B.T.M.; Hering E.S. "Nivel de metais pesados no liquido percolado e na água subterrânea do Aterro Sanitário e Incinerador de Resíduos Sólidos de Ribeirão Preto”. Em fase de preparação. 



\section{INTRODUÇ̃̃O}

O atual momento histórico aponta para uma reflexão a respeito das sociedades contemporâneas e seus impactos sobre a saúde e meio ambiente. Fazendo uma breve retrospectiva histórica podemos focalizar elementos cruciais que têm estado envolvidos nessa temática, contribuindo significativamente para os padrões de produção e consumo prevalecentes hoje, na maior parte do planeta.

Durante milhões de anos os homens viveram da caça e coleta dos frutos, sempre procurando novos espaços quando os recursos tornavam-se escassos, numa relação relativamente harmoniosa com o meio natural. As intervenções sobre o meio ambiente se intensificaram conforme as comunidades foram se formando e a população aumentando sobre uma mesma localidade.

Com o surgimento das cidades e o aumento populacional, aumentava a demanda por bens de consumo. O atendimento a essas demandas pressupunha mudanças na forma de produção, determinando uma maior intervenção na natureza. Desde muito cedo, observou-se o surgimento de problemas ambientais, como a poluição das águas e o acúmulo de lixo. Já na Idade Média, tem-se o registro de epidemias decorrentes da proliferação de roedores nos lixões das cidades (Carvalho \& Tella, 1997). 
Os séculos XIX e XX foram marcados pela divisão social e técnica do trabalho, que aumentou a produtividade, desenvolveu tecnologias de produção e, conseqüentemente, gerou um aumento gradativo de consumo. Nas décadas de 40 e 50, do século passado, houve mudanças muito mais profundas no comportamento dos indivíduos devido ao rápido desenvolvimento capitalista, que trouxe como modelo de qualidade de vida uma sociedade com altos padrões de consumo, incentivando a produção de descartáveis e a utilização de materiais artificiais.

Este padrão de produção e consumo tem sido agravado nas últimas décadas com a mudança do perfil essencialmente rural da sociedade para um ambiente predominantemente urbano (Taschner \& Bogus, 1986), criando um modelo de vida caracterizado por uma maior produção, um maior consumo de energia, uma maior emissão de gases, um aumento na geração de resíduos e, conseqüentemente, da poluição do ambiente, principalmente nos países desenvolvidos, trazendo como conseqüência inevitável a degradação dos recursos naturais existentes.

A poluição ambiental pode ser definida como toda ação ou omissão do homem que, através da descarga de material ou energia nas águas, solo e ar, cause um desequilíbrio nocivo no meio ambiente (Valle, 1995).

Os efeitos da poluição ambiental são muito mais complexos e difusos do que se poderia avaliar de início; suas consequiências, além de disseminadas, podem ser também cumulativas e crônicas, tornando mais complexa a ação de despoluir. Uma fonte poluidora exerce efeitos de diferentes dimensões sobre a biosfera e a biota, atingindo, conseqüentemente, o solo, o ar e as águas (Fig. 1). 


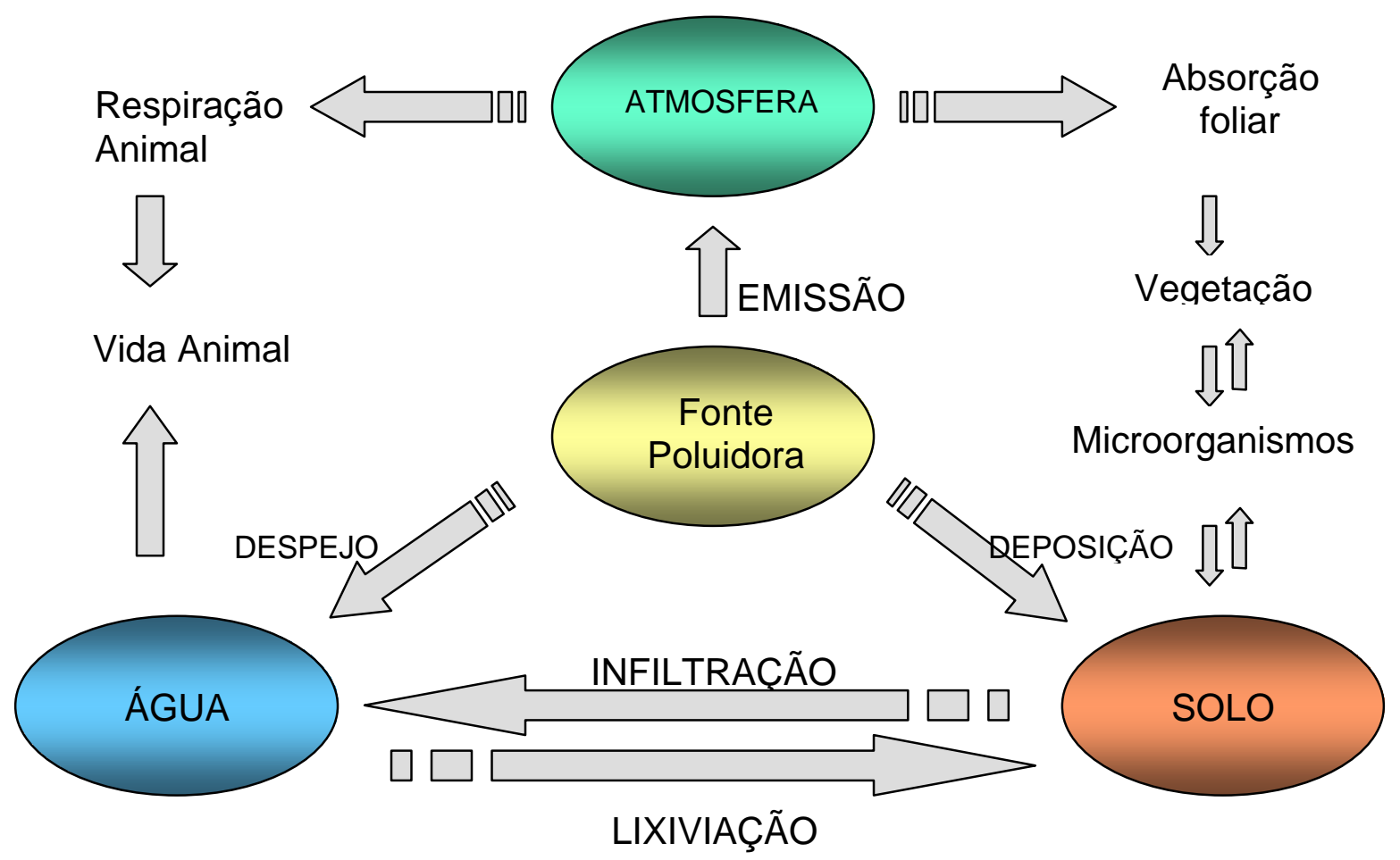

Fig. 1 - Propagação dos efeitos da poluição no meio físico e na biota. (Adaptada de Valle, 1995)

A crescente degradação ambiental, marcadamente presente neste último século, tem originado muitos questionamentos acerca dos problemas que a contaminação urbana poderia desencadear sobre a saúde da população. Nesse contexto, o aumento na quantidade e variedade dos resíduos sólidos gerados pelas atividades domésticas, sociais e industriais emerge como um dos problemas prioritários da sociedade atual (Brunner \& Brown, 1988; CETESB, 1990; Takayanagui, 1993, D’Almeida \& Vilhena, 2000).

Os resíduos sólidos são considerados a expressão mais visível e concreta dos riscos ambientais, ocupando um importante papel na estrutura de saneamento de uma comunidade urbana e, conseqüentemente, nos aspectos relacionados à saúde pública. Além das consequiências para a saúde comunitária, deve-se considerar ainda o 
impacto que a disposição inadequada desses resíduos provocam no solo, na atmosfera, na vegetação e nos recursos hídricos (Moritz, 1995)

\subsection{Resíduos Sólidos, definição e classificação}

Segundo a NBR 10.004/87, os resíduos sólidos podem ser definidos como: "aqueles resíduos em estado sólido e semi-sólido, que resultam de atividades da comunidade de origem: industrial, doméstica, hospitalar, comercial, de serviços, de varrição e agrícola. Também estão incluídos nesta definição os lodos provenientes de sistemas de tratamento de água, aqueles gerados em equipamentos e instalações de controle de poluição, bem como determinados líquidos cujas particularidades tornem inviável seu lançamento na rede pública de esgotos ou corpos de água, ou exijam para isso soluções técnica e economicamente inviáveis face à melhor tecnologia disponível (ABNT, 1987; p.1,2)

A ABNT, através desta mesma norma (ABNT, 1987), classifica os resíduos sólidos urbanos em três classes, a saber:

Classe I - Perigosos: Estão incluídos os resíduos que apresentam as seguintes características: inflamabilidade, corrosividade, reatividade, toxicidade e/ou patogenicidade.

Classe II - Não Inertes: são compostos por resíduos que podem apresentar propriedades como: combustibilidade, biodegradabilidade ou solubilidade em água. 
Classe III - Inertes: são compostos por resíduos que quando amostrados de forma representativa e submetidos a um contato estático ou dinâmico com água, à temperatura ambiente, não apresentam atividade. Como exemplo destes materiais, pode-se citar as rochas, tijolos, vidros e certos plásticos e borrachas que não são prontamente decompostos.

Dentre os diferentes tipos de resíduos gerados em áreas urbanas os resíduos produzidos em serviços de saúde, mesmo constituindo-se em pequena parcela em relação ao total dos resíduos sólidos urbanos gerados (cerca de 2\%), são particularmente importantes pelo risco potencial que apresentam, podendo ser fonte de microorganismos patogênicos, cujo manuseio, tratamento e/ou descarte inadequado pode acarretar a disseminação de doenças infecto-contagiosas, principalmente devido ao caráter infectante de algumas de suas frações componentes, além da existência eventual de quantidades de substâncias tóxicas que aumentam os riscos e os problemas associados a esse tipo de resíduos (Risso, 1993; Takayanagui, 1993; Blenkharn, 1995; Malavaud \& Marty, 1997; Padhye et al., 1998; Vrijheid, 2000; CDC,2002).

Segundo a Resolução CONAMA N.05/93 (Brasil, 1993), os resíduos de serviços de saúde - RSS são definidos como resíduos gerados em hospitais, farmácias, laboratórios, consultórios médicos, odontológicos e veterinários, bancos de sangue e leite, além de estações rodoferroviárias, portos e aeroportos. Esta Resolução também classifica os RSS em quatro grupos descritos a seguir, além de serem considerados como resíduos perigosos pela característica de patogenicidade, de acordo com NBR10.004/87 (ABNT,1987). 
Grupo A - Resíduos Infectantes: São os resíduos que apresentam risco potencial à saúde pública e ao meio ambiente devido à presença de agentes biológicos.

Grupo B - Resíduos de Origem Química: Resíduos que apresentam risco potencial à saúde pública e ao meio ambiente devido às suas características químicas. Enquadram-se neste grupo, dentre outros: drogas quimioterápicas e produtos por elas contaminados; resíduos farmacêuticos e resíduos químicos perigosos.

Grupo C - Resíduos Radioativos: Enquadram-se nesse grupo os materiais radioativos ou contaminados com radionuclídeos, provenientes de laboratórios de análises clínicas, serviços de medicina nuclear e radioterapia.

Grupo D - Resíduo Comum: Todo aquele resíduo que não se enquadra nos grupos descritos anteriormente. Por exemplo, resíduo da atividade administrativa, dos serviços de varrição e limpeza de jardins e restos alimentares que não entraram em contato com pacientes.

No Brasil há algumas determinações técnicas e legais que orientam o manuseio, tratamento e disposição de resíduos sólidos urbanos em geral e os específicos como os RSS.

$1^{\text {o) }}$ O Decreto 8468 de 8/9/1976 aprova o regulamento da Lei $\mathrm{N}^{\circ} 997$ de 31/5/1976, que dispõe sobre a prevenção e o controle da poluição do meio ambiente (São Paulo,1976).

$2^{\circ}$ ) A Portaria MINTER $\mathrm{N}^{\circ} 53$ de 1/3/79 estabelecia normas aos projetos específicos de tratamento e disposição de resíduos sólidos, proibindo o descarte de resíduos, principalmente os perigosos, diretamente no solo ou em cursos de água sem tratamento e considerava como obrigatória a incineração de RSS e similares. 
$3^{\circ}$ ) A Resolução CONAMA Nº6 de 19/9/91, desobrigou a incineração de RSS e a Resolução $N^{\circ} 5$ de 5/8/93, 1 estabeleceu novas diretrizes para a gestão dos RSS, dentre elas, a exigência de um Plano de Gerenciamento dos Resíduos de Serviços de Saúde (PGRSS) e a existência de um Gerente de Resíduos em cada estabelecimento de saúde, estando em vigor em todo território nacional, juntamente com a última legislação existente nessa área: a Resolução CONAMA No 283 de 12 de julho de 2001, que apresenta determinações mais específicas sobre o gerenciamento dos RSS nos serviços de saúde (BRASIL, 2001).

No Estado de São Paulo, a Resolução Conjunta nº 1 de 29/06/1998, dispõe, dentre outros, sobre a exigência da apresentação de um PGRSS por todo estabelecimento de saúde e pela existência de um gerente de resíduos nesses locais, reforçando a necessidade técnica e legal de um sistema de gerenciamento dos RSS mais eficiente.

Ainda nesse mesmo estado, além dos órgãos públicos de vigilância sanitária e ambiental, há um importante setor, CETESB - Companhia de Tecnologia de Saneamento Ambiental, que também tem a incumbência técnica e legal de fiscalizar e orientar os geradores de resíduos sólidos no Estado, de modo a impedir a contaminação ambiental e garantir maior segurança à saúde pública.

\subsection{Sistemas de Disposição e Tratamento dos Resíduos Sólidos}

Historicamente, existem três formas básicas adotadas pela sociedade urbana para disposição de resíduos sólidos: lixão ou vazadouro, aterro controlado e aterro sanitário (Charnock \& Wells, 1985). 
Os lixões ou vazadouros, como mostra o esquema da Fig. 2, resultam da simples descarga do lixo a céu aberto sem levar em consideração: a área em que está sendo feita a descarga, a percolação dos líquidos derivados da decomposição do lixo, a liberação de gases para a atmosfera e a proliferação de insetos, roedores e outros animais que podem transmitir doenças ao homem (Serra et al., 1998). Embora muito utilizados no Brasil, por cerca de $70 \%$ dos seus municípios (IBGE, 2002), representam uma forma inadequada e ilegal de disposição de resíduos sólidos.

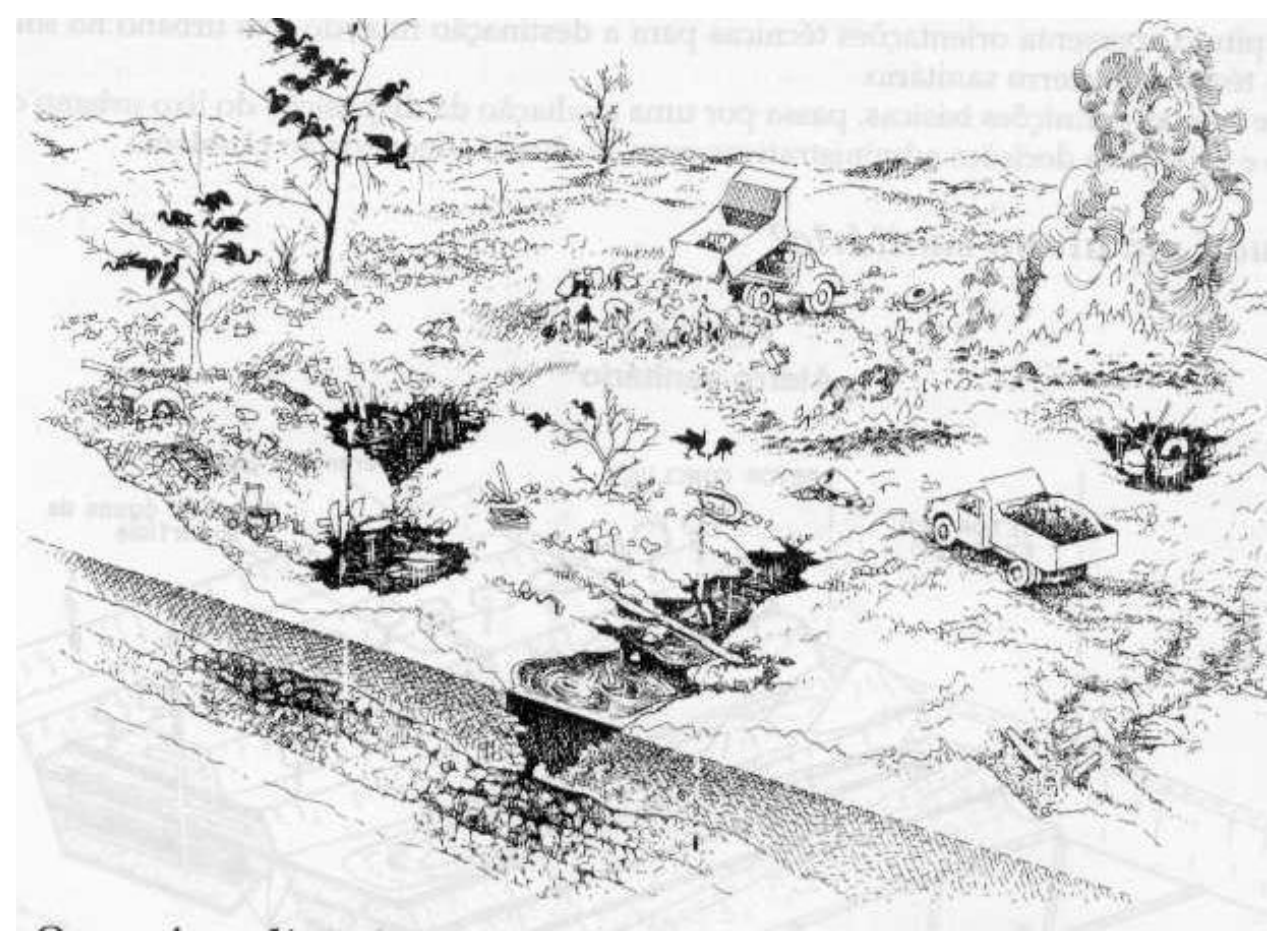

Fig. 2 - Esquema de um lixão a céu aberto, com a presença dos catadores e animais no local de descarga dos caminhões e o acúmulo de chorume na superfície do solo, bem como a sua absorção pelas camadas subterrâneas. (Fonte: Jardim et al., 1995).

Aterro controlado diferencia-se dos lixões apenas pelo fato do lixo não ficar exposto a céu aberto, por ser periodicamente coberto com terra. $O$ solo não é 
impermeabilizado e nem sempre possui sistema de drenagem dos líquidos percolados, tampouco captação de gases formados pela decomposição da matéria orgânica.

Aterro sanitário refere-se a uma instalação previamente planejada para a posterior disposição de resíduos sólidos, visando a não causar danos nem perigo ao meio ambiente e à saúde pública.

Antes de se projetar um aterro sanitário devem ser realizados estudos geológicos e topográficos para a seleção da área e verificação do tipo de solo. Também deve ser feita a impermeabilização do solo, os líquidos percolados devem ser captados por drenos horizontais para tratamento e os gases liberados durante a decomposição captados por drenos verticais. O lixo é compactado e coberto diariamente com camada de terra de 20 a $40 \mathrm{~cm}$ (Serra et al.,1998). O esquema da Fig. 3 mostra o perfil de um aterro sanitário em funcionamento.

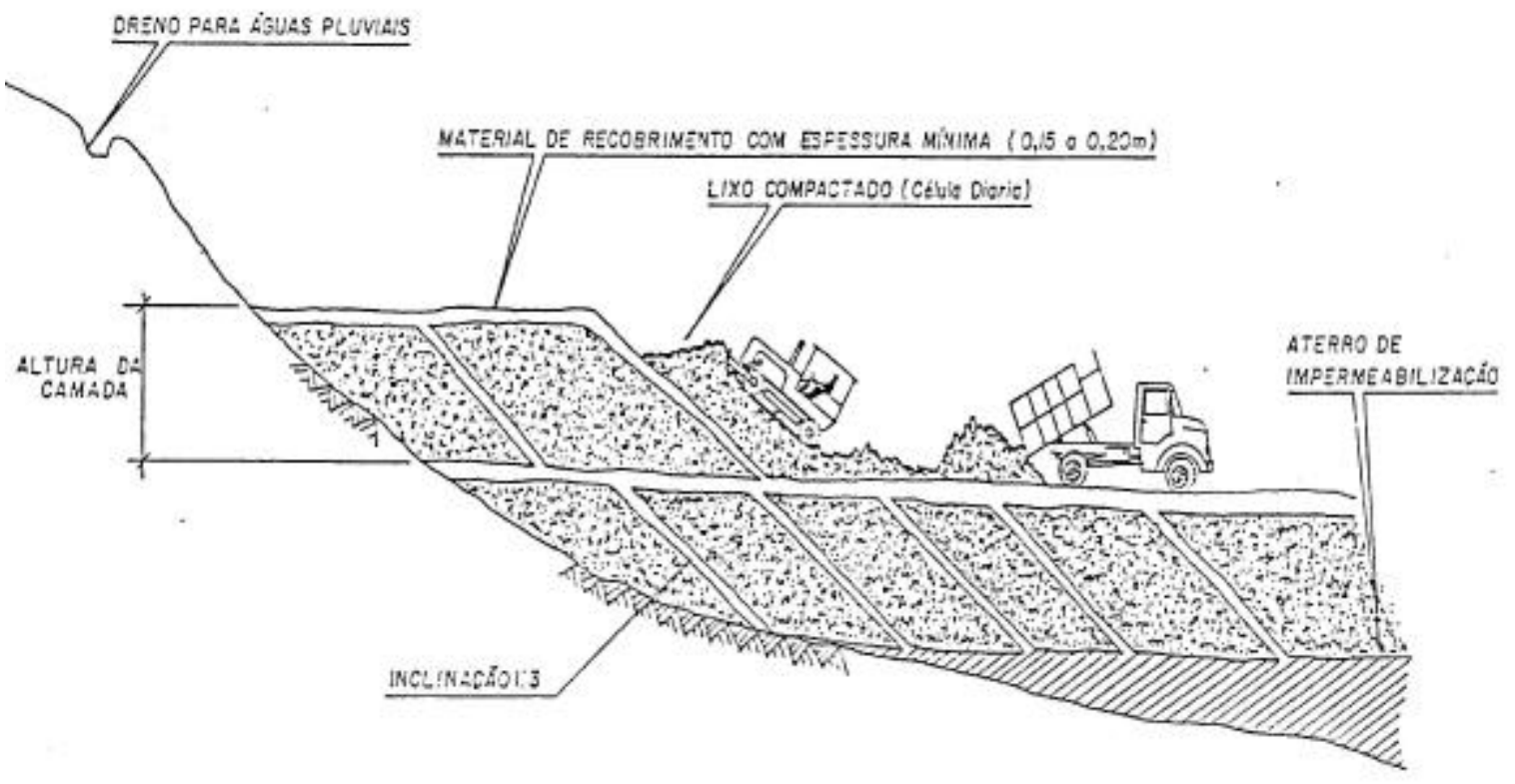


Fig. 3 - Esquema das características da construção de um Aterro Sanitário, mostrando a operacionalização em condições ideais de funcionamento. (Fonte: Alvarenga et al., 1986).

Os aterros sanitários, embora importantes, apresentam segundo alguns autores, algumas limitações como o tempo de vida razoavelmente curto e a grande dificuldade na obtenção de locais adequados para sua implantação nas proximidades dos centros urbanos, que não aqueles considerados de recarga dos aqüíferos (Viana,1999).

Além disto, têm sido descritos na literatura diversas outras questões que podem estar ligadas à instalações de aterros sanitários, no que diz respeito ao impacto social e biológico causado às populações circunvizinhas e também aos trabalhadores do local (Moritz, 1995; Elliott et al., 1997; Baxter et al., 1999).

Em relação ao tratamento de resíduos sólidos, são descritas na literatura diferentes técnicas, dentre elas: compostagem, incineração, tratamento com microondas, plasma-pirólise e reciclagem.

A incineração, processo de tratamento de resíduos através da oxidação a altas temperaturas, sob certas condições controladas é considerada uma das técnicas mais adequadas para o tratamento dos resíduos dos serviços de saúde (Cerqueira \& Alves,1999), embora contestada por diversos segmentos da academia, pela possibilidade de contaminação do ar, solo e água, bem como de animais e vegetais, é ainda muito utilizada nos países industrializados (Shima \& Beccari, 1996).

Esse método de tratamento converte materiais combustíveis transformando-os em escórias, cinzas e gases, estes últimos, eliminados para a atmosfera por meio de chaminés, enquanto as escórias e cinzas podem ser dispostas em aterros sanitários. 
A incineração por calor seco consta de um equipamento composto por duas câmaras, a primeira, conhecida como câmara de combustão primária, operando a uma

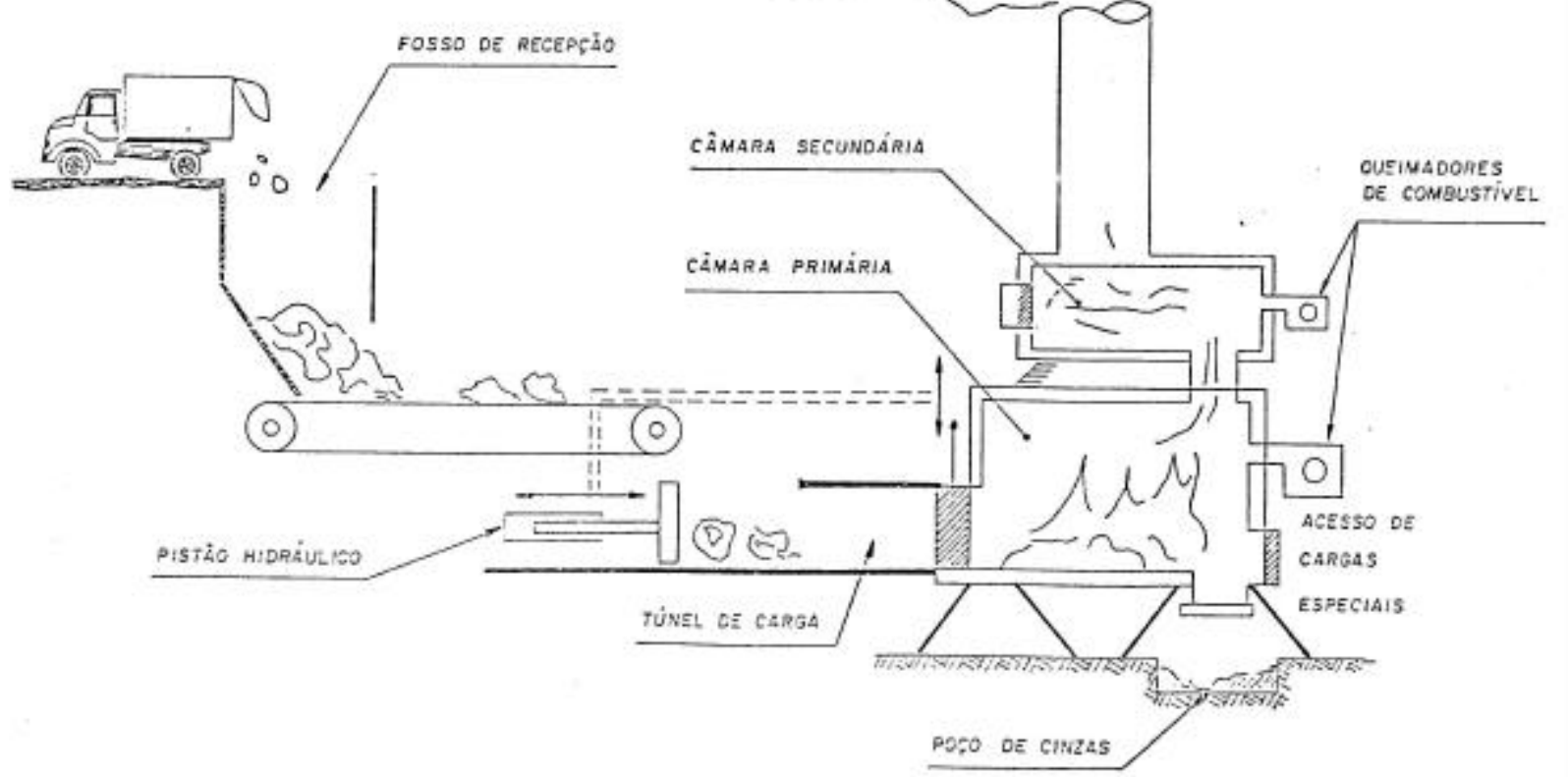

temperatura mínima de $800{ }^{\circ} \mathrm{C}$ e a câmara de combustão secundária a $1000{ }^{\circ} \mathrm{C}$. O gás emitido do incinerador deve ser filtrado e sair por um conduto elevado a cerca de 140 metros de altitude (Brunner \& Brown, 1988; D’Almeida \& Vilhena, 2000). A Fig. 4, apresenta esquematicamente a estrutura e funcionamento do incinerador.

Fig. 4 - Representação simplificada da estrutura de um incinerador mostrando a operacionalização em condições ideais de funcionamento. (Fonte: Alvarenga et al., 1986).

A incineração diminui o volume de resíduos sólidos em cerca de $90 \%$ e o peso a 15\% (Lindenberg, 1982; Ellison apud Haight, 1991; Kosson et al., 1996), sendo essa uma das mais importantes vantagens; porém, apresenta a desvantagem de concentrar o nível de metais pesados e outros compostos como dioxinas e furanos nas 
cinzas e fumaças derivadas do processo, sendo necessário garantir uma combustão completa para se evitar a emissão de poluentes gasosos na atmosfera (Hoffman et al., 1997).

A incineração, que foi muito utilizada nesta última década tem sido pouco indicada atualmente devido a fortes restrições nas legislações de países da América do Norte, Europa e Ásia, pelos riscos de poluição ambiental (Blenkharn, 1995; Moritz, 1995; Urbanowicz, 1998; Wassermann, 1999; Haishima, 2000).

O tratamento de RSS por microondas é relativamente recente, embora já está bastante difundido em vários países como alternativa promissora em relação aos métodos tradicionais de tratamento. $\mathrm{O}$ tratamento se inicia pela trituração dos resíduos em câmara fechada e dotada de pressão negativa para impedir dispersão de aerossóis no ambiente externo. Na etapa seguinte inicia-se o aquecimento e umidificação do material através de jatos de vapor úmido, gerado na própria máquina. A seguir, a massa de resíduos é conduzida através de um tubo onde localizam-se os geradores de microondas. Finalmente um dispositivo descarrega os resíduos triturados e desinfetados em um contêiner para que sejam removidos para um aterro sanitário. Os vapores são tratados por filtros antes de lançados na atmosfera. Este sistema não contribui para a diminuição da ocupação do solo em aterros devido a que o volume dos resíduos não é diminuído (Ribeiro Filho, 1997).

Atualmente, vem sendo desenvolvida uma outra maneira de tratar os RSS, por meio de um processo denominado de "tocha de plasma" ou "plasma pirólise". Tecnologia que associa as altas temperaturas geradas pelo plasma com a pirólise dos resíduos. Por meio da tocha de plasma se produz eletricamente um campo de energia radiante de altíssima intensidade que aplicado sobre os resíduos produz a dissociação 
das ligações moleculares existentes nos compostos sólidos, líquidos ou gasosos, sejam eles perigosos ou não, orgânicos ou inorgânicos. Estes resíduos fundem-se e ficam inertes, gerando um produto vitrificado similar a um mineral de alta pureza. $\mathrm{O}$ volume de gases inicialmente gerado é mais baixo do que na combustão convencional e apresenta uma redução de volume extremamente elevada, podendo ser superior a 99\% (Shima e Beccari, 1995; Daver, 1997)

\subsection{Resíduos sólidos urbanos e a contaminação por metais pesados}

O gerenciamento de resíduos perigosos tem-se transformado, nas últimas décadas, em um dos temas ambientais mais complexos. O número crescente de materiais e substâncias identificadas como perigosas e a produção desses resíduos em quantidades cada vez maiores têm exigido soluções mais eficazes e investimentos maiores por parte de seus geradores e da sociedade em geral. Além disso, com a industrialização crescente dos países ainda em desenvolvimento, esses resíduos passam a ser gerados em regiões nem sempre preparadas para processá-los ou, pelo menos, armazená-los e tratá-los adequadamente.

As atividades com maior potencial de geração de resíduos perigosos são as indústrias químicas, as refinarias de petróleo, a siderurgia, as indústrias de metais não ferrosos, de papel e celulose, de processamento de couros e de instalações que executam serviços de galvanoplastia, decapagem e pintura. Poder-se-ia mesmo afirmar que toda atividade industrial pode gerar algum tipo de resíduo classificado como perigoso pela legislação ambiental (Eyer, 1995).

Por outro lado, existem também os resíduos dos serviços de saúde (RSS), que representam um risco à saúde humana e ambiental, pela presença, principalmente, de 
agentes biológicos, além de uma série de contaminantes químicos presentes nesses resíduos, dentre os quais destacam-se os metais pesados (OSHA, 1991; Takayanagui, 1993; Allerman \& Poulsen, 2000; Takayanagui,2000).

A expressão "metal pesado" é comumente utilizada para designar metais classificados como poluentes, englobando um grupo muito heterogêneo de metais, semi-metais e mesmo não metais como o selênio. Na lista de metais pesados estão com maior freqüência os seguintes elementos: cobre, ferro, manganês, molibdênio, zinco, cobalto, níquel, vanádio, alumínio, prata, cádmio, cromo, mercúrio e chumbo (CETESB, 2001).

Metais pesados como chumbo, mercúrio, cádmio, arsênico, cromo, zinco e manganês, dentre outros, estão presentes em diversos tipos dos resíduos levados para aterros sanitários municipais e incineradores, podendo ser encontrados nesse material: lâmpadas, pilhas galvânicas, baterias, resto de tintas, resto de produtos de limpeza, óleos lubrificantes usados, solventes, embalagens de aerossóis, resto de amálgama utilizada em consultórios odontológicos, materiais fotográficos e radiográficos, embalagens de produtos químicos, pesticidas, fungicidas e inseticidas, componentes eletrônicos descartados isoladamente em placas de circuitos impressos, resíduos de produtos farmacêuticos, medicamentos com prazos de validade vencidos, latarias de alimentos, aditivos alimentares, e plásticos descartados (WHO, 1988; WHO, 1989; WHO, 1992; WHO, 1995; WHO, 2001; Eyer, 1995).

A concentração de metais pesados no meio ambiente, com sua disseminação no solo, água e atmosfera tem sido motivo de crescente preocupação no mundo. Os metais pesados podem ser percolados por meio do chorume, que é o liquido resultante da decomposição de resíduos. O chorume mistura-se com a água de chuva e outros 
líquidos, originalmente existentes no lixo, infiltrando-se no solo e, quando alcança o lençol freático, contamina a água subterrânea. A contaminação dessas águas tem consequiências que perduram por tempo indefinido e são de difícil controle. Além de provocar a contaminação da água, essa disposição inadequada polui também o solo, atingindo as plantas, os animais e o homem (Magossi \& Bonacella, 1991; Serra et al., 1998).

Por outro lado, a incineração de lixo forma materiais particulados que transportam metais pesados, dioxinas e furanos policlorinados, que são carreados pela fumaça e levados pelo vento, precipitando-se no solo contaminando, assim, o ambiente. Os metais pesados, uma vez no solo, podem ser assimilados pelos vegetais, podendo ter um efeito fitotóxico para o homem ao serem introduzidos na cadeia alimentar (Glasser \& Chang,1991; Serra et al., 1998, Cerqueira \& Alves, 1999).

Durante a incineração, os metais pesados são particularmente importantes pela resistência que possuem; são elementos cuja concentração é a mesma, antes e depois da incineração. Estes metais tóxicos são volatilizados e logo condensados na superfície das partículas de cinza suspensas no ar, podendo passar para a vegetação ou solo, e por sua vez, podem ser facilmente inaladas ou ingeridas pelo homem (Denison \& Silbergeld, 1988; Serra et al., 1998).

Os metais pesados que são incorporados no solo podem seguir diferentes vias de fixação, liberação ou transporte, segundo a representação da Fig. 5. Os metais podem ficar retidos no solo, seja dissolvidos em solução ou fixados por processos de adsorção, complexação e precipitação. Também, podem ser absorvidos pelas plantas e, assim, serem incorporados às cadeias tróficas, ou também podem passar para a atmosfera por volatilização ou mover-se para águas superficiais ou subterrâneas. 


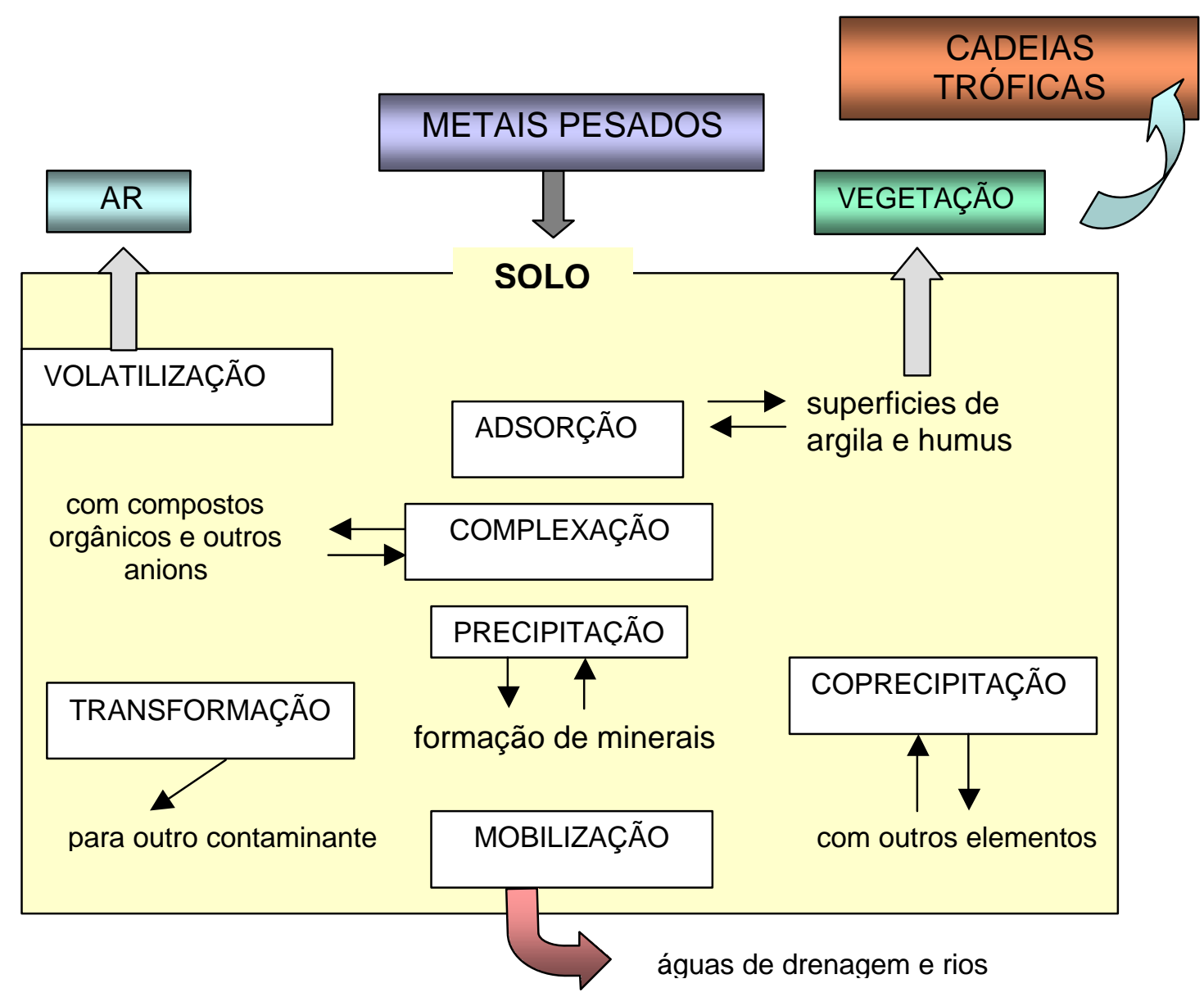

Fig. 5 -Dinâmica dos metais pesados no solo (Adaptada de Anta, 1996 apud Garcia \& Dorronsoro, 2002)

\subsection{Efeito toxicológico dos metais pesados no ser humano}

Os metais pesados apresentam peso atômico relativamente alto e caracterizam-se pelo efeito bioacumulativo. Os metais pesados, em concentrações superiores às legalmente recomendadas, têm sido responsabilizados por causar agravos à saúde, além de uma série de doenças carcinogênicas (Denilon \& Silbergeld, 1988; Magossi \& Bonacella, 1991; Serra et al., 1998).

Os efeitos tóxicos desses metais encontram-se amplamente descritos na literatura, sendo que a gravidade depende do grau de exposição aos mesmos. Dentre 
os efeitos adversos, apontam-se danos no sistema nervoso central, no sistema hepático, no sistema renal, no sistema hematopoiético e no sistema esquelético (Denison \& Silbergeld, 1988; Kreiss, 1990; Stoewsand et al., 1990; Reif et al., 1993; Yourtee, 1994; Boischio \& Henshel, 1996; Cranmer et al., 1996; Kosatsky \& Foran, 1996; Silvany-Neto et al., 1996; Urban et al., 1996; Weiss, 1996; Banks et al.,1997; Cory-Slechta, 1997; Snyder et al., 1997; Bucheim et al., 1998; Costa, 1998; Harada et al., 1998; Hu, 1998; Beuter et al., 1999; Fu et al., 1999; Gorell et al., 1999; Hudnell, 1999; Iregren, 1999; Keen et al., 1999; Kelley, 1999; Lai et al., 1999; Pal et al., 1999; Staessen et al., 1999; Viaene et al., 1999).

Dentre os metais pesados, podem ser citados o mercúrio, chumbo, cádmio, cromo, manganês e zinco, como os mais estudados pelos seus efeitos na saúde; uma descrição mais detalhada desses metais é apresentada a seguir:

Mercúrio: O mercúrio existe em três formas diferentes: elementar, inorgânica e orgânica. Os compostos inorgânicos estão associados a danos à saúde, porém são os compostos orgânicos as formas mais tóxicas e as que passam na cadeia alimentar. Estudos têm demonstrado que independentemente da natureza do mercúrio poluente, o metilmercúrio é essencialmente o mais tóxico e o mais amplamente conhecido (Grandjean et al., 1994; Cranmer et al., 1996).

O mercúrio pode ser absorvido por animais aquáticos na forma de metilmercúrio e etilmercúrio.

Extensos estudos do efeito do metilmercúrio originam-se a partir do desastre acontecido em Minamata, no Japão, em 1956, quando uma fábrica que utilizava metilmercúrio como catalizador na síntese de aldeídos, desprezava seus efluentes nos corpos d'água, o que contaminou a Baia de Minamata, tendo sido reportados 65 casos 
fatais e mais de 2000 casos com seqüelas de variada etiologia (Weiss, 1996; Harada et al., 1998).

Mercúrio inorgânico e orgânico têm sido responsabilizados por causar uma série de disfunções no sistema nervoso central e sistema nervoso periférico, com sintomas variados, dentre os quais podemos assinalar: perda de memória, diminuição dos níveis de inteligência, tremores anormais, falta de coordenação motora, diminuição da velocidade de resposta motora, excitação, distúrbio do sono e mudanças na personalidade que podem desencadear um quadro de demência. Nos casos de exposição muito prolongada ou excessiva pode haver atrofia muscular severa e lesões renais. Também têm sido associados à infertilidade, aborto, malformações congênitas e a diversos tipos de câncer (Yourtee, 1994; Boischio \& Henshel, 1996; Cranmer et al., 1996; Goyer,1996; Kosatsky \& Foran et al., 1996; Urban et al., 1996; Weiss, 1996).

Chumbo: Historicamente, o chumbo é reconhecido como um dos mais antigos e nocivos metais (Corona, 1998). O chumbo pode ser encontrado em diferentes estados de oxidação $\mathrm{Pb}^{0}, \mathrm{~Pb}^{+2}, \mathrm{e} \mathrm{Pb}^{+4}$; porém, a forma $\mathrm{Pb}^{+2}$ representa a maior causa de problemas biológicos (CEHN, 1999).

O trato gastrointestinal serve como via primária de entrada no corpo humano; também as fumaças contendo chumbo podem ser inaladas, resultando na absorção de partículas muito pequenas através do pulmão (CEHN, 1999).

A maior parte do chumbo é incorporada ao tecido ósseo, devido à semelhança entre as propriedades dos compostos de chumbo e cálcio. Por deslocar o cálcio dos ossos, processos degenerativos como osteoporose, podem ser observados após uma exposição prolongada (Banks et al., 1997; Cory-Slechta, 1997; Bucheim et al., 1998). 
Mesmo baixas concentrações de chumbo são capazes de inibir enzimas responsáveis pela catalização de uma etapa essencial na síntese de hemoglobina, levando a quadros de anemia crônica. Apresenta também efeitos adversos no Sistema Nervoso Central, podendo causar retardo mental, distúrbios do aprendizado, disfunções cognitivas e encefalopatias nas crianças. O chumbo tem sido associado com transtornos do sistema hematopoiético, endócrino, renal e reprodutivo (SilvanyNeto et al., 1996; Hu, 1998; Banks et al., 1997; Cory-Slechta, 1997; Bucheim et al., 1998).

Mulheres grávidas, lactantes e crianças pequenas são os grupos mais sensíveis à exposição ambiental ao chumbo. Como a placenta é permeável a esses metais, os fetos podem ser atingidos, nascendo já afetados (Gerhard et al., 1998).

Manganês: Mineral essencial, porém tóxico quando é absorvido em excesso. A contaminação por manganês tem sido associada com deficiências neurológicas, transtornos comportamentais e doenças neuro-psiquiátricas (Hudnell, 1999; Lai et al., 1999; Mergler et al., 1999)

Estudos recentes indicam que os primeiros sinais de neurotoxicidade do manganês são difusos e envolvem funções neuromotoras, sensoriais, cognitivas e fisiológicas. Os primeiros sintomas são debilidade muscular, tremores anormais, dor de cabeça, inclinação ao caminhar, salivação e reações psicóticas, quadro que pode desencadear a denominada "loucura mangânica", que é seguida por uma disfunção extrapiramidal que apresenta sinais da doença de Parkinson (Beuter et al., 1999; Gorell et al., 1999; Hudnell, 1999; Iregren, 1999; Keen et al., 1999; Lai et al., 1999; Pal et al., 1999). 
Os danos parecem ser irreversíveis, mesmo quando os pacientes são retirados da fonte de poluição. Estudos apontam que o feto está relativamente protegido, em função da placenta se constituir numa barreira biológica que diminui a absorção do manganês (Huang et al., 1993; Fechter, 1999).

Cádmio: Produto da mineração e soldagem do zinco e chumbo. Representa importante fonte de contaminação ambiental. O cádmio é também encontrado no solo devido à precipitação no ar e ao uso de alguns fertilizantes compostos (Cai, 1995).

Aproximadamente, 2 a 7\% do cádmio ingerido são absorvidos através do trato gastrointestinal sendo sua absorção beneficiada quando existe deficiência em cálcio, ferro ou proteína. A absorção através do trato respiratório é mais eficiente, variando de 15 a 50\% da dose inalada (Lauwerys et al.,1994).

Extensos estudos do efeito do cádmio originam-se a partir do desastre acontecido em Toyama, Japão (1962), quando o cádmio procedente de uma exploração mineira, contaminou as plantações de arroz da localidade, desencadeando uma série de transtornos na população exposta, como dor lombar, mialgia das extremidades inferiores, deformações do esqueleto e osteoporose com fraturas múltiplas (WHO,1992).

O cádmio também tem sido associado à danos neurológicos, causando polineuropatias, disfunção dos túbulos renais com manifestação de proteinúria, aberrações cromosômicas, perda do olfato, redução na formação de glóbulos vermelhos e remoção de cálcio dos ossos. Tem sido associado também com câncer e outras doenças mutagênicas (Kreiss, 1990; Stoewsand et al., 1990; Fu et al., 1999; Kelley, 1999; Viaene et al., 1999; Staessen et al., 1999). 
Cromo: O cromo é um metal que ocorre naturalmente e pode formar uma grande variedade de compostos altamente tóxicos. Tem sido demonstrado que os compostos de cromo hexavalente são muito mais tóxicos que os compostos de cromo trivalente. A população em geral está exposta ao cromo, geralmente na forma trivalente, através da alimentação e da ingestão de água potável. Estima-se que o ser humano ingere até $60 \mathrm{ug}$ por dia de cromo a partir dos alimentos (WHO, 1998).

O aparelho respiratório é o principal alvo da intoxicação com cromo, o qual quando inhalado provoca dispnéia e tosse. A forma hexavalente do cromo é considerada, também, um carcinogênico muito potente, tendo sido associado com a incidência de tumores malignos de pulmão e de danos renais. A mortalidade por câncer pulmonar tem sido associada à exposição ocupacional ao cromo hexavalente (Becker, 1999; Flora, 2000). Também é considerado irritante das mucosas e da pele, pela sua propriedade corrosiva (Snyder et al., 1997; Costa, 1998; Barceloux, 1999a).

Cobre: O cobre é um elemento essencial para todas as formas de vida em baixas concentrações; porém, altos níveis deste mineral têm sido associados a sintomas gastrointestinais, como diarréia, dor abdominal, náusea e vômito (Pizarro et al., 1999).

Ingestões acidentais de cobre foram descritas principalmente associadas com a ingestão de água e alimentos cozidos em recipinetes de cobre ou que tenham sido preparados em máquinas defeituosas. Existem relatos de intoxicação pelo consumo de vinho preparado com misturas a base de cobre, que causaram febre, diminuição do apetite, fraqueza muscular e sobretudo uma patologia pulmonar que desencadeia o câncer do pulmão e a cirrose do fígado (WHO, 2001). 
Zinco: $\mathrm{O}$ zinco forma lentamente precipitados solúveis com os íons $\mathrm{CO}_{3}$, $\mathrm{NO}_{3}, \mathrm{PO}_{4}$ e Si. O zinco é um elemento fortemente absorvido nas reações que acontecem no solo. Os compostos de zinco, se presentes em quantidades superiores às recomendadas, podem produzir irritação e corrosão do trato intestinal, podendo ainda levar à necrose renal ou nefrite, nos casos mais severos. A exposição ocupacional à fumaça contendo óxido de zinco provoca fatiga, calafrios, febre, mialgia, tosse, leucocitose, sede, sabor metálico na boca, e salivação. Os compostos de zinco não são considerados carcinogênicos (Barceloux, 1999b).

\subsection{Avaliação de risco e os resíduos sólidos}

Os resíduos sólidos urbanos são considerados uma preocupação, não apenas para os administradores públicos, como também para cientistas da área e para a própria população que já começa a se organizar em movimentos populacionais contrários à instalação de usinas de tratamento de lixo, incineradores ou mesmo aterros sanitários (Elliot, 1998; Wakefield \& Elliot, 2000).

Há uma vasta literatura sobre a síndrome "Not in my back yard" (NIMBY), traduzida como "não em meu quintal”, surgida nas últimas décadas do século XX nos EUA, que significou uma forte reação de comunidades organizadas contra a instalação de sistemas de tratamento e disposição de resíduos sólidos no ambiente urbano (Eyles et al., 1993; Elliot et al., 1998). Esta preocupação diz respeito ao risco que o indivíduo pode sofrer quando exposto a sistemas de processamento de resíduos sólidos, em especial os RSS (Golberg et al., 1995; OMS, 2001).

O conceito de risco está associado, tanto à natureza do perigo, quanto à possibilidade de ocorrência de dano devido à exposição a um determinado agente 
perigoso. Este agente, ou perigo é considerado como a fonte de risco existente, podendo ser uma substância ou uma ação que desencadeia o dano (Cole, 1995; Peña et al., 2001).

Avaliação de risco é uma técnica interdisciplinar que permite determinar a possibilidade de sofrer um dano pela exposição a um perigo. O processo de avaliação de risco, que consiste em uma forma de abordagem que vem sendo utilizada também, na área de saúde ambiental, é relativamente novo; porém, guarda antigas raízes ligadas à preocupação do homem em garantir uma proteção à saúde humana e ao ambiente físico pela exposição a agentes causadores de danos, baseados na prevenção e redução de riscos (Peña et al., 2001).

A avaliação de risco não se constitui numa fórmula para tratar a problemática de uma situação de risco, porém contribui como uma estratégia na tomada de decisões para a identificação, avaliação, controle e redução dos riscos associados com diversas atividades humanas (CSA, 1991).

Têm sido desenvolvidos estudos sobre avaliação de risco para diferentes situações existentes na sociedade, dentre eles, os resíduos sólidos urbanos, envolvendo toda sua dinâmica de processamento.

Segundo o informe da Reunião da Divisão Bilthoven da OMS, realizada em abril de 2000, o risco potencial para a saúde humana provocado pela disposição e incineração de resíduos, tanto perigosos quanto não perigosos, gera permanente preocupação pública, pelo fato de que os dados disponíveis, no nível mundial, são insuficientes, existindo escassa informação quantitativa sobre exposição a sustâncias perigosas liberadas no ambiente (OMS, 2001). 
A OMS, em seu relatório "Métodos de Avaliação de Risco para a saúde derivados da exposição à substâncias perigosas liberadas por aterros sanitários" (OMS, 2001), considera que o processo de avaliação de risco pode ser organizado em cinco fases, a saber:

1. Identificação do Perigo: Essa etapa caracteriza-se pela identificação de potenciais impactos adversos, caracterização do local e de áreas circunvizinhas, caracterização de contaminantes potencialmente adversos e identificação das vias de migração e transporte, bem como caracterização dos receptores.

Dentre os questionamentos essenciais que devem ser respondidos nessa etapa podemos citar a forma como está sendo realizada a utilização atual do local, informação sobre natureza dos resíduos depositados e tratados no local, acesso ao local pelo público em geral, emanação de substâncias que gerem preocupação, existência de outras fontes de exposição nas imediações do local de estudo, tamanho, características e composição da população em risco.

2. Estimativa do risco: Medição e estimativa das concentrações dos contaminantes no meio ambiente que geram preocupação, com os quais os seres humanos poderiam estar em contato, como o solo, ar, alimentos, água e outros meios existentes dentro e fora do local.

Neste momento devem ser respondidas questões como: concentrações máximas, superação das normas existentes e comparação com concentrações normais. 
3. Avaliação de risco: Esta fase tem como meta estimar a severidade e probabilidade de que se produza um dano. Para tal fim são utilizadas três técnicas: Avaliação da fonte/mecanismo de emissão, avaliação da exposição, avaliação da dose/resposta.

Se esta análise indicar que existe potencial exposição da população até um raio de $2 \mathrm{Km}$ de distância, deverá ser considerada a possibilidade de se efetuar novos estudos ou ações que permitam avaliar o impacto ambiental através de diagramas de fluxo que levem em consideração todas as possíveis vias de contaminação.

4. Gerenciamento do risco: Constitui o conjunto de medidas planejadas para as ações político-administrativas, a partir de dados oriundos do processo de avaliação de risco em uma determinada situação. Esta fase envolve negociações e decisões para resolver até que nível o risco é tolerável; tem que se decidir se devem ser realizados estudos epidemiológicos ou vigilância à saúde; também, deve-se avaliar a necessidade de se coletar informação adicional para a avaliação da exposição ou se é necessária a realização de novas medidas (Peña et al., 2001).

5. Comunicação do risco: Nesta fase os atores envolvidos devem transferir informação à comunidade acerca dos níveis de risco para a saúde e ambiente, importância desses riscos, decisões e ações ou meios políticos com os quais poderiam contar para o controle e gerenciamento dos riscos (Peña et al., 2001). 
Nesse contexto, a monitorização ambiental de metais pesados, que são definidos pela OMS (2001) como contaminantes prioritários pela sua toxicidade, permanência no ambiente, mobilidade e bioacumulação, deve servir de ponto de partida para realização de processos de avaliação de risco, determinando, a partir daí, a existência de vias de exposição completas até populações expostas a esse tipo de contaminantes.

\subsection{Problemática dos resíduos sólidos}

Na Conferência das Nações Unidas sobre Meio Ambiente e Desenvolvimento, realizada no Rio de Janeiro, em 1992 -ECO/92, conforme o documento “Agenda 21”, analistas do mundo todo interpretam as catástrofes ambientais como decorrência, em grande parte, do atual estágio de desenvolvimento global e dos padrões de produção e consumo, especialmente nos países industrializados (Sodré, 1997).

$\mathrm{Na}$ atualidade, a sociedade moderna apresenta um aumento inusitado da produtividade enquanto cresce, também, a desigualdade na distribuição dos bens entre indivíduos e nações. $\mathrm{O}$ acesso a bens de consumo e, por consequiência, a geração de resíduos guarda uma estreita relação com as diferenças entre países desenvolvidos e em desenvolvimento, em função da economia, do sistema sócio-cultural, da ideologia e do sistema político vigente, como também das divergências entre diferentes estratos sociais (Sodré, 1997).

Pode-se citar, como exemplo, a produção diária per capita de lixo urbano nos Estados Unidos que é de aproximadamente de $2 \mathrm{Kg}$ por pessoa, na Europa atinge cerca de $1 \mathrm{~kg}$ por pessoa, enquanto nos países em desenvolvimento esses valores dificilmente ultrapassam $800 \mathrm{~g}$ por pessoa. Sabe-se que um indivíduo na América do 
Norte consome quase 20 vezes mais que uma pessoa da Índia ou da China, e 60 vezes mais que uma pessoa de Bangladesh (Carvalho \& Tella, 1997).

Segundo a Agência de Proteção Ambiental (EPA), os Estados Unidos da América precisam construir 500 aterros por ano para deposição dos resíduos gerados, sabendo-se que vem ocorrendo um aumento de 80\% desses resíduos desde 1960 (Ferreira, 1999).

A facilidade que se tem para gerar resíduos em grandes quantidades, principalmente nos países desenvolvidos, é uma constatação, porém, o espaço físico nesses mesmos países para a construção de aterros é extremamente reduzido (Ferreira, 1999).

Nos países em desenvolvimento a realidade não é muito diferente; apesar de serem países com menor geração de resíduos per capita, o aumento da população associado com as dificuldades tecnológicas e econômicas geram problemas semelhantes aos existentes nos países desenvolvidos, quanto ao gerenciamento dos resíduos sólidos, imperando, portanto, a necessidade de transformação dos atuais padrões de vida, mediante a adoção efetiva de propostas para redução, reutilização e reciclagem dos resíduos sólidos em nível mundial.

\section{Realidade no Brasil}

A Pesquisa Nacional de Saneamento Básico 2000 (IBGE, 2000), revela que das 228.413 toneladas de lixo geradas diariamente no Brasil, $21 \%$ tem como destinação lixões a céu aberto ou áreas alagadas, $37 \%$ são levadas a aterros controlados, 36\% vão para aterros sanitários, 2,8\% são utilizadas na compostagem, $0,9 \%$ vão para usinas de triagem e $0,5 \%$ são incineradas. 
O lixão a céu aberto, que vêm diminuindo sensivelmente nesta última década, é um sistema de disposição ambientalmente inadequado, mas, por outro lado, o uso de aterros sanitários como principal método de disposição parece também não solucionar, a longo prazo, as dificuldades inerentes ao tratamento e disposição de resíduos sólidos (Viana, 1999).

Os aterros, embora importantes, apresentam algumas limitações como o tempo de vida razoavelmente curto e a grande dificuldade na obtenção de locais adequados para sua implementação nas proximidades dos centros urbanos, sem que se trate de locais de recarga do aqüífero ou inadequados por outros motivos.

A problemática dos resíduos dos serviços de saúde (RSS) é também uma questão que merece maior atenção. Na grande maioria das cidades brasileiras, igualmente como acontece nos países latinoamericanos, os RSS não recebem tratamento especial, tendo como destino final o mesmo local utilizado para descarte dos demais resíduos urbanos. Esses locais, geralmente constituem-se em aterros inadequados ou lixões a céu aberto, com livre acesso a um grande número de pessoas que praticam catação desses resíduos, tornando-se um grupo vulnerável à contaminações devido ao contato direto com diversos tipos de agentes biológicos, químicos e, até mesmo, radioativos (Risso, 1993; Takayanagui, 1993; Blenkharn, 1995; Malavaud \& Marty, 1997).

\section{Situação no Estado de São Paulo}

O Estado de São Paulo, embora considerado como o estado mais desenvolvido do país, ainda possui uma situação deficitária em relação ao gerenciamento dos resíduos sólidos gerados. 
A cidade de São Paulo, por exemplo, possui atualmente, dificuldades inerentes ao uso de aterros sanitários como principal método de disposição de lixo urbano. No fim da década de 90, Gentile (1998) já previa que para o ano 2001, São Paulo teria a saturação dos dois únicos aterros sanitários da cidade (Bandeirantes e São João) e não haveria mais locais para dispor as 20.150 toneladas de lixo geradas diariamente (IBGE, 2000).

No caso da cidade de São Paulo, além de faltar locais apropriados para a implementação de novos aterros, está-se vivenciando uma situação preocupante com o aumento de lixões clandestinos espalhados pela cidade, o que representa grande risco para a saúde pública. Ainda, outro agravante é causado pelo considerável aumento da produção de resíduos em conseqüência do aumento da população e dos padrões de produção e consumo (Viana, 1999).

Outro problema associado à utilização de aterros sanitários está relacionado com a presença de chorume, dada à inexistência, até pouco tempo, de um método de tratamento adequado. Em alguns casos, parte deste chorume é re-circulado no aterro, mas o restante acaba gerando dificuldades para sua disposição. Isso ocorre, em parte, devido à grande oscilação de volume desse líquido dentro do aterro.

Devido às suas características poluidoras, como por exemplo, a elevada concentração de metais pesados e a alta demanda bioquímica de oxigênio, o chorume causa grandes impactos no meio ambiente (Schalch \& Rezende, 1991; Jardim et al., 1995).

\section{Situação em Ribeirão Preto}

Desde 1974, a cidade de Ribeirão Preto, situada na região nordeste do Estado de São Paulo, a exemplo de outras cidades brasileiras, começou a busca de soluções 
para a destinação final de seus resíduos sólidos. Naquele período teve instalado o "Antigo Lixão Juliana" oficialmente reconhecido pela Prefeitura Municipal. No entanto, sua localização ficava exatamente sobre a zona correspondente ao afloramento da formação Botucatu - Pirambóia, atualmente denominado Aqüífero Guarani, caracterizada geologicamente como uma área de recarga do extenso aqüífero da região, portanto totalmente inadequada para descarga de resíduos, o que não impediu seu funcionamento de 1974 até 1979, como lixão a céu aberto, sem controle dos resíduos ali dispostos e representando área de alto impacto ambiental que até hoje exige cuidados e estudos para remediação.

De 1979 a 1989 foi habilitada uma outra área para disposição de resíduos sólidos do município denominado "Lixão de Serrana", localizado a 7,5 Km da cidade de Ribeirão Preto, nas margens da Rodovia Abraão Assed, que une o Município de Ribeirão Preto com a cidade de Serrana, também localizado dentro da zona do arenito da formação Botucatú - Pirambóia. O "Lixão de Serrana" possuía uma área de aproximadamente 50 mil $\mathrm{m}^{2}$ e o volume de descarga em 1989 era de 210 toneladas diárias. Segundo consta em Estudo de Impacto Ambiental (Alvarenga et al., 1986), os resíduos urbanos predominantemente domésticos e os resíduos provenientes dos serviços de saúde eram transportados por caminhões até o local e lançados em buracos abertos no solo, sendo recobertos com uma camada de terra. O lixo hospitalar recebia uma camada de cal antes da cobertura, o que não impedia sua catação prévia por inúmeras pessoas que ali trabalhavam clandestinamente.

Do ponto de vista técnico, esse era também um local inadequado para a disposição de resíduos, devido à inexistência de obras preliminares que facilitassem a percolação do chorume para camadas subterrâneas, alcançando em alguns pontos, 
atualmente monitorados, o lençol de águas. Além disso, nas épocas de chuva o acesso ao local ficava prejudicado o que impedia a cobertura imediata com uma camada de terra, caracterizando-se num sistema de disposição do tipo lixão a céu aberto. Somado a isso havia a questão de sua inadequada localização, do ponto de vista geológico, por situar-se em área de recarga do Aqüífero Guarani (Alvarenga et al., 1986).

A partir de 1990 a disposição de resíduos sólidos do município passou a ser executada em um aterro sanitário construído de acordo com as normas técnicas para receber resíduos sólidos do tipo Classe II e III (ABNT, 1987); também teve instalado um incinerador a calor seco para tratamento dos resíduos hospitalares antes de sua disposição final no aterro.

Para a seleção do local foi realizada uma avaliação de sete possíveis locais para disposição de resíduos sólidos no município, tendo sido considerados os seguintes parâmetros: direção dos ventos, distância de áreas urbanizadas, espessura da camada de rocha básica sobre o Arenito Botucatu, espessura da camada de solo sobre a rocha básica, uniformidade da espessura da camada de solo, profundidade do lençol freático, velocidade de percolação, proximidades de cursos de água, proximidade de habitações isoladas e declive do terreno (Alvarenga et al., 1986).

Após avaliação, foi selecionada uma área de $201.400 \mathrm{~m}^{2}$, dentro da qual o aterro sanitário passou a ocupar $135.000 \mathrm{~m}^{2}$, localizado sobre a formação basáltica da Serra Geral, a qual não é considerada geologicamente uma zona de recarga de aqüífero (Alvarenga et al., 1986).

O emprendimento foi implantado em 1990 numa etapa continua até o aterro ocupar gradativamente toda a área disponível, o que estava previsto para acontecer em 9 anos após o início das operações, ou seja, até 1999. O Aterro Sanitário foi 
projetado para receber no final de sua vida útil 244 toneladas de resíduos, por dia (Alvarenga, et al., 1986).

Através de relatório, em 1999, do extinto Departamento de Urbanização e Saneamento do Município, responsável, na época, pela instalação e manutenção dessas operações, pode-se constatar pelo registro de alguns fatos que, provavelmente, estariam ocorrendo problemas em sua operação os quais poderiam estar afetando a qualidade ambiental do local, devido ao não-cumprimento de algumas das condições, tais como:

“...o projeto original do Aterro, previa a superposição de quatro camadas; porém, está-se trabalhando já numa extensão da vida útil do mesmo, com a inclusão de duas camadas sobre as quatro operadas,... atualmente, o líquido percolado é bombeado da volta à célula da superfície, até que se instale o sistema de tratamento do chorume..." (Anexo A).

O Módulo I do Aterro Sanitário funcionou até outubro de 2000, alcançando a sétima célula, com a disposição de um volume de 430 toneladas/dia, volume $76 \%$ maior do que o inicialmente estimado pelo EIA-RIMA (Alvarenga et al., 1986), que também previa o término de seu funcionamento na quarta célula. Atualmente está-se trabalhando no Módulo II, que se constitui numa extensão da área útil do Aterro Sanitário de aproximadamente $75 \mathrm{mil} \mathrm{m}$, em operação desde novembro de 2000.

O Incinerador, do tipo AB Garcez, com capacidade de 500 Kilos/hora, foi planejado para uma operação inicial de 7 toneladas/dia no início podendo chegar a 19 toneladas/dia. Nos últimos anos o volume máximo de RSS incinerados foi de 
aproximadamente 9 ton/dia, funcionando em 3 jornadas de 8 horas diariamente (Alvarenga, et al., 1986).

Segundo Relatórios das Ações de Controle em Sistema de Incineração de Serviços de Saúde da CETESB, o referido incinerador passou a sofrer penalidades por falta de licença de funcionamento, devido à freqüente constatação da emissão de fumaça preta, o que refletia problemas ligados ao equipamento (Anexo B).

Devido a essas irregularidades, o Incinerador ficou fora de funcionamento durante sete meses no ano 1999 e novamente de janeiro a setembro de 2001, por problemas estruturais em suas instalações; nesse período, os resíduos dos serviços de saúde foram dispostos no Aterro Sanitário, em área separada dos resíduos domiciliares.

Atualmente, os RSS do município estão passando por um momento de transição em relação ao processo de tratamento, com o envolvimento de outro setor industrial e adotando-se a sistema de desinfecção por microondas.

Segundo a OMS, mundialmente há uma escassez de informação sobre os níveis de contaminação do ambiente em áreas localizadas próximas a usinas de processamento de resíduos, tais como: usinas de compostagem, centros de reciclagem, usinas de tratamento com incineradores ou outros métodos (OMS, 2001), o que dificulta a tomada de decisões político-administrativas mais profícuas e incisivas diante de problemas ambientais.

Assim, esta pesquisa tem como finalidade contribuir para a aquisição de novos conhecimentos sobre a contaminação ambiental por metais pesados, decorrentes da disposição de resíduos sólidos urbanos, além de subsidiar as ações municipais nessa área de atuação. 


\subsection{Objetivos}

Considerando o tempo de funcionamento do Aterro Sanitário e do Incinerador de Resíduos Sólidos de Ribeirão Preto-SP, assim como a necessidade de obter conhecimento sobre os níveis de metais pesados em áreas circunvizinhas a locais de disposição e tratamento de resíduos sólidos, foram formulados os seguintes objetivos para o presente estudo:

- Analisar os níveis de cádmio $(\mathrm{Cd})$, cromo $(\mathrm{Cr})$, chumbo $(\mathrm{Pb})$, manganês $(\mathrm{Mn})$, zinco $(\mathrm{Zn})$ e cobre $(\mathrm{Cu})$, no solo, vegetais, chorume e água subterrânea na área do Aterro Sanitário e Incinerador Municipal de Resíduos Sólidos de Ribeirão Preto.

- Gerar informação sobre a situação ambiental em relação à presença de metais no entorno do Aterro Sanitário e Incinerador Municipal de Resíduos Sólidos de Ribeirão Preto, a fim de subsidiar as ações político-administrativas municipais. 


\section{MATERIAL E MÉTODOS}

\subsection{Delineamento da Pesquisa}

Esta pesquisa constitui-se num estudo transversal, definido como um estudo no qual as observações ou mensurações das variáveis de interesse são feitas simultaneamente, de forma que os dados obtidos representam uma "radiografia" sobre uma determinada situação em um dado momento (Forattini, 1992, Pereira, 1995). Desse modo, esta investigação trata especificamente da avaliação dos níveis de metais na área do Aterro Sanitário e Incinerador Municipal de Ribeirão Preto-SP, nos anos 2000 e 2001.

Como primeiro passo, foi solicitada a aprovação da execução do projeto junto ao Departamento de Água e Esgoto de Ribeirão Preto (DAERP), entidade responsável pela gestão de resíduos sólidos do Município, e, também, a aprovação do Comitê de Etica em Pesquisa da Escola de Enfermagem de Ribeirão Preto/USP.

Visando o alcance dos objetivos traçados para esta investigação foi elaborada uma metodologia que envolveu um conjunto de procedimentos que se iniciaram com delimitação do local do estudo, escolha dos instrumentos e preparação dos materiais para coleta, prosseguindo com a demarcação dos pontos para coleta das amostras, 
adoção de técnicas analíticas, validação dos métodos, além do tratamento estatístico dos dados levantados.

As variáveis estudadas constituíram-se pelos metais: cádmio, cromo, chumbo, manganês, zinco, cobre e mercúrio presentes nas matrizes: solo, vegetais, água subterrânea e líquido percolado nos pontos demarcados.

\subsection{Procedimento Metodológico}

\section{Local de Estudo}

O município de Ribeirão Preto está localizado na região Nordeste do Estado de São Paulo, mais precisamente na porção Norte-Noroeste da Bacia do Paraná, na província geomorfológica denominada "Cuestas Basálticas" (Laguna,2000). Atualmente, possui uma população de cerca de 504.923 habitantes e uma área de 651 $\mathrm{km}^{2}$ (IBGE, 2000).

O presente estudo foi realizado no Aterro Sanitário e Incinerador de Resíduos de Sólidos de Ribeirão Preto, localizado nas margens da Rodovia Mário Donega, que oferece acesso às cidades de Dumont e Pradópolis, próximo ao Anel Viário, situado entre as coordenadas $21^{\circ} 10^{\prime}$ a $21^{\circ} 15^{\prime}$ de latitude Sul e $47^{\circ} 50^{\prime}$ a $47^{\circ} 51^{\prime}$ de longitude Oeste (Figuras 6 e 7). 


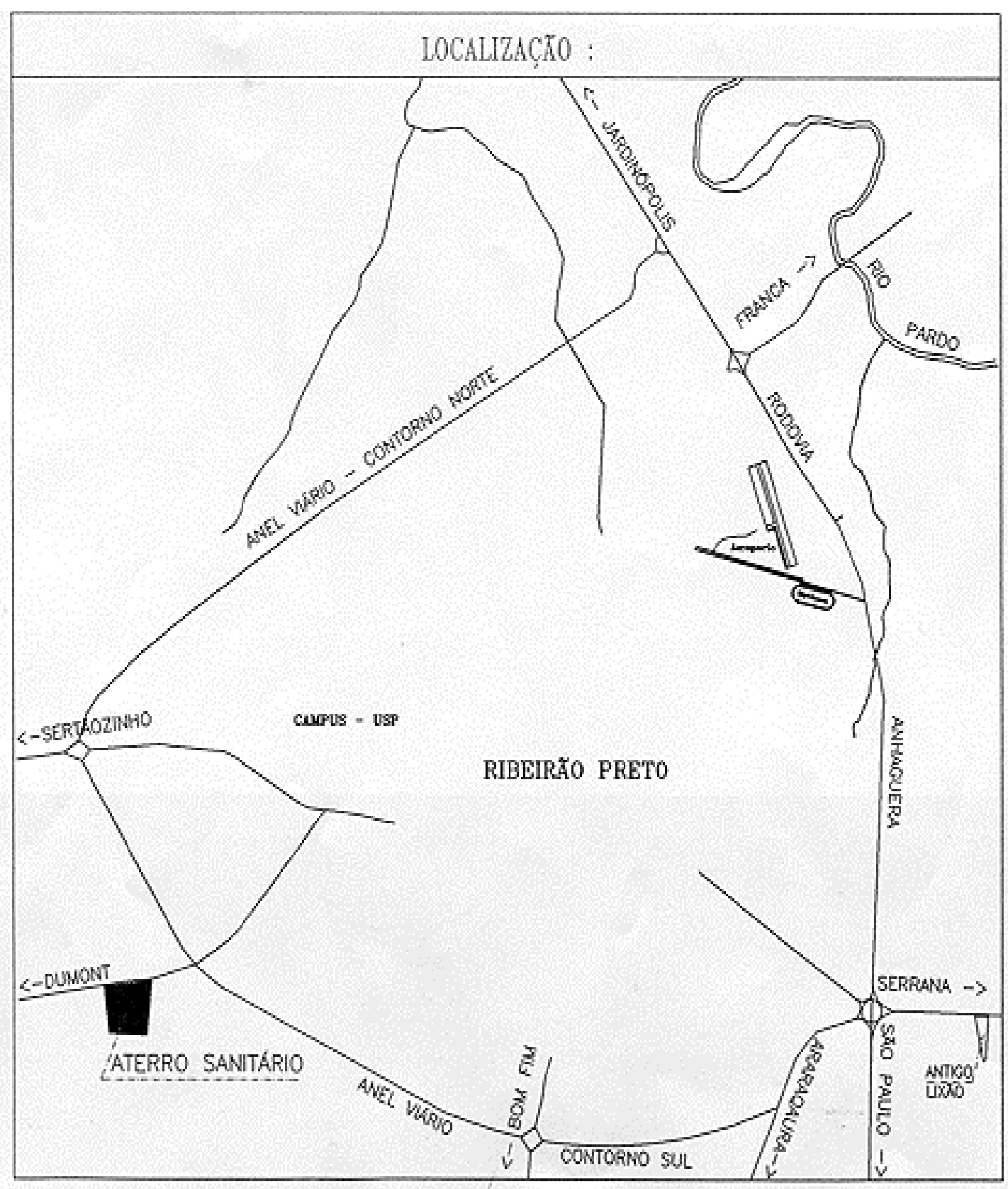


Fig. 6 -Mapa de localização do Aterro Sanitário Incinerador de Ribeirão Preto (Fonte: Alvarenga et al., 1986).

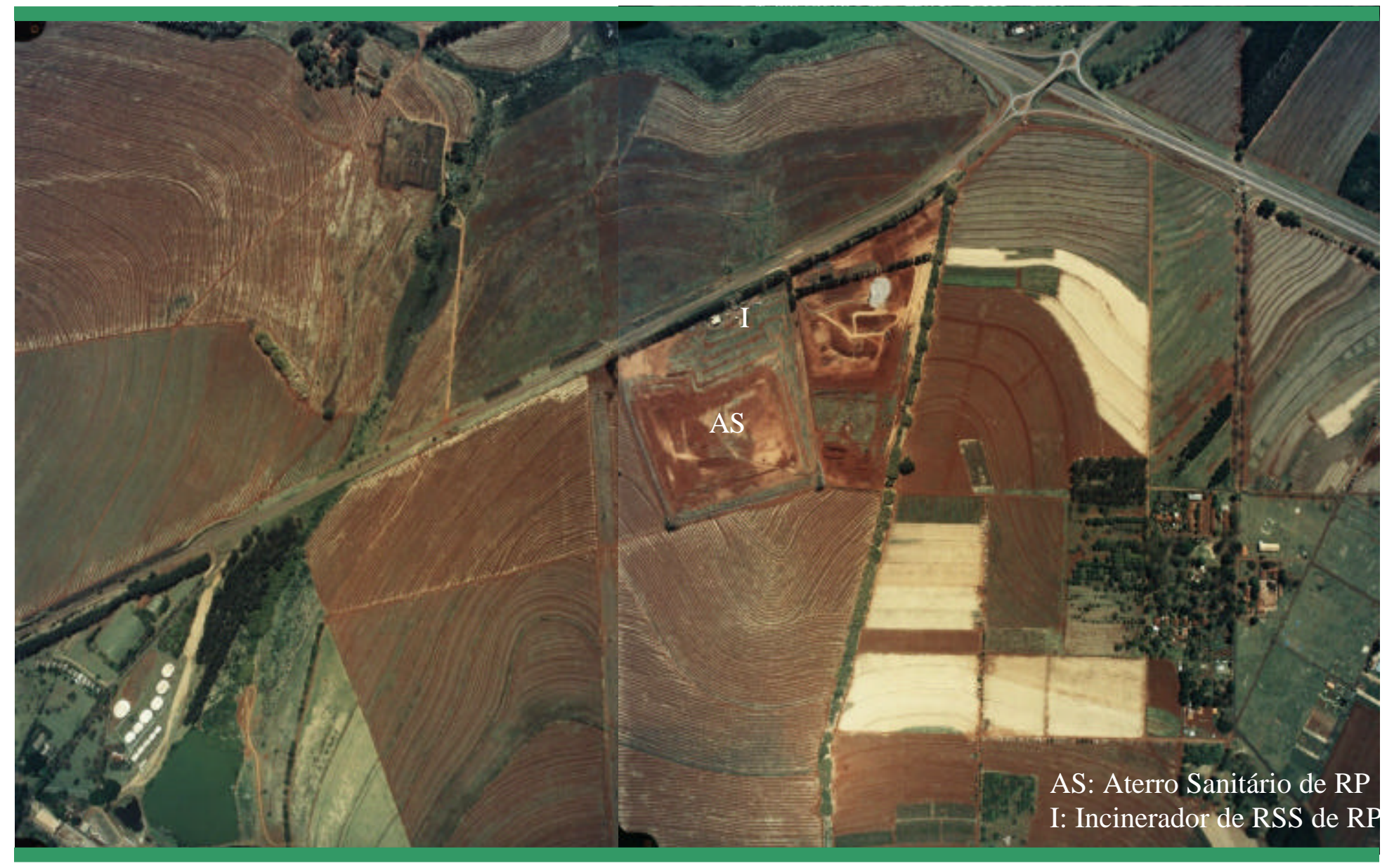

Fig. 7 - Foto Aérea do Aterro Sanitário e Incinerador de Ribeirão Preto e das áreas circunvizinhas (Fonte: Secretaria Municipal de Planejamento, 2002). 


\section{Demarcação dos pontos de coleta}

A demarcação dos pontos de coleta, realizada em junho de 2000, foi executada no local de estudo por uma equipe de topógrafos, liderada por um engenheiro agrimensor da firma "Paulo Mano Engenharia", após planejamento prévio e estudo da área (Fig. 8).

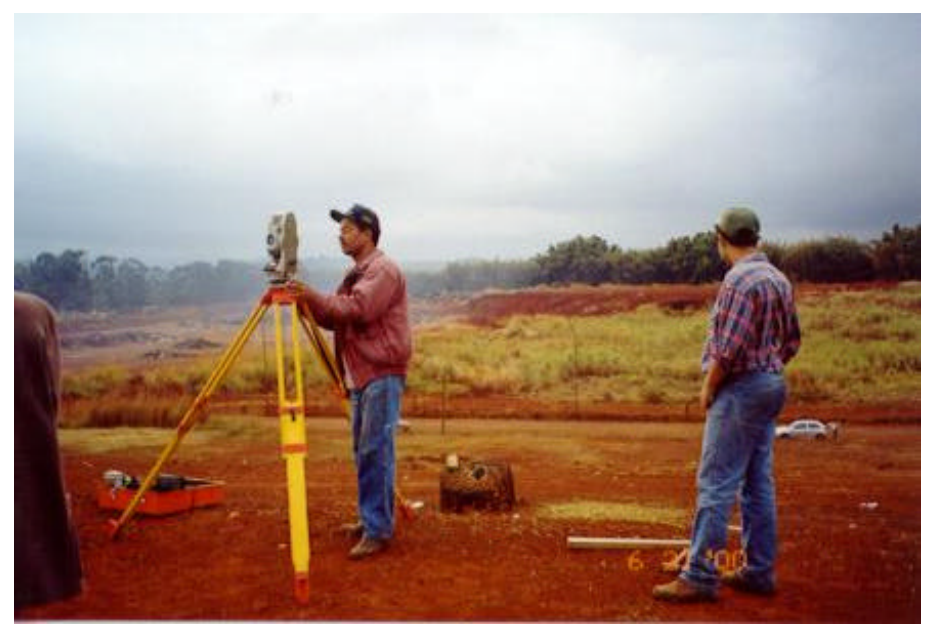

Fig. 8 - Momento de determinação dos pontos de coleta de amostras de solo e vegetais no Aterro Sanitário da Cidade de Ribeirão Preto - SP. (Fonte: Takayanagui \& Segura-Muñoz, 2000)

Essa demarcação dos pontos de coleta foi iniciada com a definição de um ponto central no Aterro Sanitário, a partir do qual foram delimitados os pontos de sondagem nos sentido Norte, Sul, Leste e Oeste, com base na orientação do norte magnético, iniciando-se pelos limites das células do Aterro Sanitário considerados no estudo como "ponto zero". 
Inicialmente, havia sido planejada a coleta das amostras nos pontos: zero, 50, 100 e 200 metros para cada uma das 4 direções (Norte, Sul, Leste, e Oeste). Porém, a existência de extensos canaviais fechados limitou o acesso para a demarcação e coleta em alguns pontos no sentido Oeste e Sul (Fig. 9); motivo pelo qual, a distribuição dos pontos de coleta acabou sofrendo algumas alterações.

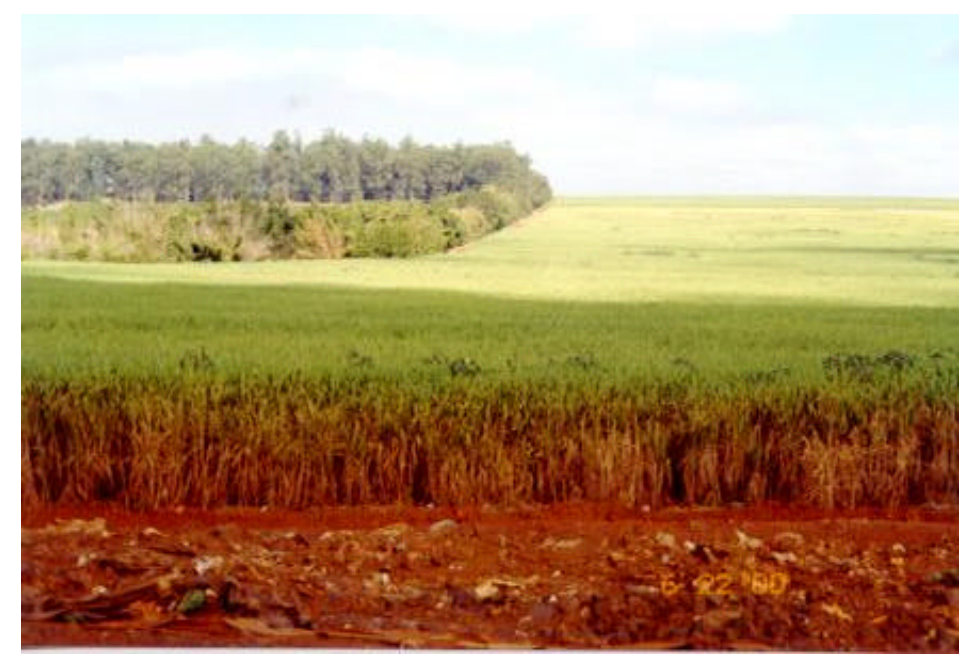

Fig. 9 - Canaviais limítrofes no sentido Sul do Aterro Sanitário da Cidade de Ribeirão Preto - SP (Fonte: Takayanagui \& Segura-Muñoz, 2000).

Assim, foram selecionados quatro pontos de coleta para a direção Norte e igualmente para a direção Leste, com as distâncias de 0, 50, 100 e 200 metros. Para a direção Oeste, os quatro pontos corresponderam às distâncias de 0, 50, 100 e 115 metros e, no sentido Sul, os valores foram de 0, 22 e 554 metros (Fig. 10). 


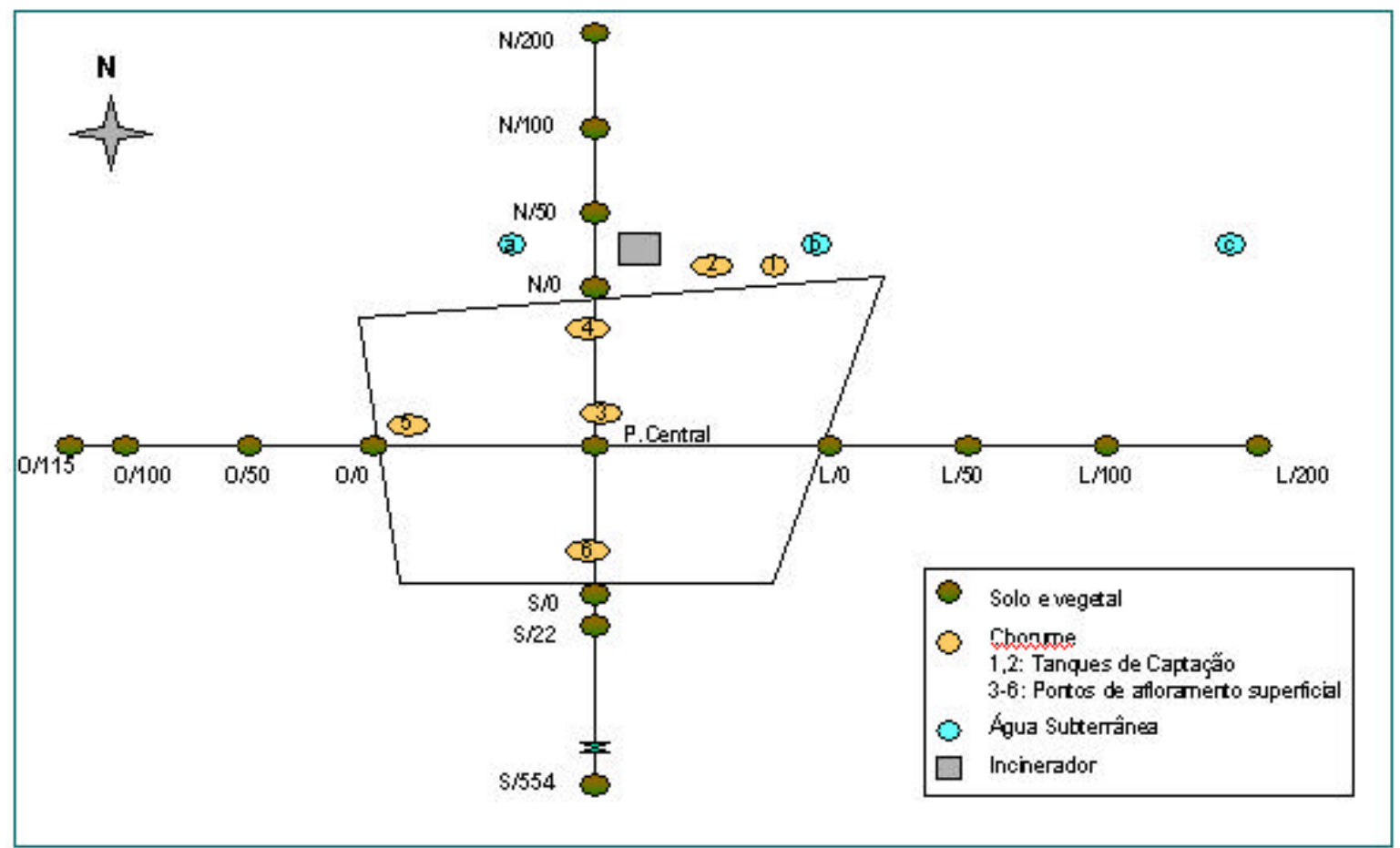

Fig. 10: Pontos de coleta delimitados para cada matriz segundo sua distribuição espacial

(Fonte: Projeto Topográfico da Coleta de Amostras, Anexo C)

\section{Instrumentos para coleta de dados}

Todos os materiais utilizados para coleta e acondicionamento eram de polietileno e foram previamente submergidos em solução de ácido nítrico a 30\% por 24 horas, para eliminação de metais interferentes (VARIAN, 1988; APHA,1998; Voegborlo et al., 1999) e posteriormente enxaguados com água Milli-Q no Setor de Metais do Laboratório de Pediatria e Puericultura do HCFMRP/USP.

Para a coleta de amostras de solo, foram utilizados instrumentos de jardinagem de teflon ou polietileno. Para o armazenamento do material foram utilizadas caixas de polietileno providas de tampa $(28 \times 40 \times 12 \mathrm{~cm})$. Tomou-se o cuidado de não se utilizar equipamentos de metal, a fim de se evitar contaminação no momento da coleta. 
Para a coleta de amostras de vegetal, também foram utilizados instrumentos de jardinagem de teflon ou polietileno. Para o armazenamento dessas amostras foram utilizados sacos de polietileno com fechamento hermético do tamanho de 15 x 20 $\mathrm{cm}$. Para a coleta de amostras de chorume e água, foram utilizadas garrafas de polietileno de $300 \mathrm{ml}$, providas de tampa. Todos os equipamentos para acondicionamento das amostras foram etiquetados e devidamente identificados.

\section{Coleta das amostras}

Como equipe de apoio, participaram da coleta de amostras quatro alunos do Curso de Graduação de Enfermagem da EERP/USP, que haviam freqüentado a Disciplina Introdução a Saúde Pública, os quais foram previamente orientados, através de um treinamento de 8 horas, sobre: tipo de investigação, relevância de estudos dessa natureza, cuidados necessários para a coleta de amostras ambientais visando a análise de metais pesados e efeitos toxicológicos dos metais pesados.

Durante a coleta de dados contamos também com apoio da equipe de "Paulo Mano Engenharia”, contratada especialmente para a demarcação dos pontos de coleta, além do pessoal técnico ligado às instalações do Aterro Sanitário e Incinerador Municipal.

A data de coleta, 21 de junho de 2000, foi definida em função da necessidade de se obter amostras que refletissem as condições da época mais seca do ano. Segundo dados do Núcleo de Agronomia de Alta Mogiana, situado na área vizinha ao Aterro Sanitário de Ribeirão Preto, nos meses de abril, maio e junho, que antecederam a coleta, não foram registradas chuvas, exceto nos dias 18 de abril e 2 
de maio, nos quais foram registradas precipitações de 0,2 e $0,9 \mathrm{~mm}$, respectivamente (Anexo D).

Solo: Em cada um dos pontos delimitados foi coletada uma amostra de solo de aproximadamente $500 \mathrm{~g}$, tendo sido traçado previamente a coleta, um quadrado de 20 x $20 \mathrm{~cm}$, e feita uma escavação de até $20 \mathrm{~cm}$ de profundidade, de onde foi retirada a amostra (Shallari et al., 1998). Foram coletadas amostras de solo de um total de 16 pontos (Fig. 10), e imediatamente armazenadas em caixas de polietileno (Fig.11).

Vegetais: Foram coletadas amostras de folhas, caule e raiz de plantas existentes em cada um desses locais. Cada uma das secções da planta coletada foi guardada separadamente em sacos de polietileno, devidamente identificados. A vegetação nesse local é escassa constituindo-se, em quase sua totalidade, de pequenos arbustos, com pouca variedade de espécies. Foram coletadas amostras de um total de 15 pontos. No ponto denominado Oeste/100 não havia vegetais no momento da coleta (Fig. 10).

Líquido percolado: Duas amostras de chorume foram extraídas dos tanques coletores, localizados no lado Norte do Aterro Sanitário. Outras quatro amostras foram recolhidas em diferentes pontos de afloramento superficial espontâneo, todos estes localizados sobre o Aterro Sanitário, totalizando seis amostras de chorume (Fig. $10)$.

Água: No dia de coleta não foram localizados pontos de água superficial nos locais selecionados na área demarcada para a pesquisa. O curso de água mais próximo é representado pelo Córrego Monte Alegre, tributário do Ribeirão Preto, este por sua vez, componente da Bacia do Rio Pardo. Trata-se de um curso d'água, oriundo de área intensamente modificada, recebendo influência direta de um complexo 
agroindustrial produtor de açúcar e álcool e da instalação humana participante (Alvarenga et al., 1986).

Já, em 1986, eram ressaltadas como remotas as possibilidades do Córrego Monte Alegre ser utilizado algum dia para abastecimento público. Isto porque, sua vazão seria insuficiente para o abastecimento da cidade, além do fato de haver usinas de cana de açúcar situadas nas suas cabeceiras, o que representa uma ameaça constante à qualidade de suas águas, inviabilizando sua captação para o consumo humano (Alvarenga et al., 1986).

Optou-se, então, por fazer a coleta de água de três poços artesianos a jusante do Aterro Sanitário, localizados nos sentidos norte e leste (Fig. 10), os quais vêm sendo monitorados semestralmente pelas autoridades municipais responsáveis pelo aterro; cabe salientar que o poço a montante do aterro (sentido Sul), encontrava-se seco, impossibilitando a coleta nesse ponto.

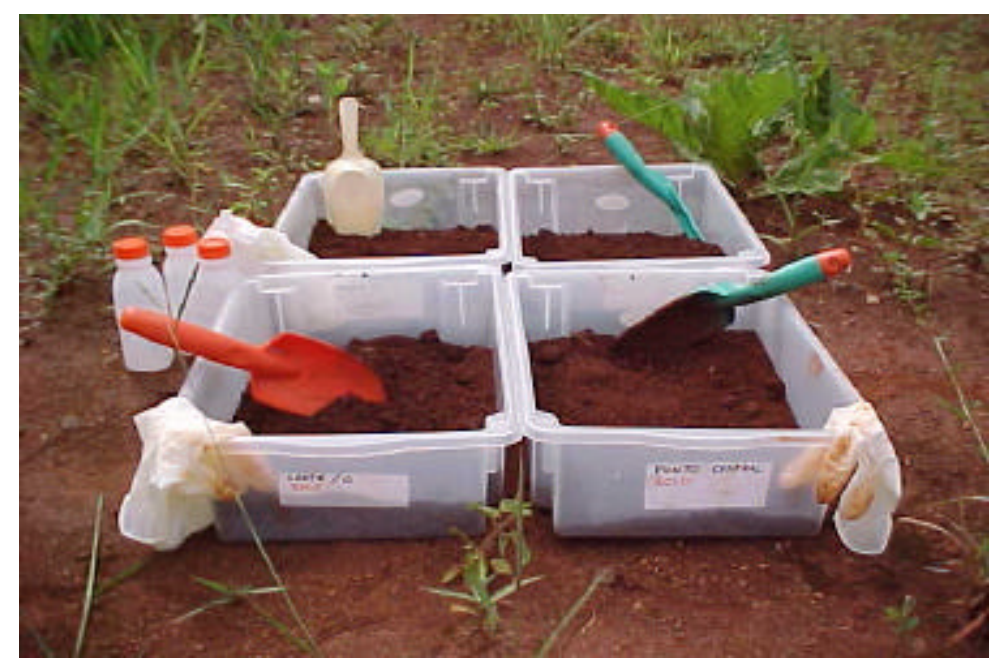

Fig. 11- Materiais utilizados para a coleta de solo, vegetais, água e chorume no local. (Fonte: Segura-Muñoz \& Takayanagui, 2000) 
Amostras-controle: Para a coleta de amostras-controle, selecionou-se a Mata Santa Teresa - Estação Ecológica de Ribeirão Preto, considerada como uma área significativamente representativa de ecossistemas brasileiros (Aita, 1997), está constituída por 154,16 ha de floresta semidecidual, sobre terra-roxa estruturada, entre as coordenadas $21^{\circ} 13^{\prime}$ a $21^{\circ} 15^{\prime}$ de latitude Sul e $47^{\circ} 53^{\prime}$ a $47^{\circ} 56^{\prime}$ de longitude oeste. Situa-se ao Sul da zona urbana de Ribeirão Preto, numa altitude média de $570 \mathrm{~m}$ (CONSEMA, 1995). Nesse local foram coletadas duas amostras de cada matriz (solo e vegetais), mantendo-se as mesmas condições de coleta no Aterro Sanitário, definidas para as amostras desse estudo no Aterro Sanitário.

No total foram coletadas em duplicata 122 diferentes amostras nos pontos de monitoramento selecionados na área do Aterro Sanitário Municipal e da Mata de Santa Teresa de Ribeirão Preto, SP (Tab. 1).

Tab. 1- Distribuição das amostras coletadas na Área do Aterro Sanitário Municipal e da Mata Santa Tereza de Ribeirão Preto.

\begin{tabular}{|c|c|c|c|c|c|c|c|}
\hline $\begin{array}{lr} & \text { Local } \\
\text { Matriz } & \\
\end{array}$ & Leste & Norte & Oeste & Sul & $\begin{array}{l}\text { Ponto } \\
\text { Central }\end{array}$ & $\begin{array}{l}\text { Ponto } \\
\text { Controle }\end{array}$ & Total \\
\hline Solo & 8 & 8 & 8 & 6 & 2 & 4 & $\mid 36$ \\
\hline Raiz & 8 & 8 & 6 & 6 & 2 & 4 & $\mid 34$ \\
\hline Folha & 8 & 8 & 6 & 6 & 2 & 4 & $\mid 34$ \\
\hline Chorume & & $6^{*}$ & 2 & 2 & 2 & & $\mid 12$ \\
\hline $\begin{array}{l}\text { Água } \\
\text { subterrânea }\end{array}$ & 2 & 4 & & & & & 6 \\
\hline Total & 26 & 34 & 22 & 20 & 8 & 12 & 122 \\
\hline
\end{tabular}




\section{Transporte}

Após a coleta, as amostras de solo foram levadas ao Laboratório de Saúde Ambiental da Escola de Enfermagem de Ribeirão Preto/USP. As amostras de vegetais, de chorume e de água foram levadas ao Setor de Metais do Laboratório de Pediatria da Faculdade de Medicina do Hospital das Clínicas de Ribeirão Preto.

\section{Preparação das amostras}

Solo: As amostras de solo foram mantidas à temperatura ambiente por 30 dias em caixas de polietileno, em local fresco e arejado, deixando-as estendidas em caixas de polietileno e protegidas para evitar contaminação por agentes externos. Após a secagem, as amostras foram homogeneizadas manualmente utilizando-se morteiros de polietileno; a seguir, foram peneiradas para separação das partículas maiores ou restos vegetais, mediante a utilização de peneiras de polietileno com $1,5 \mathrm{~mm}$ de luz de malha (Shallari et al. 1998), no Laboratório de Pesquisa de Saúde Ambiental da Escola de Enfermagem de Ribeirão Preto/USP.

Uma vez homogeneizada e peneirada era separada uma amostra de solo de aproximadamente 200 gramas, através da técnica de quartejamento, que consiste em dividir a amostra em quatro partes iguais e tomar iguais quantidades de cada uma delas para compor a amostra a ser analisada. As amostras foram, então, levadas ao Setor de Metais, do Laboratório de Pediatria e Puericultura do Departamento de Pediatria da FMRP/USP, para a realização das análises posteriormente.

Vegetais: As folhas e as raízes foram secadas em estufa a $40^{\circ} \mathrm{C}$ por 48 horas e, a seguir foram trituradas para a obtenção de fragmentos menores, os quais foram utilizados para a realização das análises químicas. Devido ao fato dos vegetais 
coletados serem de pequeno porte, optou-se por excluir da análise a matriz caule, considerando-se que as raízes e folhas seriam suficientes para a detecção de metais que pudessem ter sido absorvidos pela via aérea ou radicular.

Líquido percolado e água: Foi adicionado $\mathrm{HNO}_{3}$ de alta pureza às amostras e mantidas a $-18{ }^{\circ} \mathrm{C}$ até o momento das análises.

\section{Método de Extração de Metais Pesados}

Todos os materiais utilizados no processo de extração e detecção de metais foram sumergidos em solução de $\mathrm{HNO}_{3}(30 \%$ v/v), por 12 horas como mínimo.

Solo: No primeiro momento foi utilizado o método de extração de metais pesados em solo, recomendado pela VARIAN (1988), que pode ser descrito da seguinte forma: 0,100 g de solo foi pesado em cadinhos de teflon de $100 \mathrm{ml}$, posteriormente digerido em banho de areia entre $110^{\circ} \mathrm{C}$ e $120^{\circ} \mathrm{C}$, com $0,5 \mathrm{ml}$ de ácido perclórico a $72 \%$ e 5,0 ml de ácido fluorídrico a $48 \%$, evitando-se a secagem completa da amostra. O resíduo foi recuperado com 5,0 ml de ácido clorídrico $6 \mathrm{~N}$ e 15,0 ml de água MilliQ, sendo o conteúdo transferido para um frasco volumétrico de $25 \mathrm{ml}$ e completado o volume com água Milli-Q.

Os resultados obtidos mediante esse método de extração não correspondiam a realidade mediante a confirmação do resultado utilizando amostras certificadas de solo. Por este motivo, foi necessário modificar o método proposto para extração de metais no solo, adotando-se o método publicado pela Australian Standard Association: "Extração de metais e metalóides do solo por Água Regia - Método de Digestão em Placa Aquecida" (Anexo E). 
O método acima citado pode ser resumido da seguinte forma: foi pesada $1,000 \mathrm{~g}$ de cada amostra em balões de bocal esmerilhado de $250 \mathrm{ml}$; as amostras foram umedecidas com água Milli-Q e depois foram adicionados $10 \mathrm{ml}$ de água regia. Os frascos foram tampados e deixados em repouso por 16 horas na temperatura ambiente. Após esse tempo, as amostras foram digeridas em sistema de refluxo durante 2 horas, evitando-se ebulição intensa. Após o término da digestão e resfriamento das amostras foram adicionados $10 \mathrm{ml}$ de $\mathrm{HNO}_{3}$ a $1 \%$ (v/v), e o resíduo transferido quantitativamente para balões volumétricos de $100 \mathrm{ml}$ completando-se o volume com água Milli-Q. Após centrifugação em tubos cônicos, o sobrenadante foi separado e reservado para posteriores análises.

Vegetais: Para extração foi pesada $1,000 \mathrm{~g}$ de amostra seca em tubo de vidro Kjeldahl, adicionando-se $10 \mathrm{ml}$ de $\mathrm{HNO}_{3}$ concentrado e levado a uma temperatura de 80 a $110{ }^{\circ} \mathrm{C}$. Após completa digestão, o conteúdo foi esfriado e filtrado, utilizando-se papel de filtro Whatman 40, sendo então, transferido quantitativamente para frasco volumétrico de $25 \mathrm{ml}$ e completado o volume com água Milli-Q (VARIAN, 1988; Tack et al., 1998).

Chorume: Foi colocado 1,00 $\mathrm{ml}$ de amostra em tubo de vidro Kjeldahl e realizada a digestão com $10 \mathrm{ml}$ de ácido nítrico concentrado e levado a uma temperatura de 80 a $110{ }^{\circ} \mathrm{C}$. Após completa digestão, o conteúdo foi filtrado utilizando papel de filtro Whatman 40, transferido quantitativamente para um frasco volumétrico de $25 \mathrm{ml}$, completado-se o volume com água Milli-Q (VARIAN, 1988).

Água: As amostras de água foram centrifugadas e o sobrenadante separado para posterior leitura dos metais pesados (APHA,1998). 


\section{Dosagem de brancos}

Para todas as determinações executadas foram realizadas análises dos brancos concomitantemente, utilizando-se nestes casos, unicamente os reagentes usados na detecção das diferentes matrizes submetidos ao mesmo tratamento. Os valores obtidos na análise dos brancos foram subtraídos dos valores detectados para cada amostra.

\section{Leitura de Metais Pesados}

As dosagens de cromo, chumbo, cádmio, manganês e cobre foram realizadas por Espectrofotometria de Absorção Atômica com Forno de Grafite (EAA-FG), num espectrofotômetro VARIAN-ZEEMAN modelo 640-Z (Fig. 12). A dosagem de mercúrio foi realizada por espectrofotometria de Absorção Atômica com Geração de Hidreto (EAA-VGA) num Espectrofotômetro VARIAN, modelo AA-200 (Fig. 13). Dosagens de zinco e cobre, foram realizadas por Espectrofotometria de Absorção Atômica de Chama (EAA-Chama) num Espectrofotômetro marca Perkin Elmer modelo 380 (Fig. 14). As condições de análise para cada metal são especificadas no Anexo F. 


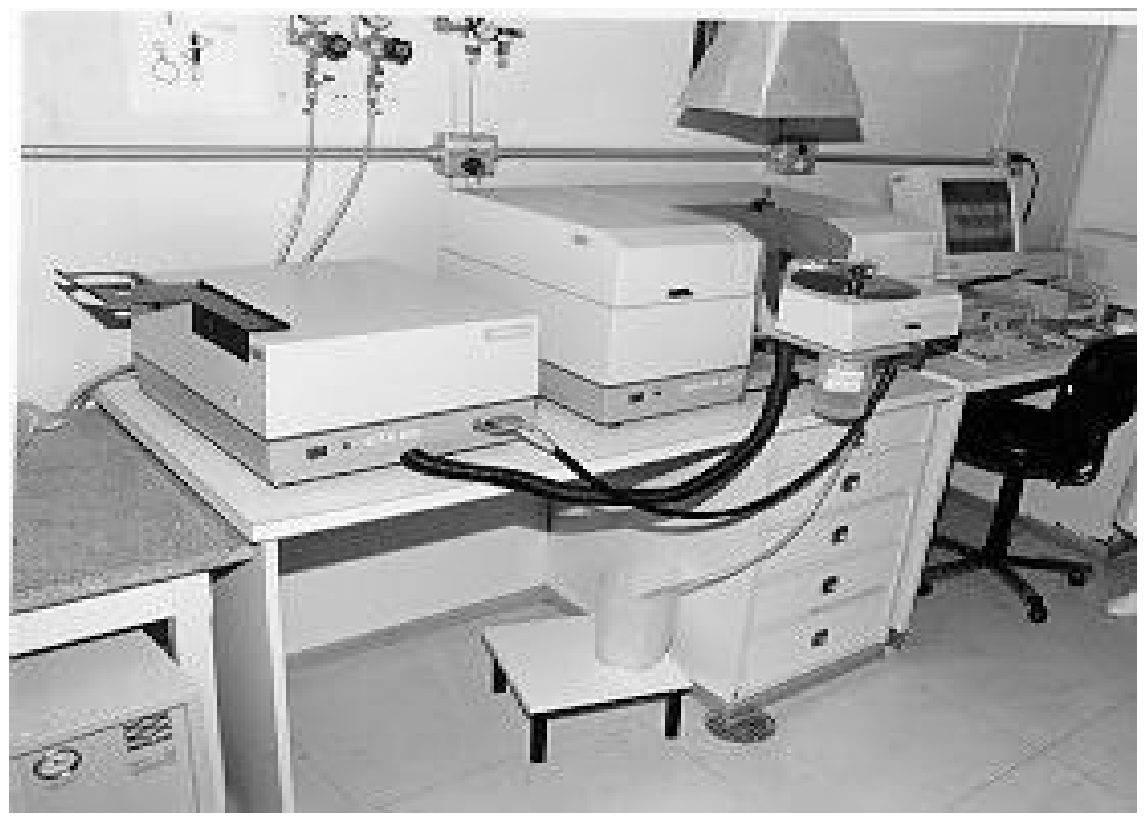

Fig. 12 - Espectrofotômetro de Absorção Atômica com Forno de Grafite (EAA-FG), Setor de Metais do Laboratório de Pediatria do Hospital das Clínicas da FMRP/USP (Fonte: Trevilato, 2000)

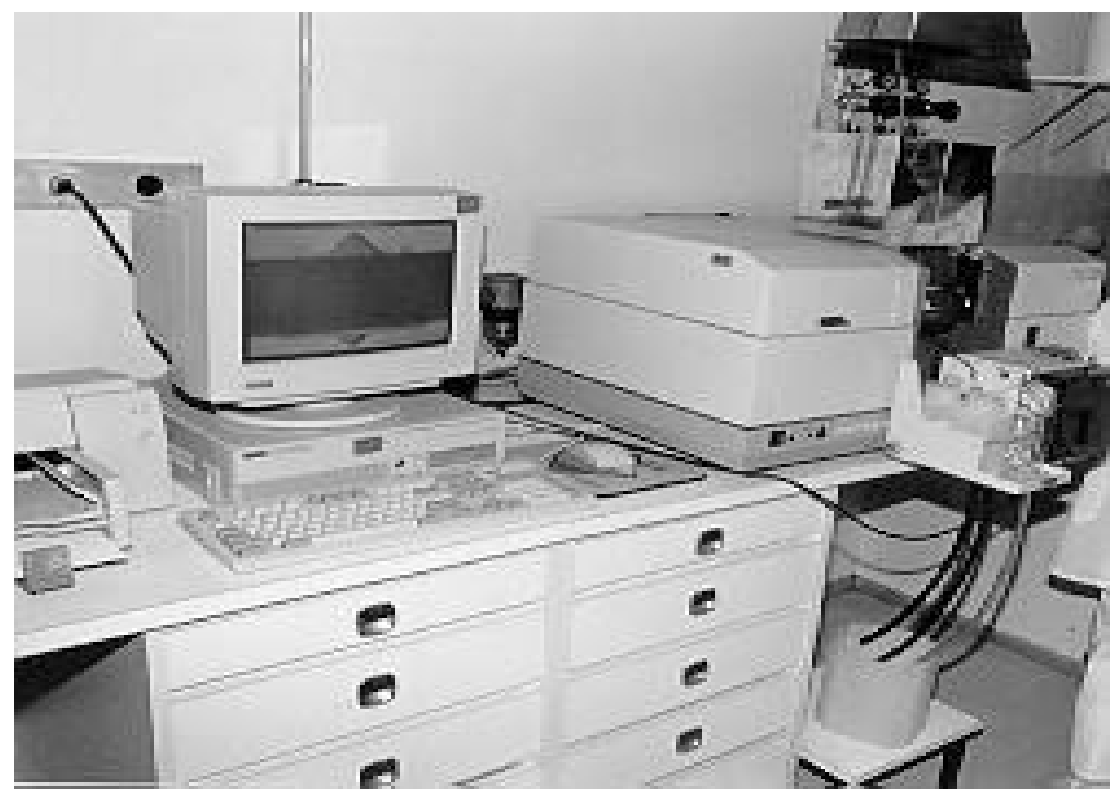

Fig. 13 - Espectrofotômetro de Absorção Atômica com Gerador de Hidretos (EAA-VGA), Setor de Metais do Laboratório de Pediatria do Hospital das Clínicas da FMRP/USP (Fonte: Trevilato, 2000). 


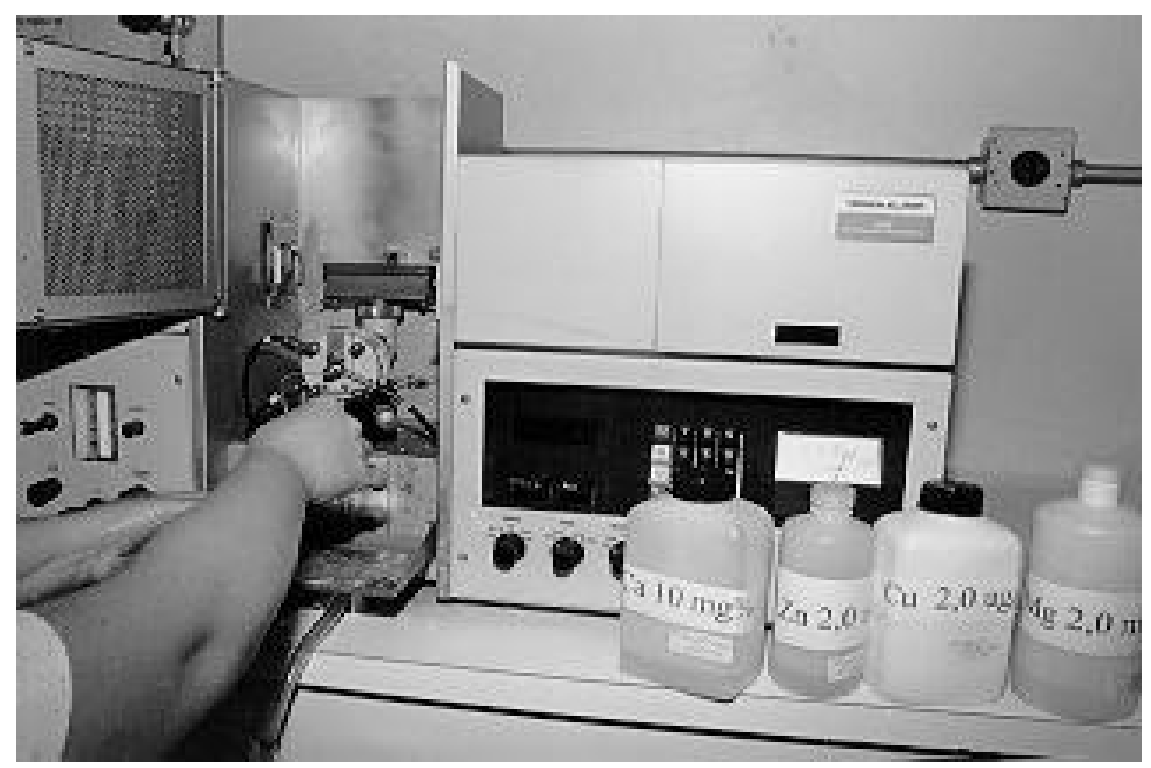

Fig. 14 - Espectrofotômetro de Absorção Atômica com Chama (EAA-Chama), Setor de Metais do Laboratório de Pediatria do Hospital das Clínicas da FMRP/USP (Fonte: Trevilato, 2000).

\section{Limites de detecção}

Na Tab. 2, estão apresentados os limites de detecção dos métodos utilizados para a análise dos metais pesados, objeto deste estudo e os respectivos métodos adotados.

Tab. 2: Métodos e limites de detecção de metais do Setor de Metais do Laboratório de Pediatria e Puericultura, FMRP/USP.

\begin{tabular}{l||cc}
\hline \multicolumn{1}{c||}{ Metal analisado } & Limite de & Método \\
& Detecção & \\
\hline \hline Cádmio $(\mathrm{Cd})$ & $0,0001 \mathrm{mg} / \mathrm{L}$ & EAA-FG \\
Chumbo $(\mathrm{Pb})$ & $0,001 \mathrm{mg} / \mathrm{L}$ & EAA-FG \\
Cromo $(\mathrm{Cr})$ & $0,002 \mathrm{mg} / \mathrm{L}$ & EAA-FG \\
Mercúrio $(\mathrm{Hg})$ & $0,0001 \mathrm{mg} / \mathrm{L}$ & EAA-VGA \\
Zinco $(\mathrm{Zn})$ & $0,001 \mathrm{mg} / \mathrm{L}$ & EAA-Chama
\end{tabular}




\begin{tabular}{l||cc} 
Manganês $(\mathrm{Mn})$ & $0,001 \mathrm{mg} / \mathrm{L}$ & EAA-FG \\
Cobre $(\mathrm{Cu})$ & $0,005 \mathrm{mg} / \mathrm{L}$ & EAA-FG \\
& $0,4 \mathrm{mg} / \mathrm{L}$ & EAA-Chama \\
\hline
\end{tabular}

\section{Validação dos Métodos}

Através do Setor de Metais do Laboratório de Pediatria e Puericultura do Departamento de Pediatria da FMRP/USP e da empresa representante da VARIAN ANALYTICAL INSTRUMENTS, em São Paulo, foi estabelecido contato com o Dr. Waller Graemer, diretor do Laboratório Quality Control Technologies Pty Ltd., localizado em Queensland na Austrália, com quem foi acordada a participação no controle inter-laboratorial de agosto de 2000 até junho de 2001.

Durante este período, todo mês eram recebidas amostras certificantes de solo, água potável e água não potável (Fig.15) e analizadas segundo os métodos adotados no presente estudo. Os resultados eram, então, enviados para o Laboratório Quality Control Technologies, onde eram conferidos os nossos resultados e emitido um certificado avaliando a exatidão dos mesmos. Parte dos exemplares dos certificados recebidos do controle inter-laboratorial estão apresentados no Anexo G.

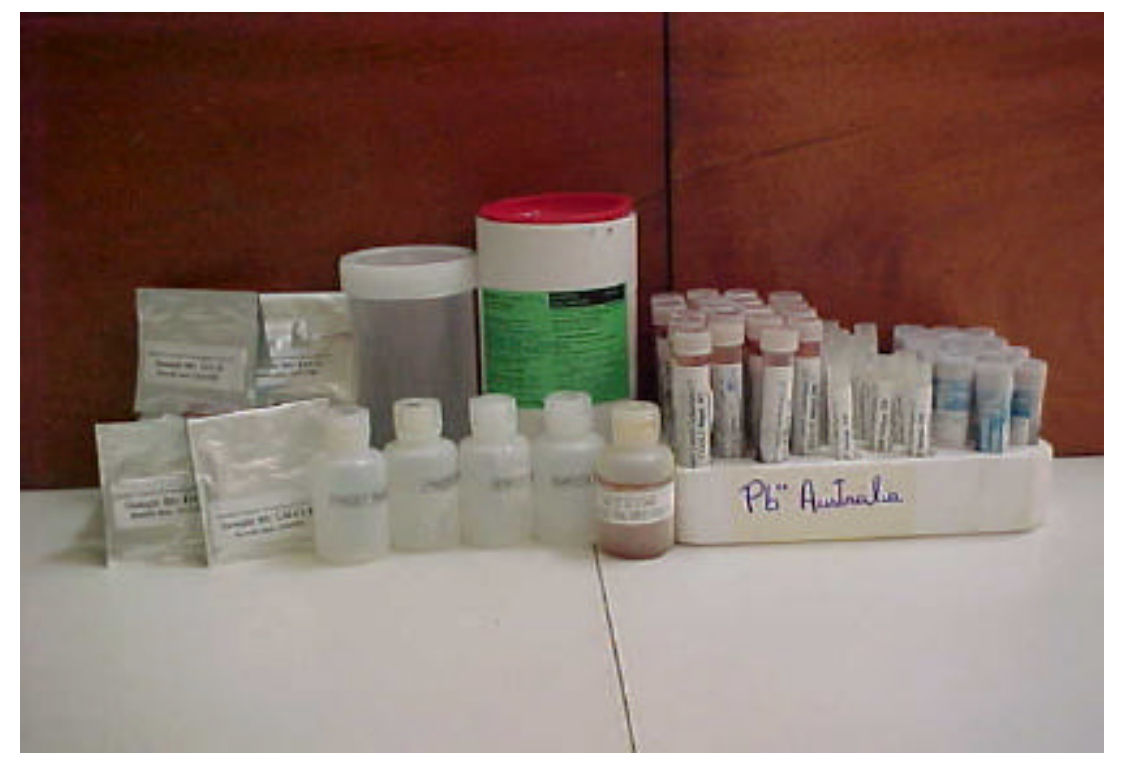


Fig. 15: Padrões certificantes provenientes do Laboratório Quality Control Technologies Pty Ltd. Queensland, Austrália (Fonte: Segura-Muñoz, 2001).

A cada análise das amostras coletadas na área do Aterro Sanitário e Incinerador de RSS, eram realizadas, concomitantemente, análise de amostras certificantes, como controle. Assim, nossos resultados eram considerados adequados quando os níveis de metais detectados nas amostras certificantes apresentavam uma margem de erro sistemático de até $20 \%$ do valor real, reportado pelo Laboratório Quality Control Technologies. O cálculo do erro sistemático (\%BIAS) foi realizado através da seguinte expressão, segundo Causon (1997).

$$
\% \text { BIAS }=[(\text { valor estimado }- \text { valor real }) / \text { valor real }] \times 100
$$

\section{Análise estatística dos dados}

Foi construído um banco de dados no Programa Microsoft Excel Versão 97; posteriormente, os dados foram transferidos ao Programa SPSS - 10.0 (Statistical Program for Social Sciences, for Windows Version 10.0), para a análise estatística.

Os valores obtidos nos diferentes pontos de coleta na área do Aterro Sanitário foram comparados com os valores obtidos no ponto-controle na Mata de Santa Teresa, utilizando-se os testes estatísticos não-paramétricos Mann-Whitney, no caso de comparação entre dois grupos de amostras e Kruskal-Wallis no caso de comparações entre mais do que dois grupos de amostras. O nível de significância utilizado foi de $\mathrm{a}=0,05$, de modo que valores de $\mathrm{p}<0,05$, indicaram a existência de diferenças significantes entre os pontos de comparação ( Zar, 1999). 
Na comparação de três grupos ou mais, além do Teste de Kruskal-Wallis, foi aplicado o Teste de Comparações Múltiplas para identificar os pontos onde havia diferença estatisticamente significante. Através do teste de Comparações Múltiplas obteve-se um valor crítico de $q$, o qual foi confrontado com o valor crítico de $q$ tabelado que varia de acordo com o número de grupos comparados. Para a comparação de cinco grupos o valor crítico de $q$ tabelado é $q=3,858$, para quatro, o $q=3.633$ e para 3 grupos o $q=3.314$; valores críticos de $q$ calculados superiores aos valores tabelados indicaram a existência de diferença estatisticamente significante (Zar,1999).

As análises estatísticas realizadas neste estudo foram baseadas nesses pressupostos teóricos.

\section{Valores de Referência}

Para a análise dos níveis de metais em solo considerou-se os Valores Orientadores para Solos no Estado de São Paulo, elaborados pela CETESB Companhia de Tecnologia de Saneamento Ambiental (CETESB, 2001).

Para a análise dos resultados do líquido percolado, consideraram-se os valores máximos permissíveis do Decreto 8468/76 (São Paulo, 1976).

Para a análise dos resultados de água subterrânea, consideraram-se os valores da Portaria 1469/2000, do Ministério da Saúde (Brasil, 2001).

Para a comparação das concentrações de metais em vegetais no Aterro Sanitário foram consideradas informações existentes na literatura científica, dada à inexistência de parâmetros nacionais que ofereçam algum valor de referência. 


\section{RESULTADOS E DISCUSSÃO}

Através do presente estudo foram quantificados os níveis de Cádmio, Cromo, Chumbo, Cobre, Manganês, Zinco e Mercúrio em diversas matrizes ambientais, tais como água, chorume, solo e vegetais (raízes e folhas).

Inicialmente são apresentados os resultados obtidos para cada metal para as matrizes solo, raiz e folha, de acordo com suas localizações espaciais na área de abrangência da pesquisa e no ponto-controle, seguidos da análise estatística, realizada segundo os testes não-paramétricos selecionados. Logo após, é realizada a discussão sobre os achados da investigação.

A seguir são apresentados os níveis de metais detectados nas amostras de chorume e nas amostras de água subterrânea coletadas naárea de estudo, seguidos pela discussão.

\subsection{Níveis de metais no solo, raiz e folha}

\section{Níveis de cádmio}

Os níveis de cádmio detectados para as diferentes matrizes solo, raiz e folha, segundo sua distribuição espacial na área do Aterro Sanitário, são apresentados na Tab. 3, a seguir: 
Tab. 3 - Nível de cádmio nas amostras de solo, raiz e folha segundo a sua distribuição espacial, expressado em $\mathrm{mg} / \mathrm{kg}$ para cada matriz.

\begin{tabular}{|c|c|c|c|}
\hline $\begin{array}{r}\text { Parâmetro } \\
\text { Ponto de Coleta }\end{array}$ & $\begin{array}{c}\text { SOLO } \\
\text { Mediana; ASQ }\end{array}$ & $\begin{array}{c}\text { RAIZ } \\
\text { Mediana; ASQ }\end{array}$ & $\begin{array}{c}\text { FOLHA } \\
\text { Mediana; ASQ }\end{array}$ \\
\hline Controle & 4,$382 ; 0,163$ & 0,$055 ; 0,001$ & 0,$012 ; 0,001$ \\
\hline Central & 14,$948 ; 0,153$ & 0,$292 ; 0,006$ & 0,$094 ; 0,001$ \\
\hline Leste/0 & 13,$486 ; 0,328$ & 0,$533 ; 0,004$ & 0,$086 ; 0,004$ \\
\hline Leste/50 & 15,$015 ; 0,144$ & 1,$031 ; 0,004$ & 0,$027 ; 0,003$ \\
\hline Leste/100 & 15,$256 ; 0,233$ & 0,$856 ; 0,002$ & 0,$013 ; 0,001$ \\
\hline Leste/200 & 15,$627 ; 0,013$ & 1,$445 ; 0,002$ & 0,$023 ; 0,002$ \\
\hline Norte/0 & 28,$029 ; 0,042$ & 2,$945 ; 0,012$ & 0,$565 ; 0,007$ \\
\hline Norte/50 & 25,$665 ; 0,354$ & 2,$221 ; 0,006$ & 0,$514 ; 0,002$ \\
\hline Norte/100 & 29,$558 ; 0,219$ & 1,$285 ; 0,005$ & 0,$055 ; 0,010$ \\
\hline Norte/200 & 13,$810 ; 0,733$ & 1,$042 ; 0,028$ & 0,$084 ; 0,001$ \\
\hline Oeste/0 & 13,$468 ; 0,068$ & 1,$094 ; 0,010$ & 0,$193 ; 0,005$ \\
\hline Oeste/50 & 13,$225 ; 0,160$ & 0,$504 ; 0,007$ & 0,$043 ; 0,003$ \\
\hline Oeste/100 & 13,$334 ; 0,062$ & N.E.." & N.E.." \\
\hline Oeste/115 & 14,$029 ; 0,053$ & 1,$029 ; 0,007$ & 0,$012 ; 0,003$ \\
\hline $\mathrm{Sul} / 0$ & 12,$729 ; 0,191$ & 1,$566 ; 0,007$ & 0,$035 ; 0,003$ \\
\hline $\mathrm{Sul} / 22$ & 13,$288 ; 0,112$ & 1,$549 ; 0,005$ & 0,$015 ; 0,001$ \\
\hline Sul/554 & 14,$445 ; 0,047$ & 1,$290 ; 0,004$ & 0,$018 ; 0,001$ \\
\hline
\end{tabular}

- Mediana, calculada a partir de n=6; Amplitude Semi-quartílica (ASQ)

* $\quad$ N.E.: não encontradas espécies vegetais

Fonte: Banco de dados (Anexo H).

Na comparação dos níveis de cádmio entre o ponto-controle e o pontocentral, foram encontradas diferenças estatisticamente significantes para solo, raiz e folha ( $\mathrm{p}=0,002)$, onde os níveis de cádmio foram menores para o ponto-controle.

Na comparação dos níveis de cádmio para os pontos Leste/0, Norte/0, Oeste/0, Sul/0 e o ponto-controle, foram encontrados valores estatisticamente significantes mediante o Teste Kruskal-Wallis para as matrizes solo, raiz e folha 
(p 0). De acordo com (ZAR, 1999), nas comparações múltiplas para cinco grupos, valores superiores a $q=3,858$ indicam que existe diferença significante entre os pontos de comparação, como anteriormente descrito na metodologia.

$\mathrm{Na}$ Tab. 4, observa-se que o ponto Norte/0 apresentou diferenças significantes ao serem comparados com o ponto controle para as três matrizes avaliadas. O ponto Oeste/0 apresentou diferenças para as matrizes solo e folha, enquanto que o ponto Leste/0 apresentou diferença significante unicamente para a matriz solo e o ponto Sul/0 unicamente para raiz. Sendo que em cada um desses pontos os valores foram superiores aos detectados para o ponto controle.

Tab. 4 - Valores críticos de $q$ obtidos na comparação dos níveis de Cd do grupo controle com os níveis das amostras coletadas no limite 0 do Aterro Sanitário.

\begin{tabular}{cc|cccc}
\hline \hline Matriz & Amostra & Leste/0 & Norte/0 & Oeste/0 & Sul/0 \\
\hline \hline Solo & Controle & $4,2^{*}$ & $6,7^{*}$ & $4,1^{*}$ & 1,6 \\
Raiz & Controle & 1,7 & $6,7^{*}$ & 3,3 & $5,0^{*}$ \\
Folha & Controle & 3,3 & $6,1^{*}$ & $5,5^{*}$ & 1,7 \\
\hline \multicolumn{7}{l}{ * Diferença estatisticamente significante }
\end{tabular}

Na comparação dos níveis de cádmio nos pontos Leste 50, Norte/50, Oeste/50 e o ponto-controle foram encontradas diferenças estatisticamente significantes para solo, raiz e folha $\left(\mathrm{p}^{\sim}\right.$ 0). Para comparações múltiplas entre quatro grupos, valores superiores a $q=3,633$ indicam que existe diferença significante entre os pontos de comparação (Tab. 5). Observa-se que o ponto Norte/50 apresentou diferenças significantes ao ser comparado com o ponto-controle para as três matrizes avaliadas. O ponto Leste/50 apresentou diferença significante unicamente para as matrizes solo e raiz e, o ponto Oeste/50 unicamente para folha. Sendo que em cada um desses pontos os valores foram superiores aos encontrados no ponto-controle. 
Tab. 5 - Valores críticos de $q$ obtidos na comparação dos níveis de Cd do grupo controle com os níveis das amostras coletadas no limite 50 do Aterro Sanitário.

\begin{tabular}{cl||ccc}
\hline \hline Matriz & Amostra & Leste/50 & Norte/50 & Oeste/50 \\
\hline \hline Solo & Controle & $4,2 *$ & $6,2^{*}$ & 2,1 \\
Raiz & Controle & $4,2 *$ & $6,2^{*}$ & 2,1 \\
Folha & Controle & 2,1 & $6,2 *$ & $4,2 *$ \\
\hline \hline
\end{tabular}

* Diferença estatisticamente significante.

Na comparação dos níveis de cádmio nos pontos Leste 100, Norte/100, Oeste/100 com o ponto-controle foram encontrados valores estatisticamente significantes para solo, raiz e folha $\left(\mathrm{p}_{\text {máximo }}=0,002\right)$.

Para comparações múltiplas das amostras de solo, valores críticos de $q$ superiores a $q=3,633$ indicam que existe diferença significante entre os pontos de comparação, por se tratar de quatro grupos. Para comparações múltiplas das amostras de raiz e folha, valores superiores a $q=3,314$ indicam que existe diferença significante entre os pontos de comparação, dado que não existe grupo de comparação no ponto Oeste/100 (Tab. 6).

O ponto Norte/100 caracterizou-se por apresentar diferenças significantes para as três matrizes, enquanto no ponto Leste/100 a diferença foi significativa unicamente para a matriz solo.

Tab. 6 - Valores críticos de $q$ obtidos na comparação dos níveis de Cd do grupo controle com os níveis das amostras coletadas no limite 100 do Aterro Sanitário.

\begin{tabular}{cl||ccc}
\hline \hline Matriz & Amostra & Leste/100 & Norte/100 & Oeste/100 \\
\hline \hline Solo & Controle & $4,2^{*}$ & $6,2^{*}$ & 2,1 \\
Raiz & Controle & 2,7 & $5,5^{*}$ & N.E. \\
Folha & Controle & 1,4 & $4,8^{*}$ & N.E. \\
\hline \hline
\end{tabular}

* Diferença estatisticamente significante 


\section{N.E.: não encontradas amostras vegetais}

Na comparação entre os níveis de cádmio nos pontos Leste 200 e Norte/200, em relação ao ponto-controle, foram encontradas diferenças estatisticamente significantes para solo $(\mathrm{p}=0,001)$ e para raiz e folha $\left(\mathrm{p}^{\sim} 0\right)$.

Ao realizar o teste de comparações múltiplas, verificamos que os pontos que apresentaram valores de $q$ críticos superiores a 3,314 tiveram diferença significante entre eles (Tab. 7). O ponto Leste/200 apresentou diferença significante para as matrizes solo e raiz. O ponto Norte/200 para as matrizes solo e folha, quando comparados com o ponto-controle.

Tab. 7 - Valores críticos de $q$ obtidos na comparação dos níveis de Cd do grupo controle com os níveis das amostras coletadas no limite 200 do Aterro Sanitário.

\begin{tabular}{cl|cc}
\hline \hline Matriz & Amostra & Leste/200 & Norte/200 \\
\hline \hline Solo & Controle & $5,5^{*}$ & $3,9^{*}$ \\
Raiz & Controle & $5,5^{*}$ & 2,7 \\
Folha & Controle & 2,7 & $5,5^{*}$ \\
\hline \hline \multicolumn{2}{c}{ * Diferença estatisticamente significante }
\end{tabular}

Na comparação entre os níveis de cádmio no ponto Oeste/115, com respeito ao ponto controle foi encontrada diferença estatisticamente significante para solo e raiz $(\mathrm{p}=0,002)$, porém não foi detectada diferença com respeito as matriz folha $(\mathrm{p}=0,818)$.

Na comparação entre os níveis de cádmio no ponto Sul/22 com respeito ao ponto controle foi encontrada diferença estatisticamente significante para raiz $(\mathrm{p}=0,002)$, porém não foi detectada diferença com respeito às matrizes solo e folha ( $\mathrm{p}=0,041)$. Diferenças significantes foram detectadas na comparação dos níveis de cádmio no ponto Sul/554, para todas as três matrizes. 
Organizando-se os resultados obtidos das análises estatísticas, de acordo com os pontos de coleta, destacamos, na Fig. 16, que o sentido Norte apresentou uma maior frequiência de diferenças estatisticamente significativas para as três matrizes (solo, raiz e folha).

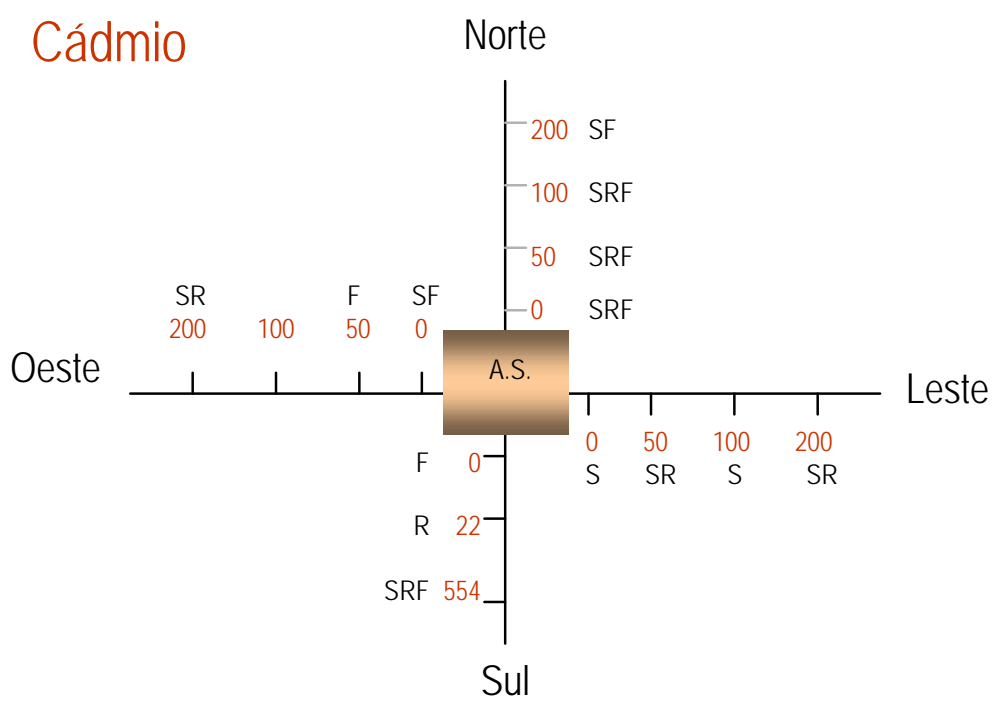

Fig. 16 - Distribuição das matrizes que apresentaram diferença estatisticamente significante para $\mathrm{Cd}$, segundo os pontos de coleta. (S: solo; R: raiz; F:folha).

Sabe-se que o cádmio ocorre na crosta terrestre em uma concentração média de $0,1 \mathrm{mg} / \mathrm{Kg}$. Este metal também pode ser introduzido no ambiente terrestre por mineração, produção de metais ferrosos, aterros, incineradores, na aplicação de fertilizantes ou procedente de lodo de efluentes domiciliares (WHO, 1992; Toppi \& Gabbrielli, 1999).

No presente estudo, pôde-se constatar, uma variação dos níveis de Cd no solo entre $12,729 \mathrm{mg} / \mathrm{kg}$ e $29,558 \mathrm{mg} / \mathrm{kg}$ (Tab. 3), observando-se as concentrações 
mais elevadas nos pontos situados no sentido Norte. Ao se comparar os valores obtidos com os valores de referência para o estado de São Paulo (CETESB, 2001), observa-se uma situação de risco, considerando que os valores de referência para este metal são de $10 \mathrm{mg} / \mathrm{kg}$ para solos de uso agrícola e de $15 \mathrm{mg} / \mathrm{kg}$ para solos de uso residencial (ANEXO I).

Ainda, as concentrações de Cd detectadas nas amostras de solo, apresentamse altas quando comparadas com os níveis de $\mathrm{Cd}$ reportados para solo coletado na vizinhança de um incinerador de resíduos municipais na Espanha, os quais variaram entre 0,15 e 0,40 mg/kg (Meneses et al., 1999; Llobet et al., 2002).

Cabe destacar que em alguns países da Europa têm sido estabelecidos valores de Cd entre 0 e 1 mg/kg para solos não contaminados (HMSO, 1991 apud Hamilton, 2000), o que pode servir como referência para comprovação de que as concentrações de Cd detectadas na área do Aterro Sanitário e Incinerador de Resíduos Sólidos do município de Ribeirão Preto representam um problema ambiental que precisa ser melhor estudado para monitoramento ou, até mesmo, para a busca de soluções de remediação da área.

Em solos com concentrações de Cd superiores aos limites máximos, verificase que poucas espécies vegetais conseguem crescer, a espécie Thlaspi caerulescens é uma das poucas espécies que tem demonstrado capacidade de sobreviver em meios contaminados por Cd, essa espécie vem sendo utilizada em processos de fitoremediação de solos contaminados por $\mathrm{Cd}$, em pesquisas realizadas em Estados Unidos (Brown et al., 1994).

Com relação aos vegetais, no presente estudo, as concentrações de $\mathrm{Cd}$ nas raízes variaram de 0,504 a 2,945 mg/kg e nas folhas de 0,012 a $0,565 \mathrm{mg} / \mathrm{kg}$. Estes 
resultados apresentam-se elevados quando comparados com os valores reportados para amostras de vegetais coletadas em área vizinha a um incinerador de resíduos municipais na Espanha, os quais foram inferiores a $0,11 \mathrm{mg} / \mathrm{kg}$ (Meneses et al., 1999).

De acordo com a literatura, sabe-se que a absorção de cádmio pelos vegetais através do solo é limitada (WHO, 1992). No presente trabalho, observou-se que as raízes apresentaram níveis de $\mathrm{Cd}$ que variaram de 1 a $10 \%$ com respeito às concentrações detectadas no solo e a concentração para folhas variou de 0,27 a 2,01\% quando comparada aos valores obtidos nas amostras de solo (Tab. 3). Esses dados evidenciam que o $\mathrm{Cd}$ concentra-se, principalmente, nas raízes e, em menor grau, nas folhas (Cataldo et al., 1983;WHO, 1992;). Sabe-se que, em condições de contaminação por $\mathrm{Cd}$, os vegetais ativam uma série de mecanismos de defesa a nível celular, dentre os quais podem ser citados: processos de imobilização na parede celular, processos de exclusão na membrana plasmática, síntese de fito-quelantes, compartimentalização em vacúolos e síntese de proteínas estressantes, que bloqueiam a absorção desse metal não essencial para a vida vegetal (Dixit et al., 2001) 


\section{Níveis de Cromo}

Os níveis de cromo presentes nas matrizes solo, raiz e folha são apresentados na Tab. 8 , a seguir:

Tab. 8 - Nivel de cromo nas amostras de solo, raiz e folha segundo a sua distribuição espacial, expressado em $\mathrm{mg} / \mathrm{Kg}$ para cada matriz.

\begin{tabular}{l|ccc}
\hline \multicolumn{1}{c|}{ Parâmetro } & SOLO & RAIZ & FOLHA \\
Ponto de Coleta & Mediana; ASQ & Mediana ; ASQ & Mediana ; ASQ \\
\hline \hline Controle & 7,$431 ; 0,004$ & 0,$176 ; 0,018$ & 0,$176 ; 0,014$ \\
Central & 21,$826 ; 0,110$ & 0,$568 ; 0,063$ & 0,$278 ; 0,011$ \\
Leste/0 & 19,$121 ; 0,097$ & 0,$946 ; 0,072$ & 0,$520 ; 0,009$ \\
Leste/50 & 25,$372 ; 0,038$ & 2,$070 ; 0,072$ & 0,$903 ; 0,028$ \\
Leste/100 & 25,$370 ; 0,027$ & 1,$540 ; 0,008$ & 0,$811 ; 0,007$ \\
Leste/200 & 22,$287 ; 0,013$ & 2,$252 ; 0,042$ & 0,$855 ; 0,013$ \\
Norte/0 & 54,$206 ; 0,147$ & 5,$066 ; 0,083$ & 1,$253 ; 0,022$ \\
Norte/50 & 46,$668 ; 0,251$ & 8,$009 ; 0,095$ & 1,$831 ; 0,023$ \\
Norte/100 & 35,$480 ; 0,026$ & 6,$302 ; 0,042$ & 1,$126 ; 0,036$ \\
Norte/200 & 30,$481 ; 0,062$ & 0,$488 ; 0,035$ & 1,$135 ; 0,042$ \\
Oeste/0 & 23,$224 ; 0,039$ & 2,$091 ; 0,044$ & 1,$193 ; 0,009$ \\
Oeste/50 & 24,$650 ; 0,097$ & 0,$993 ; 0,064$ & 0,$692 ; 0,004$ \\
Oeste/100 & 29,$096 ; 0,068$ & N.E. $\cdot \cdot$ & N.E. $\cdot$ \\
Oeste/115 & 28,$573 ; 0,027$ & 1,$136 ; 0,039$ & 0,$843 ; 0,022$ \\
Sul/0 & 14,$919 ; 0,104$ & 2,$392 ; 0,029$ & 0,$986 ; 0,016$ \\
Sul/22 & 32,$579 ; 0,010$ & 2,$180 ; 0,028$ & 0,$703 ; 0,016$ \\
Sul/554 & 30,$938 ; 0,161$ & 1,$361 ; 0,036$ & 0,$571 ; 0,005$ \\
\hline \hline
\end{tabular}

- Mediana, calculada a partir de n=6; Amplitude Semi-Quartílica (ASQ)

. $\quad$ N.E.: não foram encontradas espécies vegetais Fonte: Banco de dados (Anexo H). 
Na comparação dos níveis de cromo das amostras coletadas no ponto-controle e ponto-central, foram encontradas diferenças estatisticamente significantes para solo, raiz e folha $(\mathrm{p}=0,002)$.

Na comparação dos níveis de cromo dos pontos Leste/0, Norte/0, Oeste/0, Sul/0 com o ponto-controle, foram encontrados valores com diferenças estatisticamente significantes para solo, raízes, folhas $\left(\mathrm{p}^{\sim} 0\right)$. Ao realizar o Teste de Comparações Múltiplas, foi identificada uma diferença significante entre alguns dos pontos $(q>3,858)$. Observa-se na Tab. 9 , que o ponto Norte/0 apresentou diferenças significativas ao serem comparados com o ponto-controle para as três matrizes avaliadas. O ponto Oeste/ 0 apresentou diferença significante para a matriz solo e folha e o ponto Sul/0 unicamente para raiz.

Tab. 9 - Valores críticos de $q$ obtidos na comparação dos níveis de Cr do grupo controle com os níveis das amostras coletadas no limite 0 do Aterro Sanitário.

\begin{tabular}{cc|cccc}
\hline \hline Matriz & Amostra & Leste/0 & Norte/0 & Oeste/0 & Sul/0 \\
\hline \hline Solo & Controle & 3,3 & $6,7^{*}$ & $5,0^{*}$ & 1,6 \\
Raiz & Controle & 1,7 & $6,7^{*}$ & 3,3 & $5,0^{*}$ \\
Folha & Controle & 1,6 & $6,7^{*}$ & $5,0^{*}$ & 3,3 \\
\hline \hline
\end{tabular}

* Diferença estatisticamente significante

Na comparação dos níveis de cromo nos pontos Leste/50, Norte/50, Oeste/50 com o ponto-controle foram encontradas diferenças estatisticamente significantes para solo, raiz e folha ( $\mathrm{p}^{\sim}$ 0). Através do Teste de Comparações Múltiplas, observase na Tab. 10, que os pontos Norte/50 e Leste/50 apresentaram diferenças significantes ao serem comparados com o ponto controle para as três matrizes avaliadas. Sendo que em cada um desses pontos os valores foram superiores aos 
encontrados no ponto-controle $(q>3,633)$. O ponto Oeste/50 apresentou diferença significante unicamente para a matriz solo.

Tab. 10 - Valores críticos de $q$ obtidos na comparação dos níveis de Cr do grupo controle com os níveis das amostras coletadas no limite 50 do Aterro Sanitário.

\begin{tabular}{cl||ccc}
\hline \hline Matriz & Amostra & Leste/50 & Norte/50 & Oeste/50 \\
\hline \hline Solo & Controle & $4,2^{*}$ & $6,2^{*}$ & $3,7 *$ \\
Raiz & Controle & $4,2^{*}$ & $6,2^{*}$ & 2,1 \\
Folha & Controle & $4,2^{*}$ & $6,2^{*}$ & 2,1 \\
\hline
\end{tabular}

* Diferença estatisticamente significante

Na comparação dos níveis de cromo nos pontos Leste/100, Norte/100, Oeste/100 com o ponto-controle, foram encontradas diferenças estatisticamente significantes para solo, raiz e folha $(\mathrm{p}=0,001)$. A Tab. 11 apresenta os valores críticos de q obtidos, destacando-se que os pontos localizados no sentido Norte foram os que apresentaram diferenças significantes $(q>3,633$, para solo e $q>3,314$ para raiz e folha), com respeito ao ponto-controle para as três matrizes avaliadas. Os pontos Leste/100 e Oeste/100 somente para solo.

Tab. 11 - Valores críticos de q obtidos na comparação dos níveis de Cr do grupo controle com os níveis das amostras coletadas no limite 100 do Aterro Sanitário.

\begin{tabular}{cl||ccc}
\hline \hline Matriz & Amostra & Leste/100 & Norte/100 & Oeste/100 \\
\hline \hline Solo & Controle & $3,7 *$ & $6,2^{*}$ & $4,2^{*}$ \\
Raiz & Controle & 2,7 & $5,5^{*}$ & N.E.** \\
Folha & Controle & 2,7 & $5,5^{*}$ & N.E.** \\
\hline \hline
\end{tabular}

* Diferença estatisticamente significante

** Amostra vegetal inexistente 
Na comparação dos níveis de cromo nos pontos Leste/200, Norte/200 com respeito ao ponto controle foram encontradas diferenças estatisticamente significantes para solo, raiz e folha $(\mathrm{p}=0,001)$. Ao realizar o teste de comparações múltiplas, verificamos que no ponto Norte/200 as matrizes solo e folha apresentaram diferença significante com respeito ao ponto-controle (Tab. 12).

Tab. 12 - Valores críticos de $q$ obtidos, na comparação dos niveis de Cr do grupo controle com os níveis das amostras coletadas no limite 200 do Aterro Sanitário.

\begin{tabular}{cl|cc}
\hline \hline Matriz & Amostra & Leste/200 & Norte/200 \\
\hline \hline Solo & Controle & 2,7 & $5,5^{*}$ \\
Raiz & Controle & $5,5^{*}$ & 2,7 \\
Folha & Controle & 2,7 & $5,5^{*}$ \\
\hline \hline & Diferença estatisticamente significante
\end{tabular}

Na comparação dos níveis de cromo no ponto Oeste/115, Sul/22 e Sul/554 com respeito ao ponto-controle, foi encontrada diferença estatisticamente significante para solo, raiz e folha $(\mathrm{p}=0,002)$.

A partir da análise estatística, evidenciou-se que, mesmo abaixo dos valores de intervenção para o solo, existe diferença significativa no nível dos metais presentes em solo, raiz e folha, em vários pontos de coleta, ao serem comparados com o ponto-controle, o que pode ser indicativo de que o tipo de disposição e/ou tratamento dos resíduos sólidos municipais pode estar propiciando a alteração da composição característica de Cr no solo e na vegetação naquela área, embora não em níveis que ultrapassem os limites recomendados. O sentido Norte foi o que apresentou maior freqüência de diferenças estatisticamente significantes para as três matrizes avaliadas (Fig. 17). 


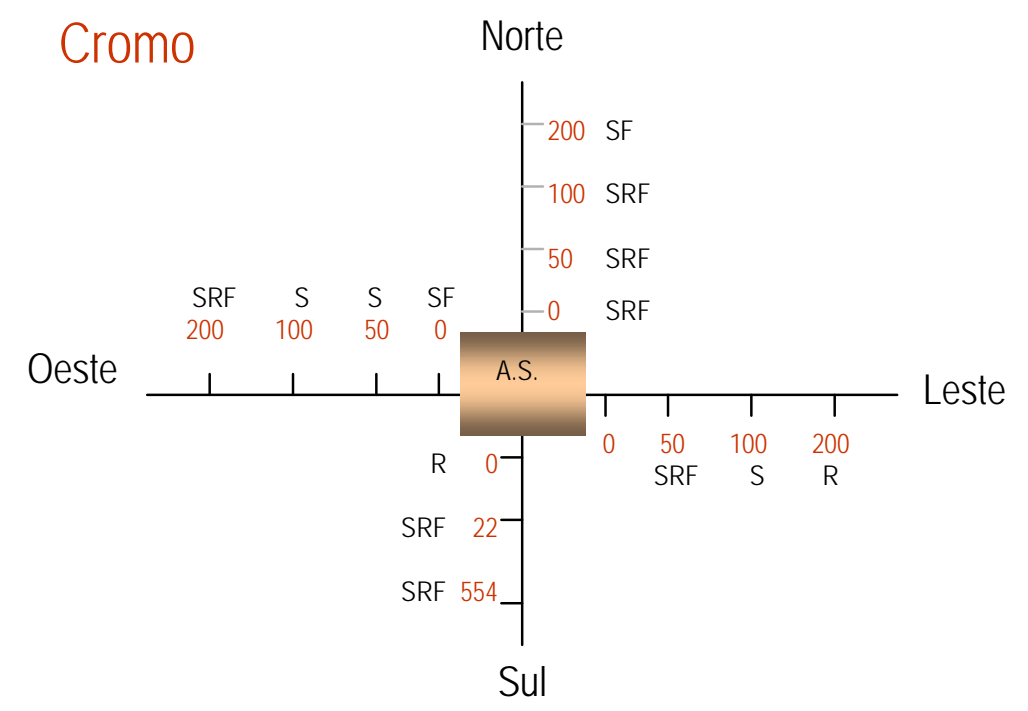

Fig. 17 - Distribuição das matrizes que apresentaram diferença estatisticamente significante para $\mathrm{Cr}$, segundo os pontos de coleta. (S: solo; R: raiz; F: folha)

Ao se comparar os valores obtidos com os valores de referência para o estado de São Paulo (CETESB, 2001), observa-se que, na maioria dos pontos de coleta, os níveis detectados de Cr no solo apresentaram-se inferiores aos níveis considerados de intervenção para solo de uso agrícola, que é de $300 \mathrm{mg} / \mathrm{kg}$ para esse tipo de solo (Anexo I).

Para diversos países da Europa têm sido estabelecidos valores entre 0 e 100 mg/kg para solos não contaminados (HMSO, 1991 apud Hamilton, 2000). Há, também na literatura, relatos de que na maioria dos solos o $\mathrm{Cr}$ ocorre em baixas concentrações, entre 2 e 60 mg/kg (WHO, 1988). As concentrações de Cr no local estão contempladas nessas faixas, razão pela qual pode ser considerado que o Cr não representa um metal poluente no solo na área do Aterro Sanitário e Incinerador de Ribeirão Preto. 
Espécies vegetais terrestres contém uma média de $2,7 \mathrm{mg} / \mathrm{kg}$ de $\mathrm{Cr}$ nos tecidos; porém, têm sido relatados níveis de Cr que vão de 0,1 a 45,2 mg/kg (Moore, 1990 apud CETESB, 2001). As concentrações de $\mathrm{Cr}$ detectadas nas amostras coletadas apresentaram um valor médio de 2,348 mg/kg para raízes e de $0,867 \mathrm{mg} / \mathrm{kg}$ para folha, destacando-se os níveis dos pontos Norte/0, Norte/50 e Norte/100, que variaram de 5,066 a 8,009 mg/kg (Tab. 8). 


\section{Níveis de chumbo}

Os níveis de chumbo presentes nas matrizes de solo, raiz e folha são apresentados na Tab. 13.

Tab. 13 - Nivel de chumbo nas amostras de solo, raiz e folha segundo a sua distribuição espacial, expressado em $\mathrm{mg} / \mathrm{Kg}$ para cada matriz.

\begin{tabular}{l||crr}
\hline Matriz & SOLO & RAIZ & \multicolumn{1}{c}{ FOLHA } \\
Ponto de coleta & Mediana; ASQ & Mediana; ASQ & Mediana; ASQ \\
\hline \hline Controle & 2,$452 ; 0,043$ & 2,$009 ; 0,135$ & 1,$842 ; 0,062$ \\
Central & 24,$658 ; 0,099$ & 9,$631 ; 0,685$ & 4,$227 ; 0,074$ \\
Leste/0 & 22,$847 ; 0,077$ & 14,$666 ; 0,432$ & 9,$617 ; 0,140$ \\
Leste/50 & 22,$505 ; 0,131$ & 17,$264 ; 0,891$ & 9,$704 ; 0,434$ \\
Leste/100 & 22,$800 ; 0,388$ & 11,$681 ; 0,380$ & 9,$160 ; 0,130$ \\
Leste/200 & 23,$269 ; 0,282$ & 8,$421 ; 0,433$ & 7,$009 ; 0,271$ \\
Norte/0 & 29,$832 ; 0,469$ & 20,$609 ; 0,249$ & 13,$620 ; 0,369$ \\
Norte/50 & 33,$954 ; 0,307$ & 19,$864 ; 0,318$ & 29,$688 ; 0,122$ \\
Norte/100 & 28,$055 ; 0,347$ & 14,$574 ; 0,316$ & 5,$250 ; 0,374$ \\
Norte/200 & 22,$838 ; 0,130$ & 10,$293 ; 0,858$ & 6,$086 ; 0,419$ \\
Oeste/0 & 22,$237 ; 0,257$ & 19,$419 ; 0,360$ & 7,$206 ; 0,120$ \\
Oeste/50 & 21,$091 ; 0,392$ & 26,$526 ; 0.950$ & 12,$452 ; 0,161$ \\
Oeste/100 & 22,$672 ; 0,162$ & N.E. $\cdot \cdot$ & N.E. $\cdot$ \\
Oeste/115 & 22,$399 ; 0,487$ & 16,$754 ; 0,652$ & 6,$075 ; 0,291$ \\
Sul/0 & 22,$570 ; 0,399$ & 12,$146 ; 0,514$ & 7,$576 ; 0,137$ \\
Sul/22 & 22,$614 ; 0,584$ & 13,$590 ; 0,701$ & 4,$943 ; 0,160$ \\
Sul/554 & 23,$310 ; 0,605$ & 15,$667 ; 0,504$ & 6,$209 ; 0,375$ \\
\hline \hline
\end{tabular}

- Mediana, calculada a partir de $\mathrm{n}=6$; Amplitude semi-quartílica (ASQ)

• $\quad$ N.E.: não foram encontradas espécies vegetais

Fonte: Banco de dados (Anexo H).

Na comparação entre os níveis de chumbo para o ponto-controle e pontocentral, foram encontradas diferenças estatisticamente significantes para solo, raiz e folha $(\mathrm{p}=0,002)$. 
$\mathrm{Na}$ comparação dos níveis de chumbo para os pontos Leste/0, Norte/0, Oeste/0, Sul/0 com o ponto-controle, foram encontradas diferenças estatisticamente significativas para solo, raiz e folha $\left(\mathrm{p}^{\sim} 0\right)$. Mediante o teste de Comparações Múltiplas, observa-se que as concentrações de chumbo apresentaram diferença significativa $(q>3,858)$ nas três matrizes avaliadas no ponto Norte/0, ao serem comparadas com os valores obtidos para o ponto-controle. Houve diferença significante nos pontos Leste/0 para solo e no ponto Oeste/0 para raiz.

Tab. 14 - Valores críticos de $q$ obtidos na comparação dos níveis de $\mathrm{Pb}$ do grupo controle com os níveis das amostras coletadas no limite 0 do Aterro Sanitário.

\begin{tabular}{cc||cccc}
\hline \hline Matriz & Amostra & Leste/0 & Norte/0 & Oeste/0 & Sul/0 \\
\hline \hline Solo & Controle & $4,8^{*}$ & $6,7^{*}$ & 2,2 & 3,0 \\
Raiz & Controle & 3,3 & $6,7^{*}$ & $5,0^{*}$ & 1,7 \\
Folha & Controle & $5,0^{*}$ & $6,7^{*}$ & 1,8 & 3,2 \\
\hline \hline
\end{tabular}

* Diferença estatisticamente significante

Na comparação dos níveis de chumbo nos pontos Leste/ 50, Norte/50, Oeste/50 e o ponto-controle foram encontradas diferenças estatisticamente significantes para solo, raízes, folhas ( $\mathrm{p}^{\sim}$ 0). A uma distância de 50 metros do limite do Aterro Sanitário, percebe-se que os pontos localizados no sentido Norte apresentaram diferença significativa $(q>3,633)$ para as três matrizes, ao serem comparados com os valores obtidos para o ponto-controle. No sentido Leste, não foi detectada diferença significante nas matrizes avaliadas e no sentido Oeste, essa diferença apresentou-se nas matrizes raiz e folha (Tab.15).

Tab. 15 - Valores críticos de $q$ obtidos, na comparação dos níveis de $\mathrm{Pb}$ do grupo controle com os níveis das amostras coletadas no limite 50 do Aterro Sanitário.

\begin{tabular}{cc||ccc}
\hline Matriz & Amostra & Leste/50 & Norte/50 & Oeste/50 \\
\hline \hline Solo & Controle & 3,2 & $6,2 *$ & 2,1
\end{tabular}




\begin{tabular}{cl||lll} 
Raiz & Controle & 2,1 & $4,2 *$ & $6,2 *$ \\
Folha & Controle & 2,1 & $6,2 *$ & $4,2 *$ \\
\hline
\end{tabular}

* Diferença estatisticamente significante

Na comparação dos níveis de chumbo nos pontos Leste/100, Norte/100, Oeste/100 com o ponto-controle foram encontradas diferenças estatisticamente significantes para solo ( $\left.\mathrm{p}^{\sim} 0,00\right)$ e para raízes e folhas $(\mathrm{p}=0,001)$. Mediante o teste de Comparações Múltiplas foi detectada diferença significante $(q>3,633)$, no ponto Leste/100 para as matrizes solo e folha, no ponto Norte/100 para as matrizes solo e raiz, no ponto Oeste/100 unicamente a matriz solo apresentou diferença significante (Tab. 16).

Tab.16- Valores críticos de $q$ obtidos, na comparação dos valores de $\mathrm{Pb}$ do grupo controle com os níveis das amostras coletadas no limite 100 do Aterro Sanitário.

\begin{tabular}{cl||ccc}
\hline \hline Matriz & Amostra & Leste/100 & Norte/100 & Oeste/100 \\
\hline Solo & Controle & $4,2^{*}$ & $6,2^{*}$ & $3,7^{*}$ \\
Raiz & Controle & 2,7 & $5,5^{*}$ & N.E. \\
Folha & Controle & $5,5^{*}$ & 2,7 & N.E. \\
\hline
\end{tabular}

* Diferença estatisticamente significante

N.E.: Não encontrada espécie vegetal

Na comparação dos níveis de chumbo nos pontos Leste/200, Norte/200, com respeito ao ponto-controle foram encontradas diferenças estatisticamente significantes para solo, raiz e folha $(\mathrm{p}=0,001)$. Mediante o Teste de Comparações Múltiplas, verificou-se diferença estatisticamente significante $(q>3,314)$ no ponto denominado Leste/200 para as matrizes solo e folha, no ponto Norte/200 evidenciose essa diferença significante para as matrizes raiz e folha (Tab. 17).

Tab. 17 - Valores críticos de $q$ obtidos, na comparação dos níveis de $\mathrm{Pb}$ do grupo controle com os níveis das amostras coletadas no limite 200 do Aterro Sanitário. 


\begin{tabular}{cc|cc}
\hline \hline Matriz & Amostra & Leste/200 & Norte/200 \\
\hline \hline Solo & Controle & $5,3^{*}$ & $3,9^{*}$ \\
Raiz & Controle & 2,4 & $5,3^{*}$ \\
Folha & Controle & $5,5^{*}$ & 2,7 \\
\hline * & Diferença estatisticamente significante
\end{tabular}

Na comparação entre os níveis de chumbo no ponto Oeste/115 com respeito ao ponto-controle, utilizando-se o Teste Mann-Whitney, foi encontrada diferença estatisticamente significante para raiz e folha $(\mathrm{p}<0,005)$. Nos pontos Sul/22 e Sul/554 os valores de chumbo foram significativamente maiores nas três matrizes avaliadas.

A partir da análise estatística ficou evidenciado que, mesmo abaixo dos valores legais e dos níveis relatados na literatura para solo e vegetais, existe diferença estatisticamente significante em quase todos os pontos demarcados, ao serem comparados com o ponto-controle (Fig. 18).

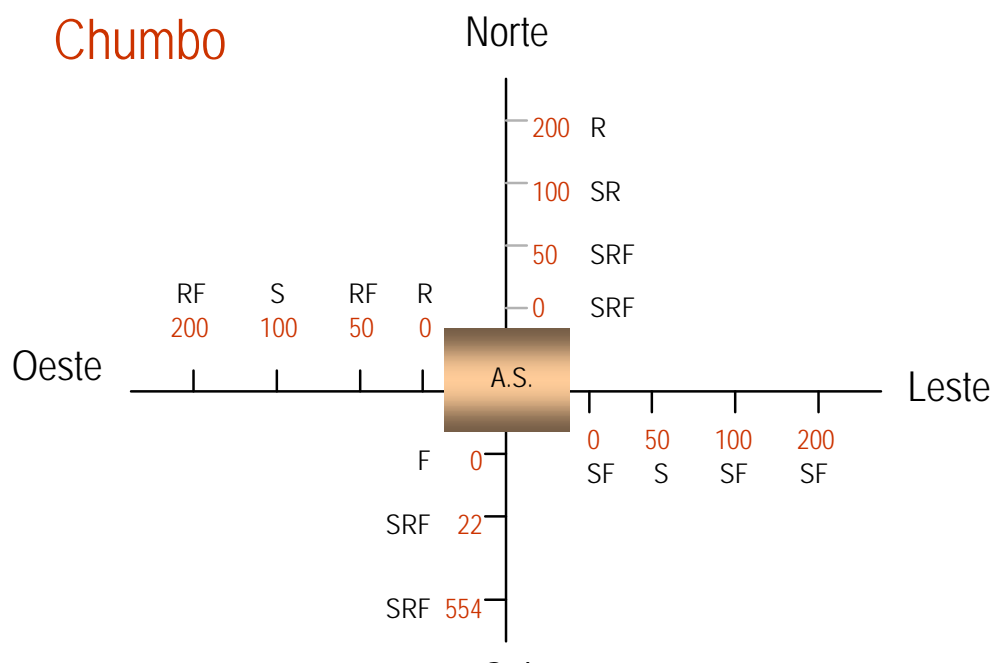

Sul

Fig. 18 - Distribuição das matrizes que apresentaram diferença estatisticamente significante para $\mathrm{Pb}$ nos pontos de coleta. (S: solo; R: raiz; F: folha). 
Ao se comparar os valores obtidos com os valores de referência para o estado de São Paulo (CETESB, 2001), observa-se que, na maioria dos pontos, os níveis detectados de $\mathrm{Pb}$ apresentaram-se inferiores aos níveis considerados de intervenção para uso agrícola, residencial, e industrial, definidos, respectivamente, como 200 $\mathrm{mg} / \mathrm{kg}, 350 \mathrm{mg} / \mathrm{kg}$ e $1200 \mathrm{mg} / \mathrm{kg}$.

Para este metal, também cabe salientar que o valor correspondente a solos não contaminados, estabelecido na Europa é de 0 a 200 mg/kg (HMSO, 1991 apud Hamilton, 2000). Solos coletados entre 100 e 200 m de distância de um Incinerador de Resíduos Municipais na Espanha apresentaram níveis superiores a 37,36 mg/kg (Schuhmacher et al., 1997). Os valores obtidos no presente estudo indicam que o $\mathrm{Pb}$ não representa um fator de risco de contaminação do solo no local estudado.

De modo geral, os níveis de $\mathrm{Pb}$ considerados normais para plantas estão compreendidos entre 1 e 12 mg/kg (Fleming \& Parle, 1977; Türkan et al., 1995); levando-se em consideração esses valores, verifica-se que 13 das 16 amostras de raiz coletadas apresentaram níveis de $\mathrm{Pb}$ superiores, enquanto unicamente 3 dentre 15 amostras de folha superaram o valor de $12 \mathrm{mg} / \mathrm{kg}$.

A partir desses resultados pode-se supor que a captação do $\mathrm{Pb}$ pela maioria dos vegetais no local de estudo acontece, primordialmente, pela via radicular, excetuando o exemplar que deu origem à amostra vegetal coletada no ponto Norte/50, que apresentou uma concentração de $\mathrm{Pb}$ na folha de $29,688 \mathrm{mg} / \mathrm{kg}$ e na raiz de 19,864 mg/kg (Tab. 13), o que pode refletir também absorção de $\mathrm{Pb}$ através das folhas, por deposição aérea do referido metal (Steinbörn \& Breen, 1999). 


\section{Níveis de Manganês}

Os níveis de manganês detectados nas matrizes de solo, raiz e folha estão apresentados na Tab. 18, a seguir:

Tab. 18 - Nível de manganês nas amostras de solo, raiz e folha segundo a sua distribuição espacial, expressado em $\mathrm{mg} / \mathrm{kg}$ para cada matriz.

\begin{tabular}{l||ccc}
\hline \multicolumn{1}{c|}{$\begin{array}{c}\text { Parâmetro } \\
\text { Ponto de Coleta }\end{array}$} & $\begin{array}{c}\text { SOLO } \\
\text { Mediana; ASQ }\end{array}$ & $\begin{array}{c}\text { RAIZ } \\
\text { Mediana ; ASQ }\end{array}$ & $\begin{array}{c}\text { FOLHA } \\
\text { Mediana ; ASQ }\end{array}$ \\
\hline \hline Controle & 432,$222 ; 0719$ & 15,$345 ; 0,085$ & 2,$774 ; 0,047$ \\
Central & 728,$956 ; 1,557$ & 528,$490 ; 0,645$ & 238,$344 ; 0,911$ \\
Leste/0 & 1037,$076 ; 0,303$ & 289,$946 ; 0,217$ & 12,$733 ; 0,186$ \\
Leste/50 & 888,$091 ; 1,041$ & 125,$155 ; 0,341$ & 69,$442 ; 0,185$ \\
Leste/100 & 1021,$890 ; 0,716$ & 131,$892 ; 0,231$ & 29,$237 ; 0,070$ \\
Leste/200 & 714,$921 ; 0,401$ & 102,$912 ; 0,195$ & 21,$057 ; 0,086$ \\
Norte/0 & 1687,$266 ; 9,809$ & 701,$624 ; 0,365$ & 329,$438 ; 0,210$ \\
Norte/50 & 2032,$152 ; 2,650$ & 951,$925 ; 0,160$ & 385,$341 ; 0,522$ \\
Norte/100 & 675,$815 ; 5,664$ & 453,$674 ; 0,576$ & 32,$084 ; 0,426$ \\
Norte/200 & 783,$002 ; 1,158$ & 198,$723 ; 0,394$ & 38,$753 ; 0,201$ \\
Oeste/0 & 921,$914 ; 0,817$ & 400,$522 ; 0,853$ & 49,$736 ; 0,295$ \\
Oeste/50 & 1427,$405 ; 0,533$ & 101,$970 ; 0,324$ & 48,$386 ; 0,182$ \\
Oeste/100 & 1100,$631 ; 2,513$ & N.E. * & N.E. * \\
Oeste/115 & 1187,$189 ; 1,203$ & 196,$993 ; 0,311$ & 47,$252 ; 0,354$ \\
Sul/0 & 934,$312 ; 0,796$ & 362,$835 ; 0,392$ & 67,$585 ; 0,069$ \\
Sul/22 & 834,$146 ; 0,502$ & 354,$998 ; 0,276$ & 20,$332 ; 0,458$ \\
Sul/554 & 708,$285 ; 3,221$ & 93,$016 ; 0,163$ & 4,$386 ; 0,185$ \\
\hline \hline
\end{tabular}

- Mediana, calculada a partir de n=6; Amplitude Semi-quartílica (ASQ)

- N.E.: não foram encontradas especies vegetais Fonte: Banco de dados (Anexo $\mathrm{H}$ ).

Na comparação entre os níveis de manganês para o ponto-controle e pontocentral, foram encontradas diferenças estatisticamente significantes para solo, raiz e folha $(\mathrm{p}=0,002)$. 
Na comparação dos níveis de manganês para os pontos Leste/0, Norte/0, Oeste/0, Sul/0 e o ponto-controle, foram encontradas diferenças estatisticamente significantes para solo, raiz e folha $\left(\mathrm{p}^{\sim} 0\right)$. Ao realizar o Teste de Comparações Múltiplas, identificamos que existe diferença significativa $(q>3,858)$ nos pontos Leste e Norte para solo, e no ponto Norte e Sul para as matrizes raiz e folha (Tab. 19).

Tab. 19 - Valores críticos de $q$ obtidos na comparação dos níveis de Mn do grupo controle com os níveis das amostras coletadas no limite 0 do Aterro Sanitário.

\begin{tabular}{cc|cccc}
\hline \hline Matriz & Amostra & Leste/0 & Norte/0 & Oeste/0 & Sul/0 \\
\hline \hline Solo & Controle & $5,0^{*}$ & $6,7^{*}$ & 1,7 & 3,3 \\
Raiz & Controle & 1,7 & $6,7^{*}$ & 3,3 & $5,0^{*}$ \\
Folha & Controle & 1,7 & $6,7^{*}$ & 3,3 & $5,0^{*}$ \\
\hline \hline
\end{tabular}

* Diferença estatisticamente significante

Na comparação entre os níveis de manganês nos pontos Leste/50, Norte/50, Oeste/50 e o ponto-controle foram encontradas diferenças estatisticamente significantes para solo, raiz e folha $\left(\mathrm{p}^{\sim} 0\right)$. Os valores críticos de q obtidos no Teste de Comparações Múltiplas dos valores de solo, raiz e folha nos pontos Leste/50, Norte/50, Oeste/50 e o controle, destacam as diferenças significativas $(q>3,633)$, nos pontos Norte/50 para as três matrizes, no ponto Leste/50 para raiz e folha e no ponto Oeste/50 apenas para solo (Tab. 20).

Tab. 20 - Valores críticos de $q$ obtidos na comparação dos níveis de Mn do grupo controle com os níveis das amostras coletadas no limite 50 do Aterro Sanitário.

\begin{tabular}{cc||ccc}
\hline Matriz & Amostra & Leste/50 & Norte/50 & Oeste/50 \\
\hline \hline Solo & Controle & 2,1 & $6,2^{*}$ & $4,2^{*}$ \\
Raiz & Controle & $4,2^{*}$ & $6,2^{*}$ & 2,1 \\
Folha & Controle & $4,2^{*}$ & $6,2^{*}$ & 2,1 \\
\hline \hline
\end{tabular}

* Diferença estatisticamente significante 
Na comparação dos níveis de manganês nos pontos Leste/100, Norte/100, Oeste/100 com o ponto-controle foram encontradas diferenças estatisticamente significantes para solo $\left(\mathrm{p}^{\sim} 0,00\right)$ e para raízes e folhas $(\mathrm{p}=0,001)$.

Na Tab. 21, são apresentados os valores críticos de $q$ obtidos, destacando-se diferenças significativas $(q>3,633)$, nos pontos Norte/100 para as matrizes raiz e folha, nos pontos Leste/100 e Oeste/100 para solo.

Tab. 21 - Valores críticos de $q$ obtidos na comparação dos níveis de Mn do grupo controle com os níveis das amostras coletadas no limite 100 do Aterro Sanitário.

\begin{tabular}{cl||ccc}
\hline \hline Matriz & Amostra & Leste/100 & Norte/100 & Oeste/100 \\
\hline Solo & Controle & $6,2^{*}$ & 2,1 & $4,2^{*}$ \\
Raiz & Controle & 2,7 & $5,5^{*}$ & N.E. \\
Folha & Controle & 2,7 & $5,5^{*}$ & N.E. \\
\hline \hline
\end{tabular}

* Diferença estatisticamente significante **N.E.: Não encontrada espécie vegetal

Na comparação dos níveis de manganês nos pontos Leste 200 e Norte/200 com respeito ao ponto-controle foram encontradas diferenças estatisticamente significantes para solo, raiz e folha $(\mathrm{p}=0,001)$. Ao realizar o Teste de Comparações Múltiplas, o ponto Norte caracterizou-se por apresentar diferença significante $(q>$ 3,314) com respeito ao ponto-controle para as matrizes raiz e folha (Tab. 22).

Tab. 22 - Valores críticos de $q$ obtidos na comparação dos níveis de Mn do grupo controle com os níveis das amostras coletadas no limite 200 do Aterro Sanitário.

\begin{tabular}{cl|cc}
\hline \hline Matriz & Amostra & Leste/200 & Norte/200 \\
\hline \hline Solo & Controle & 2,7 & 3,3 \\
Raiz & Controle & 2,7 & $5,5^{*}$ \\
Folha & Controle & 2,7 & $5,5^{*}$ \\
\hline \hline
\end{tabular}

* Diferença estatisticamente significante 
Na comparação dos níveis de manganês nos pontos Oeste/115 e Sul/22, com respeito ao ponto controle foi encontrada diferença estatisticamente significante para solo, raíz e folha $(p<0,05)$. No ponto Sul/554 foi encontrada diferença significante para as matrizes raiz e folha unicamente.

Após aplicação dos testes estatísticos, evidenciou-se que os sentidos Norte e Sul foram os que apresentaram maior número de pontos com diferenças estatisticamente significativas (Fig. 19).

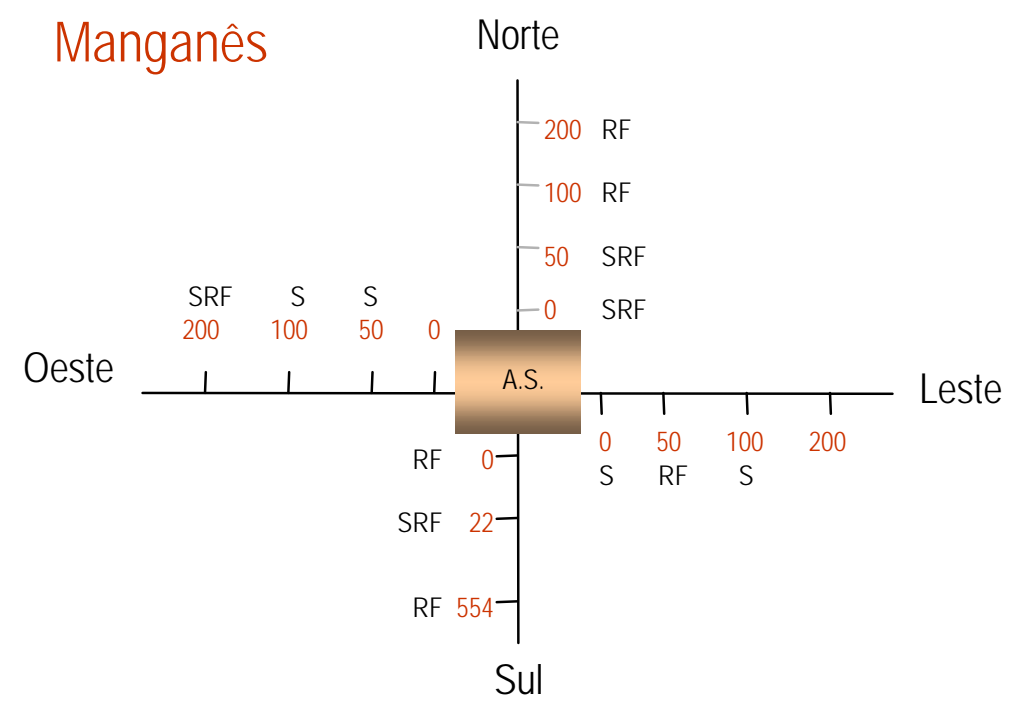

Fig. 19 - Distribuição das matrizes que apresentaram diferença estatisticamente significante para $\mathrm{Mn}$, nos pontos de coleta. (S: solo; R: raiz; F:folha).

Quanto aos níveis de Mn obtidos no presente estudo, o documento "Relatório de Estabelecimento de Valores Orientadores para solos do Estado de São Paulo" não apresenta níveis de alerta ou intervenção para $\mathrm{Mn}$ em solo, assim como em alguns países da Europa e América do Norte (CETESB, 2001).

No entanto, o Mn é um metal que naturalmente apresenta alta concentração e variabilidade, o que pode mascarar contribuições antropogênicas (Morselli et al., 
2000). Segundo a OMS (WHO, 1981), ocorrendo na crosta terrestre em uma concentração média de $950 \mathrm{mg} / \mathrm{kg}$.

Níveis de Mn até $1085 \mathrm{mg} / \mathrm{kg}$ foram relatados para solos nos arredores de um incinerador de resíduos municipais na Itália (Morselli et al., 2002). Os presentes resultados são, também, superiores aos obtidos por Schuhmacher et al. (1997) e Llobet et al. (2002), que relataram concetrações de 307,6 e 234,2 mg/kg de $\mathrm{Mn}$, respectivamente, como as máximas concentrações detectadas em solo coletado em áreas circunvizinhas a um incinerador de resíduos sólidos municipais na Catalunia, Espanha.

Ao analisar as concentrações de Mn nos vegetais coletados na área do Aterro Sanitário, observa-se que os níveis em raiz variaram entre 93,016 e 951,925 mg/kg e, em folhas, as concentrações foram de 4,386 a 385,341 mg/kg (Tab. 18). Igualmente como ocorreu com o solo, o ponto Norte/50 apresentou os maiores valores detectados para raiz e folha.

\section{Níveis de Zinco}

São apresentados os níveis de zinco detectados para as diferentes matrizes ambientais, segundo sua distribuição espacial na área do Aterro Sanitário na Tab. 23. 
Tab. 23 - Nível de zinco nas amostras de solo, raiz e folha segundo a sua distribuição espacial, expressado em $\mathrm{mg} / \mathrm{kg}$ para cada matriz.

\begin{tabular}{l|ccr}
\hline \multicolumn{1}{c||}{ Parâmetro } & SOLO & RAIZ & FOLHA \\
Ponto de Coleta & Mediana; ASQ & Mediana; ASQ• & Mediana; ASQ \\
\hline \hline Controle & 79,$654 ; 0,475$ & 17,$857 ; 0,804$ & 4,$338 ; 0,079$ \\
Central & 104,$562 ; 0,296$ & 18,$446 ; 0,543$ & 10,$960 ; 0,340$ \\
Leste/0 & 102,$098 ; 0,279$ & 40,$847 ; 0,389$ & 15,$345 ; 0,169$ \\
Leste/50 & 93,$78 ; 1,275$ & 20,$212 ; 0,459$ & 11,$336 ; 0,285$ \\
Leste/100 & 101,$523 ; 0,272$ & 19,$362 ; 0,184$ & 16,$055 ; 0,256$ \\
Leste/200 & 160,$303 ; 0,583$ & 19,$673 ; 0,093$ & 21,$969 ; 0,281$ \\
Norte/0 & 181,$753 ; 0,464$ & 172,$175 ; 0,431$ & 108,$222 ; 0,469$ \\
Norte/50 & 278,$341 ; 0,252$ & 143,$248 ; 0,261$ & 89,$685 ; 0,314$ \\
Norte/100 & 191,$900 ; 0,213$ & 34,$038 ; 0,276$ & 11,$515 ; 0,137$ \\
Norte/200 & 103,$966 ; 0,423$ & 18,$990 ; 0,115$ & 21,$145 ; 0,312$ \\
Oeste/0 & 82,$246 ; 0,278$ & 20,$938 ; 0,364$ & 27,$915 ; 0,115$ \\
Oeste/50 & 108,$900 ; 0,290$ & 57,$905 ; 0,178$ & 19,$787 ; 0,295$ \\
Oeste/100 & 103,$073 ; 0,366$ & N.E. $\cdot \cdot$ & N.E. $\cdot$ \\
Oeste/115 & 113,$287 ; 0,371$ & 31,$950 ; 0,407$ & 16,$899 ; 0,158$ \\
Sul/0 & 127,$043 ; 0,486$ & 46,$687 ; 0,193$ & 10,$027 ; 0,123$ \\
Sul/22 & 138,$940 ; 0,415$ & 46,$922 ; 0,019$ & 16,$263 ; 0,130$ \\
Sul/554 & 79,$462 ; 0,462$ & 16,$811 ; 0,424$ & 12,$002 ; 0,071$ \\
\hline \hline
\end{tabular}

- Mediana, calculada a partir de $\mathrm{n}=6$; Amplitude semi-quartílica (ASQ)

-. N.E.: não foram encontradas espécies vegetais

Fonte: Banco de dados (Anexo H).

Na comparação entre os níveis de zinco para o ponto-controle e ponto-central, foi encontrada diferença estatisticamente significativa para a matriz folha $(\mathrm{p}=0,002)$; porém a diferença nos valores obtidos para solo e raiz não foram significantes. 
Na comparação dos níveis de zinco para os pontos Leste/0, Norte/0, Oeste/0, Sul/0 e o ponto-controle, foram encontradas diferenças estatisticamente significantes para solo, raiz e folha $\left(\mathrm{p}^{\sim} 0\right)$.

Ao realizar o Teste de Comparações Múltiplas, destacaram-se as diferenças significantes $(q>3,858)$ com respeito ao ponto controle nos pontos Norte/0 para as três matrizes e Sul/0 para solo e raiz (Tab. 24).

Tab. 24 - Valores críticos de $q$ obtidos na comparação dos níveis de Zn do grupo controle com os níveis das amostras coletadas no limite 0 do Aterro Sanitário.

\begin{tabular}{cc||cccc}
\hline \hline Matriz & Amostra & Leste/0 & Norte/0 & Oeste/0 & Sul/0 \\
\hline \hline Solo & Controle & 3,3 & $6,7^{*}$ & 1,7 & $5,0^{*}$ \\
Raiz & Controle & 3,3 & $6,7^{*}$ & 1,7 & $5,0^{*}$ \\
Folha & Controle & 3,3 & $6,7^{*}$ & $5,0^{*}$ & 1,7 \\
\hline \hline
\end{tabular}

* Diferença estatisticamente significante

Na comparação dos níveis de zinco nos pontos Leste/ 50, Norte/50, Oeste/50 e o ponto-controle foram encontradas diferenças estatisticamente significantes para solo, raiz e folha ( $\mathrm{p}^{\sim}$ 0). Nos valores críticos de q obtidos destacaram-se as diferenças estatisticamente significantes $(q>3,633)$ nos pontos Norte/50 e Oeste/50 para as três matrizes quando comparados com o ponto controle (Tab. 25).

Tab. 25 - Valores críticos de $q$ obtidos na comparação dos níveis de $\mathrm{Zn}$ do grupo controle com os níveis das amostras coletadas no limite 50 do Aterro Sanitário.

\begin{tabular}{cc||ccc}
\hline \hline Matriz & Amostra & Leste/50 & Norte/50 & Oeste/50 \\
\hline \hline Solo & Controle & 2,1 & $6,2^{*}$ & $4,2^{*}$ \\
Raiz & Controle & 2,1 & $6,2^{*}$ & $4,2^{*}$ \\
Folha & Controle & 2,1 & $6,2^{*}$ & $4,2^{*}$ \\
\hline \hline
\end{tabular}

* Diferença estatisticamente significante 
$\mathrm{Na}$ comparação dos níveis de zinco nos pontos Leste/100, Norte/100, Oeste/100 com o ponto-controle foram encontradas diferenças estatisticamente significantes para solo $\left(\mathrm{p}^{\sim}\right.$ 0,00) e para raízes e folhas $(\mathrm{p}=0,001)$. A Tab. 26, apresenta os valores críticos de $q$ obtidos, evidenciando as diferenças estatisticamente significantes $(q>3,633$ para solo e $q>3,314$ para as matrizes vegetais) nos pontos Norte/100 para as matrizes solo e raiz e no Leste/100 para a matriz folha.

Tab. 26 - Valores críticos de $q$ obtidos na comparação dos níveis de Zn do grupo controle com os níveis das amostras coletadas no limite 100 do Aterro Sanitário.

\begin{tabular}{cl||ccc}
\hline \hline Matriz & Amostra & Leste/100 & Norte/100 & Oeste/100 \\
\hline Solo & Controle & 2,1 & $6,2^{*}$ & 3,3 \\
Raiz & Controle & 2,7 & $5,5^{*}$ & N.E. \\
Folha & Controle & $5,5^{*}$ & 2,7 & N.E. \\
\hline \hline
\end{tabular}

* Diferença estatisticamente significante **N.O.: Não encontrada espécie vegetal

Na comparação dos níveis de zinco nos pontos Leste 200, Norte/200 com respeito ao ponto-controle, foram encontradas diferenças estatisticamente significantes para solo, raiz e folha $(\mathrm{p}=0,001)$. Através do Teste de Comparações Múltiplas destacou-se que a esta distância do limite do Aterro Sanitário o ponto Leste/200 caracterizou-se por apresentar maiores concentrações de zinco no solo, raiz e folha, apresentando valores críticos de $q$ superiores a 3,314 (Tab. 27).

Tab. 27 - Valores críticos de $q$ obtidos na comparação dos níveis de Zn do grupo controle com os níveis das amostras coletadas no limite 200 do Aterro Sanitário.

\begin{tabular}{cl|cc}
\hline \hline Matriz & Amostra & Leste/200 & Norte/200 \\
\hline \hline Solo & Controle & $5,5^{*}$ & 2,7 \\
Raiz & Controle & $5,5^{*}$ & 2,7 \\
Folha & Controle & $5,5^{*}$ & 2,7 \\
\hline \hline
\end{tabular}


* Diferença estatisticamente significante

Na comparação dos níveis de zinco nos pontos Oeste/115, Sul/22 e Sul/554 com respeito ao ponto-controle foi encontrada diferença estatisticamente significante para solo, raiz e folha $(\mathrm{p}<0,005)$, exceto a amostra de solo $\mathrm{Sul} / 554$, que não apresentou diferença significativa com respeito ao ponto-controle.

A partir da análise estatística evidenciou-se que, mesmo abaixo dos valores de intervenção, existe diferença significativa em vários pontos de coleta na área do aterro, ao serem comparados com o ponto-controle. O sentido Leste foi o que apresentou menor frequiência na significância das diferenças estatísticas para as três matrizes avaliadas (Fig. 20); porém, destacam-se os valores estatisticamente significantes detectados no ponto Leste/200, para as três matrizes, embora não tenha sido detectado o mesmo metal em nenhum dos pontos de coleta anteriores na mesma direção (Leste/0, Leste/50 e Leste/100).

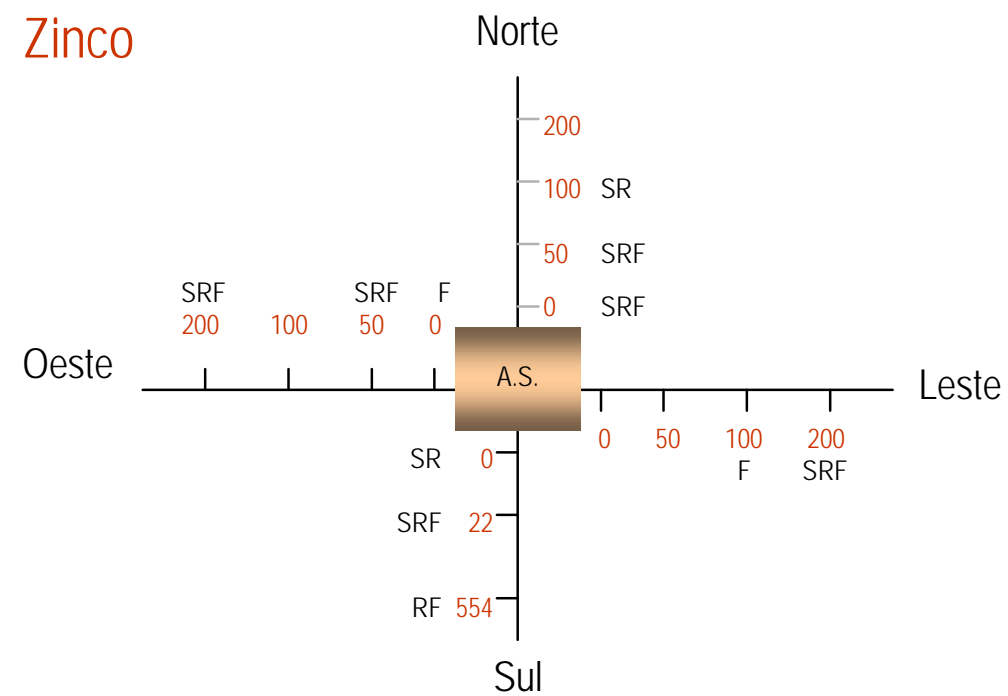

Fig. 20 - Distribuição das matrizes que apresentaram diferença estatisticamente significante para $\mathrm{Zn}$, nos pontos de coleta. (S: solo; R: raiz; F:folha) 
No ano anterior à coleta de amostras, o incinerador passou por um período de desativação, ocasião em que os resíduos provenientes de serviços de saúde foram depositados em vala séptica situada nas imediações do ponto Leste/200. A deposição de materiais contendo zinco, pode justificar este achado. A utilização de valas sépticas é uma medida emergencial geralmente indicada quando o incinerador apresentar problemas estruturais que impossibilitam o seu funcionamento ou por qualquer outro impedimento de tratamento dos resíduos.

O zinco ocorre na crosta terrestre com uma concentração de 10 a 300 mg/kg, valores estes determinados segundo a geologia do local e pelas atividades antropogênicas (WHO, 2001). Os níveis de $\mathrm{Zn}$ detectados no local, podem ser comparados às concentrações reportadas na literatura para áreas não contaminadas (Steinborn \& Breen, 1999).

Ao serem comparados com os valores de intervenção para o estado de São Paulo, verificou-se que, na época da coleta, os níveis de $\mathrm{Zn}$ encontrados no solo apresentavam-se inferiores aos valores máximos de intervenção recomendados que são: $500 \mathrm{mg} / \mathrm{kg}$ para solo de uso agrícola, $1000 \mathrm{mg} / \mathrm{kg}$ para solo de uso residencial e $1500 \mathrm{mg} / \mathrm{kg}$ para solo de uso industrial (Anexo I).

Da avaliação dos resultados de $\mathrm{Zn}$ detectados em amostras vegetais, destacam-se os valores encontrados nos pontos Norte/0 e Norte/50, que apresentaram as maiores concentrações, tanto para raízes $(143,248$ e $172,175 \mathrm{mg} / \mathrm{kg})$ como para folhas $(108,222$ e $89,685 \mathrm{mg} / \mathrm{kg})$. Considerando que valores entre 25 e $200 \mathrm{mg} / \mathrm{kg}$ são considerados normais em vegetais (Fleming \& Parle, 1977; Türkan et al., 1995), os resultados obtidos indicam que este metal encontra-se dentro dos limites normais 
na vegetação localizada nas imediações do Aterro Sanitário e Incinerador, embora, de certa forma, próximos aos valores superiores relatados.

\section{Níveis de Cobre}

São apresentados os níveis de cobre detectados para as diferentes matrizes ambientais, segundo sua distribuição espacial na área do Aterro Sanitário (Tab. 28).

Tab. 28 - Nível de cobre nas amostras de solo, raiz e folha segundo a sua distribuição espacial, expressado em $\mathrm{mg} / \mathrm{kg}$ para cada matriz.

\begin{tabular}{l||ccc}
\hline \multicolumn{1}{c||}{ Parâmetro } & SOLO & RAIZ & FOLHA \\
Ponto de Coleta & Mediana; ASQ· & Mediana; ASQ & Mediana; ASQ· \\
\hline \hline Controle & 57,$200 ; 0,014$ & 3,$748 ; 0,185$ & $<0,0075$ \\
Central & 161,$495 ; 0,242$ & 7,$177 ; 0,057$ & 6,$225 ; 0,463$ \\
Leste/0 & 162,$974 ; 0,197$ & 20,$261 ; 0,129$ & 3,$595 ; 0,122$ \\
Leste/50 & 132,$761 ; 0,346$ & 15,$754 ; 0,247$ & 2,$145 ; 0,229$ \\
Leste/100 & 142,$091 ; 0,198$ & 25,$575 ; 0,661$ & 4,$687 ; 0,362$ \\
Leste/200 & 148,$643 ; 0,171$ & 19,$247 ; 0,340$ & 6,$286 ; 0,494$ \\
Norte/0 & 268,$143 ; 0,596$ & 54,$163 ; 0,282$ & 17,$931 ; 0,166$ \\
Norte/50 & 299,$017 ; 0,423$ & 36,$493 ; 0,473$ & 16,$722 ; 0,206$ \\
Norte/100 & 257,$398 ; 0,105$ & 47,$129 ; 0,661$ & 5,$652 ; 0,254$ \\
Norte/200 & 113,$502 ; 0,702$ & 4,$539 ; 0,254$ & 4,$525 ; 0,265$ \\
Oeste/0 & 180,$219 ; 0,601$ & 20,$420 ; 0,469$ & 17,$545 ; 0,129$ \\
Oeste/50 & 153,$180 ; 0,127$ & 15,$487 ; 0,186$ & 7,$523 ; 0,024$ \\
Oeste/100 & 153,$922 ; 0,246$ & N.E. $\cdot$ & N.E. $\cdot$ \\
Oeste/115 & 162,$422 ; 0,330$ & 18,$731 ; 0,640$ & 5,$202 ; 0,006$ \\
Sul/0 & 187,$057 ; 0,592$ & 52,$368 ; 0,737$ & 2,$047 ; 0,020$ \\
Sul/22 & 159,$799 ; 0,516$ & 50,$993 ; 0,546$ & 4,$268 ; 0,015$ \\
Sul/554 & 151,$830 ; 0,589$ & 22,$393 ; 0,621$ & 3,$549 ; 0,127$ \\
\hline \hline
\end{tabular}

- Mediana, calculada a partir de n=6; Amplitude semi-quartílica (ASQ)

* N.E.: não foram encontradas especies vegetais

Fonte: Banco de dados (Anexo H). 
Para a matriz folha não foi possível aplicar o teste estatístico, pelo fato de apresentar valores abaixo do limite de detecção para o ponto-controle.

$\mathrm{Na}$ comparação entre os níveis de cobre para o ponto-controle e pontocentral, foram encontradas diferenças estatisticamente significantes para solo ( $\mathrm{p}=0,002)$; porém, a diferença nos valores obtidos para raiz não foi significante.

Na comparação dos níveis de cobre para os pontos Leste/0, Norte/0, Oeste/0, Sul/0 com o ponto-controle, foram encontradas diferenças estatisticamente significantes para solo e raiz ( $\left.\mathrm{p}^{\sim} 0\right)$. Através do Teste de Comparações Múltiplas, foram identificadas diferenças estatisticamente significantes $(q>3,858)$ nos quatro pontos para solo e nos pontos Norte/0 e Sul/0 para raiz (Tab.29).

Tab. 29 - Valores críticos de $q$ obtidos na comparação dos níveis de $\mathrm{Cu}$ do grupo controle com os níveis das amostras coletadas no limite 0 do Aterro Sanitário.

\begin{tabular}{cc|cccc}
\hline \hline Matriz & Amostra & Leste/0 & Norte/0 & Oeste/0 & Sul/0 \\
\hline \hline Solo & Controle & $3,9 *$ & $6,7 *$ & $4,2^{*}$ & $5,0^{*}$ \\
Raiz & Controle & 2,3 & $6,4^{*}$ & 2,7 & $3,9 *$ \\
\hline \hline
\end{tabular}

* Diferença estatisticamente significante

Na comparação dos níveis de cobre nos pontos Leste/ 50, Norte/50, Oeste/50 com o ponto-controle, foram encontradas diferenças estatisticamente significantes para solo, raiz e folha $\left(\mathrm{p}^{\sim} 0\right)$.

Os valores críticos de $q$ obtidos na comparação dos pontos Leste/50, Norte/50 e Oeste/50 com respeito ao ponto-controle são apresentados na Tab. 30, sendo identificadas diferenças significantes $(q>3,633)$ no ponto Norte/50 para solo e raiz e Oeste/50 para solo. 
Tab. 30 - Valores críticos de $q$ obtidos na comparação dos níveis de Cu do grupo controle com os níveis das amostras coletadas no limite 50 do Aterro Sanitário.

\begin{tabular}{cc||ccc}
\hline \hline Matriz & Amostra & Leste/50 & Norte/50 & Oeste/50 \\
\hline \hline Solo & Controle & 2,1 & $6,2^{*}$ & $4,2 *$ \\
Raiz & Controle & 3,6 & $4,9 *$ & 2,6 \\
\hline \hline
\end{tabular}

* Diferença estatisticamente significante

$\mathrm{Na}$ comparação dos níveis de cobre nos pontos Leste/100, Norte/100, Oeste/100 com o ponto-controle foram encontradas diferenças estatisticamente significantes para solo $\left(\mathrm{p}^{\sim} 0,00\right)$ e para raízes $(\mathrm{p}=0,001)$. A Tab. 31, apresenta os valores críticos de $q$ obtidos, destacando-se a diferença significativa no ponto Norte/100 para solo e raiz e no ponto Oeste/100 para solo.

Tab. 31 - Valores críticos de $q$ obtidos na comparação dos níveis de Cu do grupo controle com os níveis das amostras coletadas no limite 100 do Aterro Sanitário.

\begin{tabular}{cc||ccc}
\hline \hline Matriz & Amostra & Leste/100 & Norte/100 & Oeste/100 \\
\hline \hline Solo & Controle & 2,1 & $6,2 *$ & $4,2 *$ \\
Raiz & Controle & 2,7 & $4,1^{*}$ & N.E. \\
\hline * & Diferença estatisticamente significante & \\
\multicolumn{2}{c}{$*$ N.E.: Não encontrada espécie vegetal } &
\end{tabular}

Na comparação dos níveis de cobre nos pontos Leste/200, Norte/200, com respeito ao ponto-controle, foram encontradas diferenças estatisticamente significantes para solo e raiz $(\mathrm{p}=0,001)$. Os valores críticos de $q$ evidenciam diferenças estatisticamente significantes $(q>3,314)$ no ponto Leste/200 para solo e raiz (Tab. 32).

Tab. 32 - Valores críticos de $q$ obtidos na comparação dos níveis de Cu do grupo controle com os níveis das amostras coletadas no limite 200 do Aterro Sanitário.

\begin{tabular}{cc||cc}
\hline \hline Matriz & Amostra & Leste/200 & Norte/200 \\
\hline \hline Solo & Controle & $5,5^{*}$ & 2,7 \\
Raiz & Controle & $5,5^{*}$ & 2,7 \\
\hline \hline
\end{tabular}




\section{* Diferença estatisticamente significante}

Na comparação dos níveis de cobre nos pontos Oeste/115, Sul/22 e Sul 554 com respeito ao ponto-controle, foi encontrada diferença estatisticamente significante para solo e raiz $(\mathrm{p}<0,005)$.

A partir da análise estatística, percebe-se que a diferença foi significativa para solo e/ou raiz, na maioria dos pontos analisados (Fig. 21).

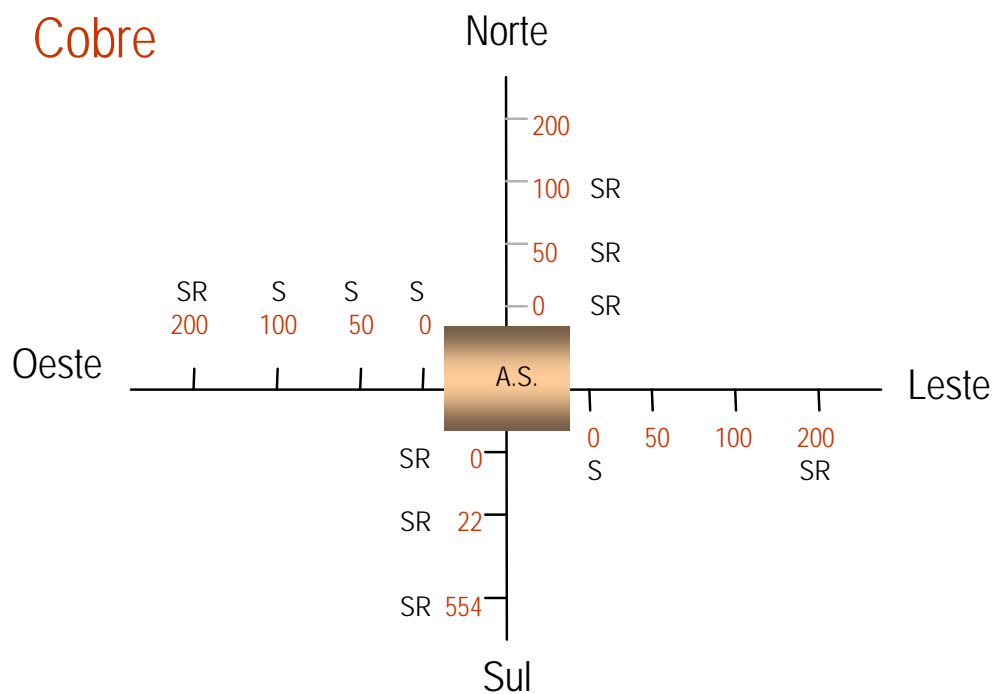

Fig. 21 - Distribuição das matrizes que apresentaram diferença estatisticamente significante para $\mathrm{Cu}$, nos pontos de coleta. (S: solo; R: raiz; F:folha)

Destacam-se os valores estatisticamente significantes detectados no ponto Leste/200, para as matrizes solo e raiz, embora não tenha sido detectado o mesmo metal em nenhum dos pontos de coleta anteriores nessa direção (Leste/0, Leste/50 e Leste/100), lembrando tratar-se de um ponto recentemente utilizado para disposição emergencial de resíduos provenientes de serviços de saúde em valas sépticas.

Sabe-se que o cobre ocorre na crosta terrestre em uma concentração média de $50 \mathrm{mg} / \mathrm{kg}$ (WHO, 1998). Ao serem comparados os resultados com os valores de intervenção para o estado de São Paulo, definidos entre os limites de 100 mg/kg para 
solo de uso agrícola, $500 \mathrm{mg} / \mathrm{kg}$ para solo de uso residencial e $700 \mathrm{mg} / \mathrm{kg}$ para solo de uso industrial (Anexo $\mathrm{H}$ ), verifica-se que o $\mathrm{Cu}$ apresentou-se, em todos os pontos, acima de $100 \mathrm{mg} / \mathrm{kg}$, o que representa risco pelo fato de que a área circunvizinha ao aterro sanitário está sendo utilizada com fins agrícolas permanentemente.

Em vegetais, consideram-se como normais concentrações de $\mathrm{Cu}$ entre 5 e 20 mg/kg (Fleming \& Parle, 1977; Türkan et al., 1995); para este metal algumas amostras de raiz apresentaram níveis acima de $40 \mathrm{mg} / \mathrm{kg}$, o que pode indicar que o transporte do metal está sendo veiculado até a raiz pelo solo. As concentrações mais elevadas foram detectadas no sentido Norte e Sul. Para as folhas, os valores mais altos corresponderam aos pontos Norte/0, Norte/50 e Oeste/0 (Tab. 28).

Destacam-se os valores estatisticamente significantes detectados no ponto Leste/200, para as matrizes solo e raiz, embora não tenha sido detectado o mesmo metal em nenhum dos pontos de coleta anteriores nessa direção (Leste/0, Leste/50 e Leste/100), lembrando tratar-se de um ponto recentemente utilizado para disposição emergencial de resíduos provenientes de serviços de saúde em valas sépticas.

\section{Níveis de Mercúrio}

Dentre os metais avaliados, o mercúrio apresentou-se como o metal menos detectado nas matrizes analisadas, estando abaixo dos limites de detecção dos métodos utilizados para as matrizes solo, raiz e folha (ANEXO H). Considera-se este achado como de grande importância, tendo em vista a toxicidade desse elemento, associado à sua capacidade de acumulação e o alto índice de bioacumulação (Garcia \& Dorronsoro, 2002). Os resultados para este metal evidenciam, portanto, que o solo 
da área do entorno do Aterro Sanitário e Incinerador pode ser considerado como solo não-contaminado por Hg (HMSO, 1991 apud Hamilton, 2000).

De um modo geral, avaliando-se a Fig. 22, na qual foram agrupados os resultados da análise estatística, pode-se observar que a maioria das amostras de solo e vegetais coletadas na área do Aterro Sanitário e Incinerador de Resíduos Sólidos de Ribeirão Preto-SP apresentaram níveis significativamente superiores às amostras coletadas na mata Santa Teresa, no período referente ao estudo, mesmo apresentando valores abaixo dos limites máximos recomendados para $\mathrm{Cr}, \mathrm{Pb}$ e $\mathrm{Zn}$. Considerandose que os dois locais apresentam tipos de solo com características semelhantes (Alvarenga, 1986; Aita, 1996), os resultados poderiam estar apontando mudanças na composição natural dos metais no solo da área do Atero Sanitário e Incinerador de Resíduos Sólidos de Ribeirão Preto

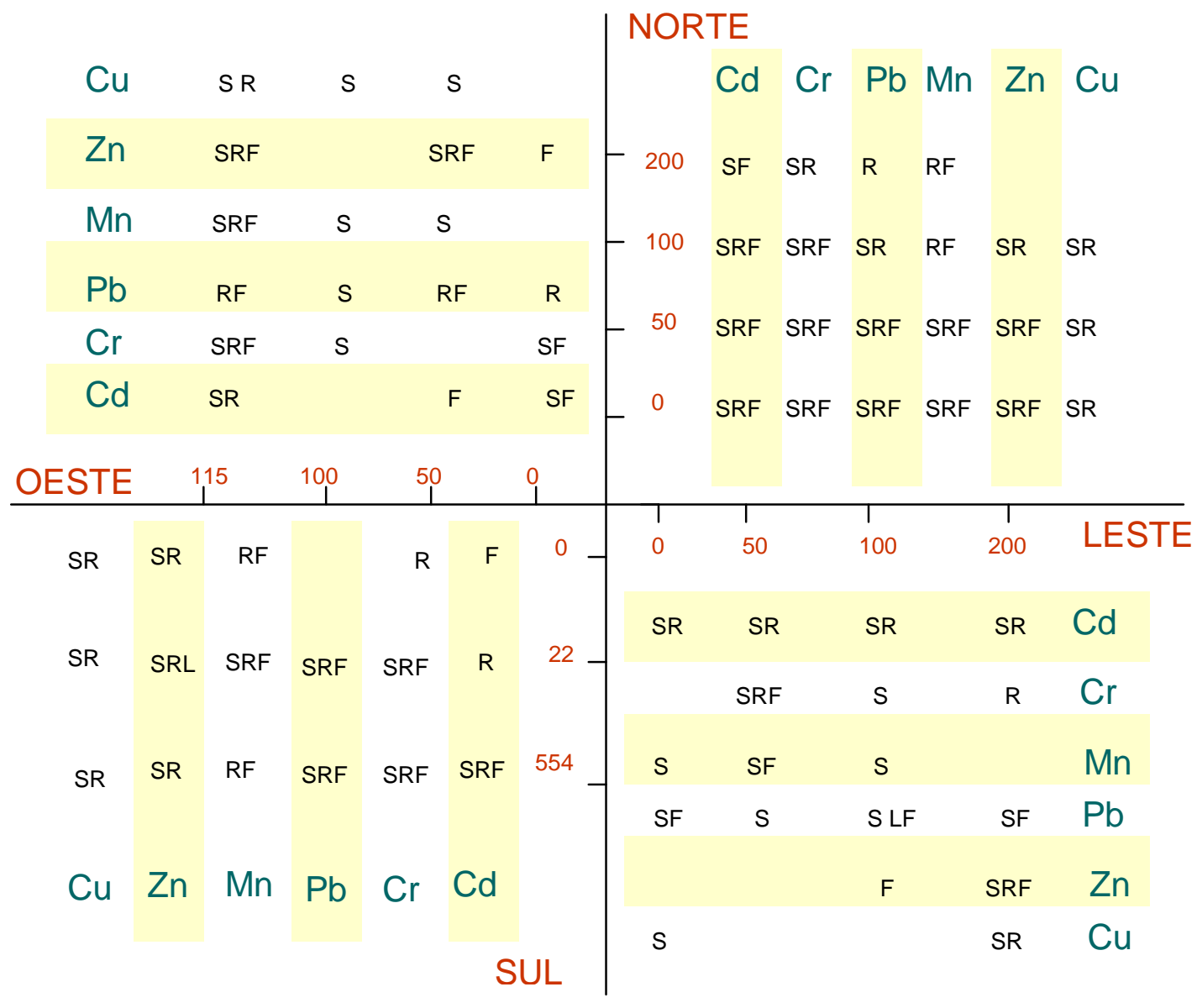


Fig. 22 - Distribuição das matrizes que apresentaram diferença estatisticamente significante para os metais avaliados segundo a localização dos pontos de coleta. (S: solo; R: raiz; F: folha)

\subsection{Possíveis fatores determinantes da distribuição espacial dos metais}

Um fator que pode estar determinando maiores concentrações dos metais analisados no sentido Norte do Aterro Sanitário refere-se à declividade do terreno. No EIA-RIMA, encontra-se descrito que o Aterro Sanitário e Incinerador localizamse numa área com declividades inferiores a 15\% e amplitudes de desnível locais de 100 a 300 m. A partir dos Perfis Topográficos da região (Fig. 23 e 24), pode ser observado que o Aterro Sanitário está localizado no terço inferior da encosta (perfis A-B e C-D), e que o sentido da declividade é predominantemente do Sul para o Norte (Alvarenga et al., 1986).

Segundo Garcia \& Dorronsoro (2002), aproximadamente 10 \% dos resídios sólidos são constituídos por metal. Os resíduos municipais no estado de São Paulo caracterizam-se por conter, aproximadamente, $60 \%$ de matéria orgânica, $10 \%$ de produtos de celulose, $20 \%$ de materiais plásticos e $10 \%$ de materiais do tipo vidro e metal (PRODAM, 2002). Os produtos metálicos e plásticos presentes nos resíduos sólidos dispostos no Aterro Sanitário podem ser fonte de metais. A degradação desses resíduos pode estar gerando líquidos contendo esses contaminantes, que podem sofrer movimentação horizontal na direção Norte, devido ao gradiente geográfico da área. 


\section{MAPA DE LOCALIZACÃO}

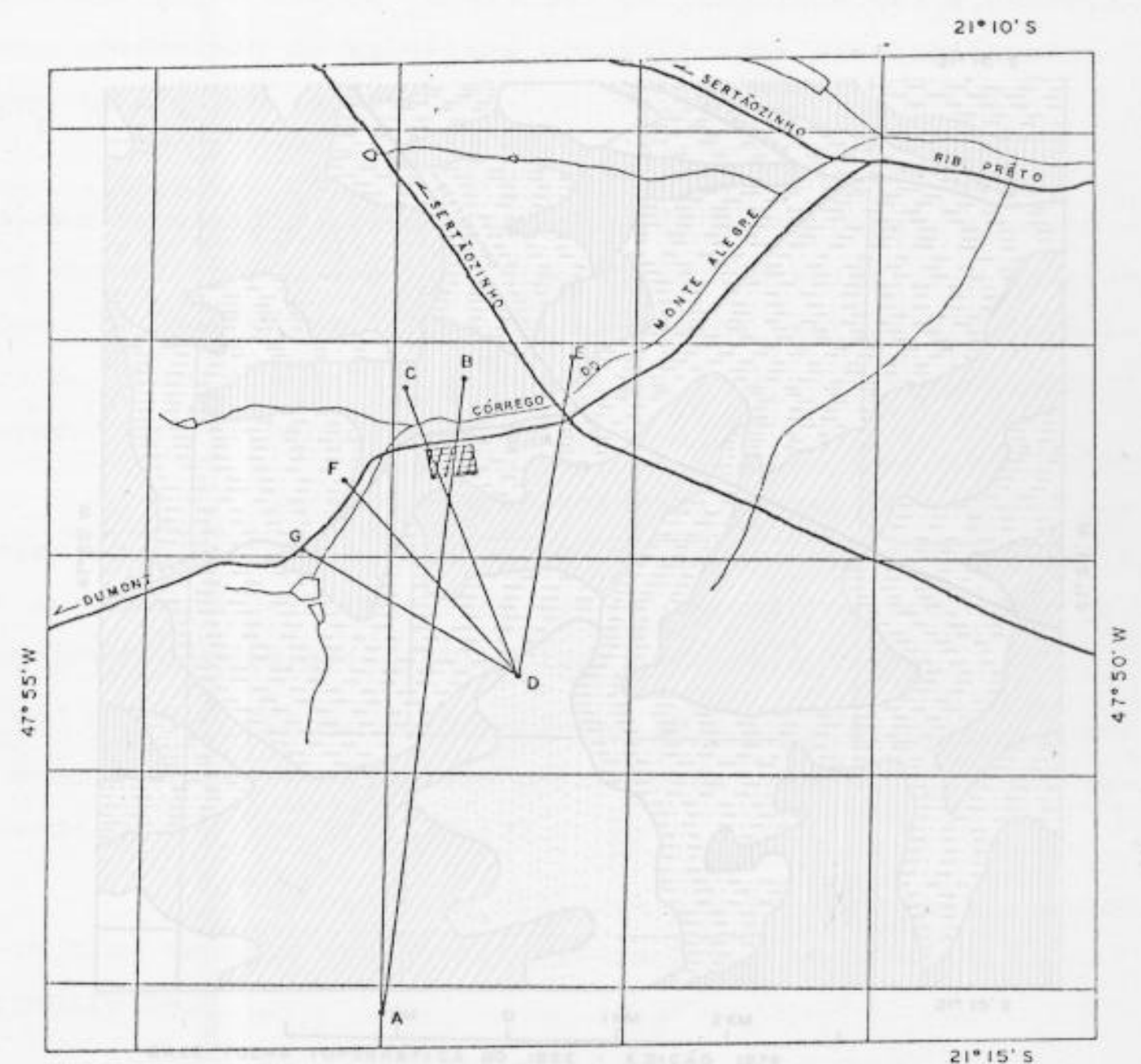

\section{LEGENOA}
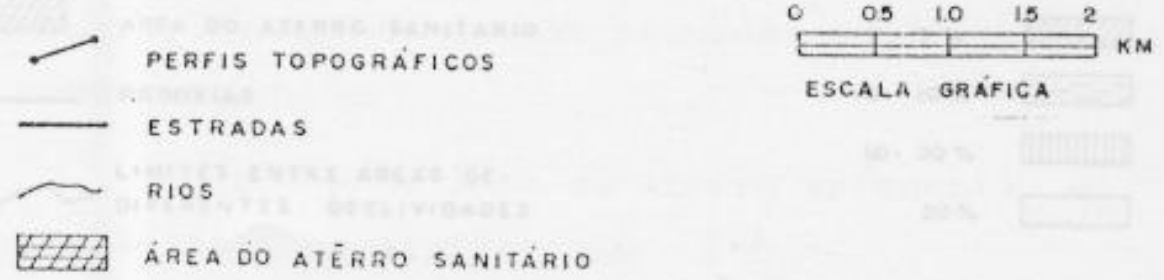

ESCALA GRAFICA

Incinerador de Ribeirão Preto delimitados entre os paralelos $21^{\circ} 10^{\prime}$ -

$21^{\circ} 15^{\prime}$ 'S e $47^{\circ} 50^{\prime}-47^{\circ} 55^{\prime} \mathrm{W}$, obtidos a partir do mapa do IBGE - folha $23-$

V-C-I-1 de 1979, escala 1:50000 (Alvarenga et al., 1986). 

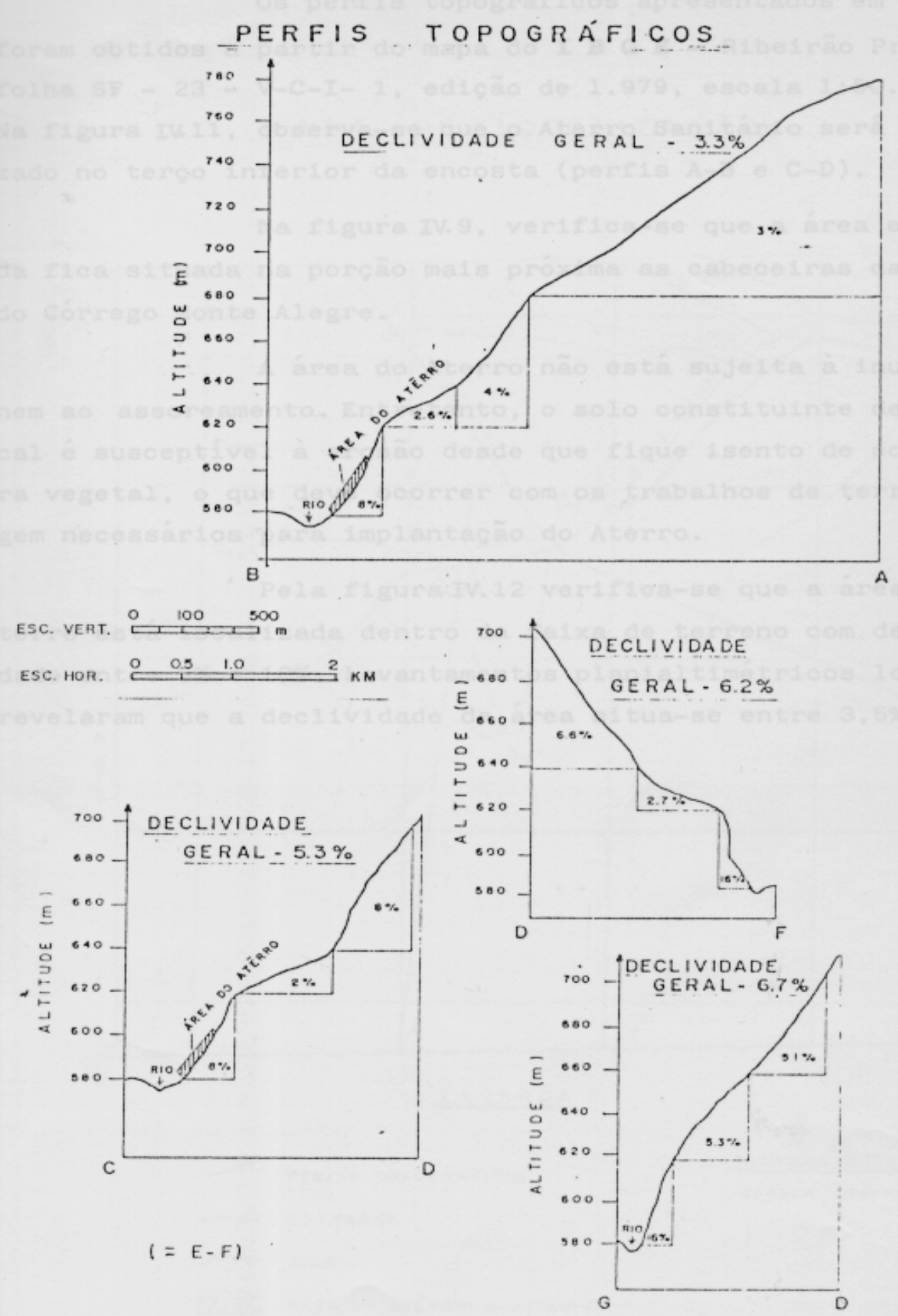

Fig. 24 - Declividade da área do Aterro Sanitário e Incinerador de Resíduos Sólidos de Ribeirão Preto, a partir dos perfis topográficos da figura anterior (Alvarenga et al., 1986) 
Outro fator que pode estar associado a esses resultados é o fato do Incinerador estar localizado do lado Norte no Aterro Sanitário, lembrando que, apesar desse equipamento ser considerado de pequeno porte pelo fato de serem processados aproximadamente 3300 ton/ano (Morselli et al., 2002), tem funcionado, durante quase 10 anos, com alguns problemas estruturais. Tais problemas têm causado, durante muito tempo, a emissão de fumaça preta (ANEXO B), indicativa de combustão incompleta ou de funcionamento deficiente dos filtros, o que pode ter favorecido o transporte de metais pesados para o meio ambiente, além de outros contaminantes químicos, dentre os quais podemos citar os furanos, as dioxinas e os hidrocarbonetos policíclicos aromáticos (Lisk, 1988; Stern et al, 1989; Ellison, s.d. apud Haight, 1991, Shima \& Beccari, 1996; Hoffman et al., 1997).

As emissões procedentes do incinerador podem ter sido a principal fonte de metais no local considerando que, aproximadamente $80 \%$ dos RSS são compostos por materiais, tais como: papel, plásticos, vidro e metais procedentes de seringas, capas de vacutainer, sacos plásticos, envólucros de remédios, garrafas de vidro, luvas e uma série de materiais cirúrgicos e de uso geral no tratamento de pacientes (Weir, 2002). Metais tóxicos, como $\mathrm{Pb}, \mathrm{Cd}, \mathrm{Mn}, \mathrm{Cr}$ e $\mathrm{Cu}$ são encontrados nesses materiais e, conseqüentemente, podem ser vaporizados na fumaça durante o processo de incineração, atingindo o meio ambiente circundante (Schuhmacher et al., 1997; Meneses et al., 1999; Garcia \& Dorronsoro, 2002; Llobet et al., 2002; Morselli et al., 2002).

Pode-se considerar a direção dos ventos como um terceiro fator que poderia ter favorecido a acumulação dos metais no sentido Norte, acarretando nessa direção os metais potencialmente contidos na fumaça emitida pelo incinerador, posto que os 
ventos predominantes naquela região sopram no sentido SE-NO, a uma velocidade média anual de $1,7 \mathrm{~m} / \mathrm{s}$, segundo consta no documento EIA-RIMA elaborado para o Aterro Sanitário e Incinerador de Resíduos Municipais de Ribeirão Preto (Alvarenga et al., 1986).

\subsection{Variabilidade nos níveis de metais em vegetais}

As análises dos vegetais mostraram grande variabilidade nos resultados obtidos para as raizes e folhas nos diferentes pontos de coleta.

Nas Fig 25 e 26, é apresentada a distribuição conjunta dos metais nas amostras de raiz e folha, em função de suas correspondentes concentrações em solo, evidenciando que altos níveis de metais no solo não significaram necessariamente um aumento das concentrações de metais nas amostras vegetais em todos os casos. Isso nos remete à compreensão de que a capacidade de absorção de metais nos vegetais difere segundo a espécie, corroborando os achados de Brown et al. (1994) e Steinbörn \& Breen (1999). Porém, quando analisada a distribuição dos metais nos vegetais, verificou-se, na maioria dos casos, que um aumento do nível de metais nas raízes estava associado com maiores concentrações nas folhas, vindo ao encontro com o exposto por Toppi \& Gabrielli (1999) e Dixit et al. (2001).

Unicamente verificaram-se quatro casos nos quais o nível de metal na folha foi mais elevado do que na respectiva raiz, como pode ser observado nos gráficos correspondentes a $\mathrm{Pb}$ e $\mathrm{Zn}$. Diante desse achado, considera-se a possibilidade de estar ocorrendo uma absorção dos metais não restrita à via radicular e também à aérea, para as espécies coletadas nesses locais, em concordância com Steinborn \& Breen (1999). 
Uma outra questão diz respeito ao $\mathrm{pH}$ do solo, reportado para esta área como ácido ( $\mathrm{pH}=5)$, segundo Alvarenga et al. (1986), o que pode ser um fator que esteja contribuindo na absorção de metais através das raízes, considerando que estes elementos estão mais disponíveis para as plantas em condições ácidas do que alcalinas (Hesse, 1971).

A caraterística argilosa do solo (Alvarenga et al., 1986), pode fazer com que a mobilidade dos metais seja baixa, ficando acumulados nos primeiros centímetros do solo, sendo lixiviados aos horizontes subsuperficiais unicamente em pequenas quantidades (Garcia \& Dorronsoro, 2002). Essa pode ser a razão pela qual, os metais estão sendo absorvidos pelas raízes dos vegetais existentes na área do Aterro Sanítario e Incinerador de Resíduos Sólidos de Ribeirão Preto. 


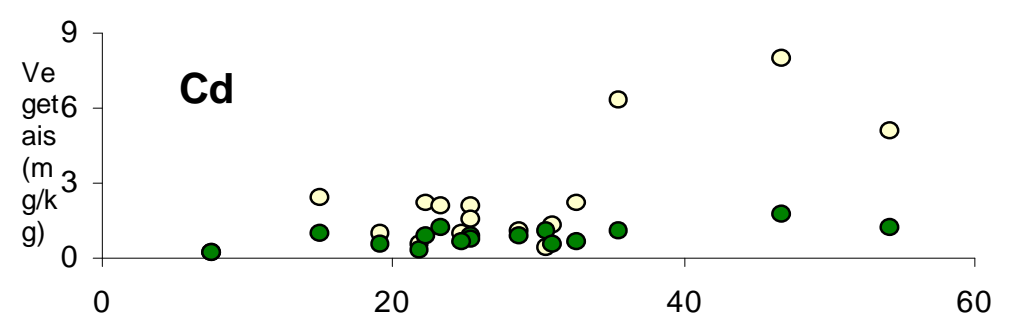

Solo $(\mathrm{mg} / \mathrm{kg})$

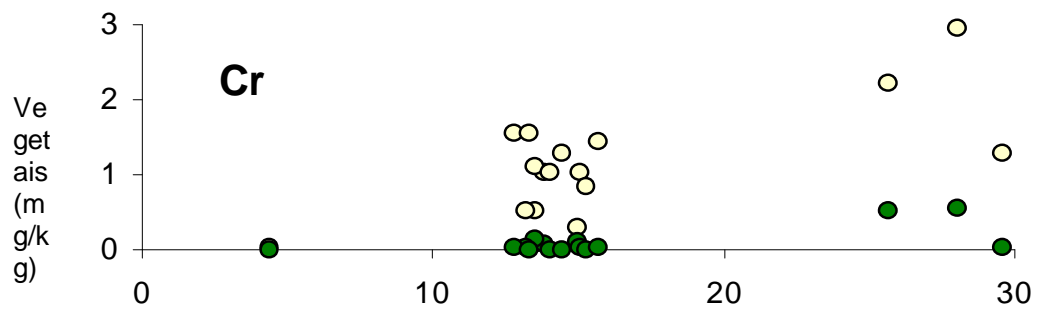

Solo $(\mathrm{mg} / \mathrm{kg})$

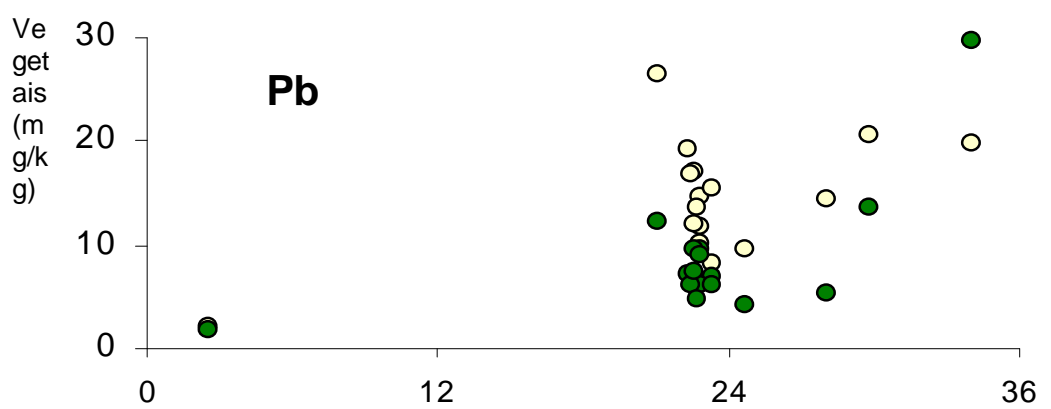

Solo $(\mathrm{mg} / \mathrm{kg})$

Fig. 25 - Correlação dos níveis de $\mathrm{Cd}$, $\mathrm{Cr}$ e $\mathrm{Pb}$ em amostras de raiz e folha e suas correspondentes amostras de solo (Fonte: Tab 3, Tab. 8 e Tab.13) 


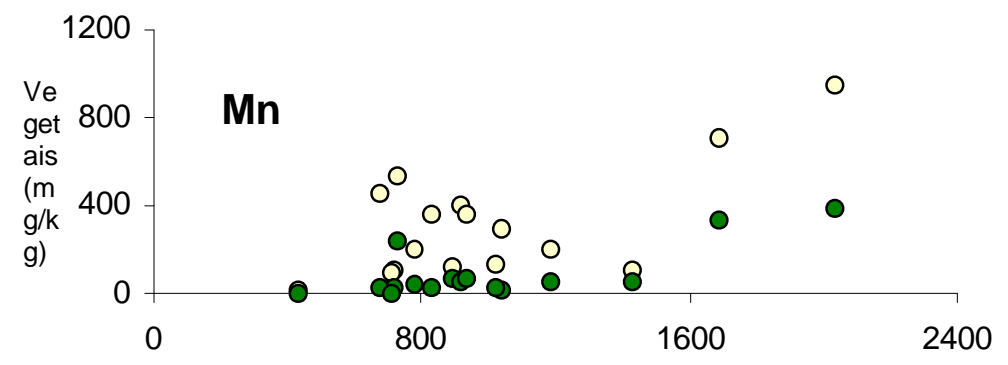

Solo $(\mathrm{mg} / \mathrm{kg})$

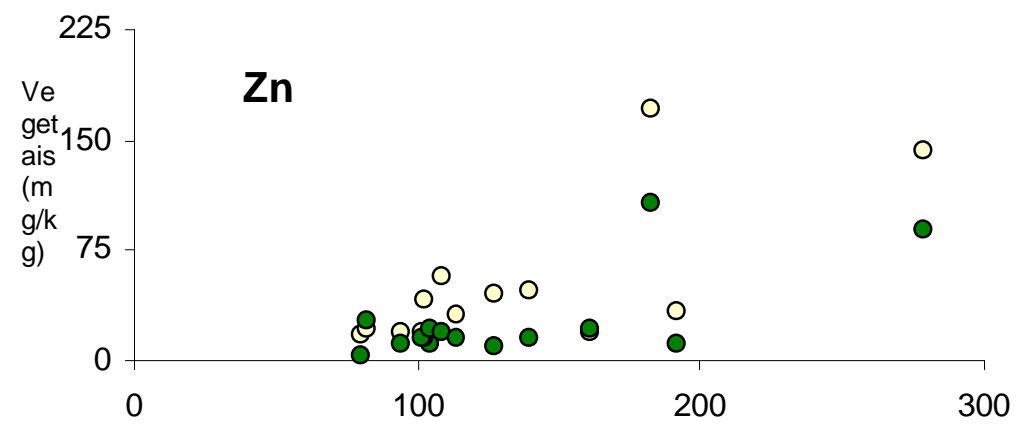

Solo $(\mathrm{mg} / \mathrm{kg})$

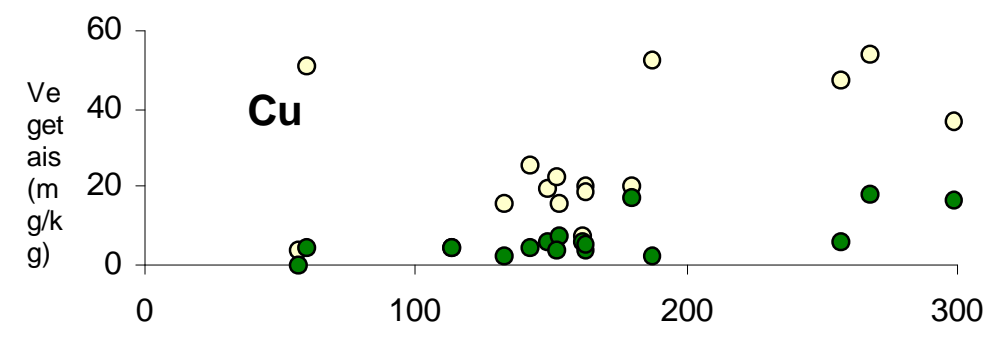

Solo $(\mathrm{mg} / \mathrm{kg})$

Fig. 26 - Correlação dos níveis de Mn, Zn e Cu em amostras de raiz e folha e suas correspondentes amostras de solo (Fonte: Tab 18, Tab.23 e Tab.28) 


\subsection{Metais pesados no liquido percolado}

$\mathrm{Na}$ Tab. 33 são apresentadas as concentrações de metais detectadas nas amostras de chorume coletadas no local de estudo (Fig.10, p. 41).

Foram encontrados níveis de Cd que variaram de 0,480 mg/L a 0,946 mg/L, dos quais as maiores concentrações foram detectadas nos pontos de afloramento superficial no ponto Norte/0 e Oeste/0 do Aterro, evidenciando uma realidade que ultrapassa os valores estabelecidos de Cd para lançamento de efluentes líquidos em cursos d'água, segundo o Decreto 8468/76 que estabelece o limite de 0,2 mg/L como valor máximo deste metal.

Um outro metal que merece destaque é o $\mathrm{Pb}$, cujos valores variaram entre 0,788 e $0,849 \mathrm{mg} / \mathrm{L}$, exceto para o ponto de afloramento superficial denominado Oeste/0, que apresentou o valor de 0,285 mg/L. Segundo o Decreto 8468/86 o nível máximo de $\mathrm{Pb}$ que pode estar contido nos efluentes líquidos é de $0,5 \mathrm{mg} / \mathrm{L}$, o que aponta para a necessidade de se avaliar a possibilidade de estarem sendo depositados no aterro materiais como baterias, pigmentos e outros produtos que apresentam esse metal na sua composição.

Ao avaliar as concentrações de Mn, pode-se observar que as concentrações mais baixas foram detectadas no chorume proveniente dos tanques de captação, destacando-se o valor detectado no ponto de afloramento superficial Oeste/0 com 6,427 mg/L; de acordo com o Decreto 8468/76, o valor máximo permitido de $\mathrm{Mn}$ para efluentes líquidos é de 1,00 mg/L.

Considerando-se que, atualmente, um dos principais usos do manganês é a fabricação de ligas metálicas e células secas, esse valor pode representar a presença 
desses materiais, geralemente oriundos de processos industriais, dentre os resíduos que estão sendo encaminhados ao Aterro.

Os valores encontrados de $\mathrm{Cu}$ variaram entre 1,8 e $4,0 \mathrm{mg} / \mathrm{L}$. Segundo o Decreto 8468/76 o nível máximo de Cu que pode estar contido nos efluentes líquidos é de $0,5 \mathrm{mg} / \mathrm{L}$, o que assinala que o $\mathrm{Cu}$ representa um fator de contaminação para o chorume gerado no local do estudo e um possível fator de risco de contaminação de corpos d'água naquela área.

O nível de $\mathrm{Cr}$ no chorume, por sua vez, não parece representar potencial risco, pelo fato de ser encontrado em nível abaixo de $0,096 \mathrm{mg} / \mathrm{L}$, valor este inferior à concentração máxima de $\mathrm{Cr}$ permitida para o lançamento de qualquer efluente líquido em cursos d'água, também considerado pelo Decreto 8468/76 como 5,0 $\mathrm{mg} / \mathrm{L}$.

Os valores de $\mathrm{Zn}$ encontrados variaram entre 0,614 e 2,307 mg/L. Do mesmo modo, o Decreto 8468/76 considera como nível máximo permitido de Zn em efluentes líquidos 5,0 mg/L, o que assinala que este metal não representa um fator de contaminação para o chorume gerado no local do estudo.

O mercúrio foi detectado nos quatro pontos de afloramento superficial de chorume, abaixo de 0,006 mg/L. Considerando que, segundo o Decreto 8468/76, o nível máximo de $\mathrm{Hg}$ que pode estar contido nos efluentes líquidos é de $0,01 \mathrm{mg} / \mathrm{L}$, os níveis detectados nesta investigação não representam um risco para a saúde. Porém, este metal poderia ser monitorado visando-se à minimização de risco de contaminação futura de outras fontes de água.

Estes resultados, referentes ao chorume, chamam a atenção quando comparados aos valores encontrados por Sisinno \& Moreira (1996), em estudo 
realizado em aterro controlado no Morro do Céu, em Niterói-RJ, no qual foram reportados níveis de $\mathrm{Cd}$ inferiores a $0,005 \mathrm{mg} / \mathrm{L}$, de $\mathrm{Cr}$ até $0,19 \mathrm{mg} / \mathrm{L}$, de $\mathrm{Mn}$ até 0,35 mg/L, de $\mathrm{Pb}$ até $0,19 \mathrm{mg} / \mathrm{L}$, de $\mathrm{Zn}$ até $0,68 \mathrm{mg} / \mathrm{L}$ e de $\mathrm{Cu}$ até $0,36 \mathrm{mg} / \mathrm{L}$, valores estes inferiores aos obtidos nesta investigação.

A materia orgânica, importante componente dos resíduos sólidos municipais, e, portanto, também do chorume formado a partir deles, é um fator que pode favorecer a fixação de metais no liquido percolado. A matéria orgânica reage formando complexos com os metais, que podem migrar para o solo. A toxicidade dos metais se potenciabiliza, dado a forte tendência de formar complexos organometálicos, que facilitam sua solubilidade, disponibilidade e dispersão. A estabilidade destes complexos frente a processos de degradação dos organismos é uma causa importante na permanência de metais no chorume. O cobre, manganês e zinco são metais que se caracterizam por apresentar complexos fortemente estáveis (Gracia \& Dorronsoro, 2002). 


\subsection{Metais pesados em água subterrânea}

A distribuição de água potável é um dos fatores mais importantes para alcançar a diminuição dos índices de mortalidade e morbidade nos países em desenvolvimento. Tradicionalmente, a qualidade microbiológica da água tem sido o aspecto que tem gerado maior preocupação em saúde pública, porém o avanço do conhecimento sobre o perigo da exposição a agentes químicos vem chamando a atenção da população e das autoridades nos últimos anos (Van-Leeuween, 2000). Dentre os diferentes contaminantes químicos, o estudo dos metais pesados vem sendo considerado prioritário nos programas de promoção da saúde, no nível mundial.

Para nossa região, é particularmente importante o monitoramento de metais em água subterrânea por representar a principal fonte de abastecimento de água. Paralelamente, a região situa-se na área do Aqüífero Guarani que é considerado um dos reservatórios de água natural mais importantes do mundo na atualidade (Alvez, 1995; Viarti, 1999).

Segundo diagnóstico efetuado pela CETESB em 1997, o uso das águas subterrâneas para o abastecimento público no Estado de São Paulo vem crescendo gradativamente. Atualmente, 71,6\% dos municípios de SP são total ou parcialmente abastecidos por águas subterrâneas, dado este que reforça a necessidade de proteção e monitoramento permanente da qualidade dessas águas (CETESB,2001).

Na Tab. 34 são apresentadas as concentrações de metais pesados detectadas nas amostras de água coletadas nos três poços artesianos existentes à jusante do Aterro Sanitário de RP, localizados na pendente hidráulica descendente do fluxo das 
águas (Fig. 10, p.41). O poço à montante do Aterro Sanitário encontrava-se seco na data de coleta.

Todos os resultados obtidos para os metais analisados apresentaram-se inferiores aos valores considerados como nível de intervenção segundo a Portaria 1469/2000 do Ministério da Saúde (Anexo I).

Considera-se importante destacar, que apesar de terem sido detetados alguns metais em concentrações superiores às recomendadas pelas normas legais para solo e chorume, esses metais ainda não atingiram, a água subterrânea no local.

Segundo Schalch \& Rezende (1991) e Jardim et al. (1995), em outras condições de disposição de resíduos, como "lixão a céu aberto" ou "aterro controlado", a elevada concentração de metais do chorume poderiam causar grandes impactos nos corpos de água circunvizinhos. Nesses sistemas de disposição não controlados, ainda muito utilizados em outros municípios do Brasil, os metais pesados podem ser percolados por meio do chorume, o qual se mistura com a água de chuva e outros líquidos, originalmente existentes no lixo, infiltrando-se no solo e subseqüentemente, contaminando a água subterrânea quando alcança o lençol freático. A contaminação dessas águas tem consequiências que perduram por tempo indefinido e são de difícil controle (Magossi \& Bonacella, 1991; Serra et al., 1998). 


\subsection{Importância dos valores de referência}

Uma das principais dificuldades para se identificar corretamente áreas com problemas de contaminação ambiental é a inexistência de valores de referência. Para as substâncias de interesse ambiental, tais como os metais pesados, os valores de referência devem ser estabelecidos em função das suas concentrações naturais, levando em consideração as variações regionais.

Para definir os limiares de toxicidade dos contaminantes químicos, em geral, como primeiro passo devem ser calculados os valores normais que apresentam as matrizes não contaminadas (solo, água, vegetação, alimentos). A partir dessa base podem-se estabelecer os níveis mínimos que representam contaminação e os níveis de toxicidade definidos, levando em consideração os possíveis efeitos em vegetais, animais, e principalmente, os potenciais agravos para a saúde humana.

Para o reconhecimento da contaminação são utilizados "níveis de referência" que conduzem a sistemas de alerta, vigilância e controle. Acima desses níveis encontram-se os níveis de intervenção que obligam a tomada de medidas corretoras (Garcia \& Dorronso, 2002).

Considerando especificamente os metais pesados, a maioria das normas são referidas à quantidade total do elemento tóxico, dada a dificuldade de extração de metais, supondo que, existe um equilíbrio entre as fases solúvel e a concentração total. Calcula-se que 10\% do total encontra-se em fase solúvel (Lindsay, 1979 apud Garcia \& Dorronsoro, 2002). Existe o consenso de que a concentração na fase assimilável é uma medida direta do grau de perigo real, enquanto que a concentração total é válida para avaliar o risco potencial ou futuro, representando uma maneira indireta de estimar a toxicidade atual do solo (Garcia \& Dorronsoro, 2002). 
Nos países desenvolvidos, nos quais há uma larga experiência de controle e monitoramento da qualidade do solo e das águas subterrâneas, é de praxe a utilização de valores orientadores como parâmetros de avaliação de indicadores ambientais. No Brasil, até 2001, não havia um padrão em relação a parâmetros que determinam limites na concentração de metais, tampouco substâncias indicativas de contaminação do solo, havendo somente diferentes orientações técnico-legais a esse respeito.

Em 2001, no estado de São Paulo, a CETESB finalizou um trabalho de organização de valores orientadores para avaliação da contaminação de solo, visando a adoção de ações de prevenção da poluição e o controle de áreas contaminadas (CETESB, 2001), com base em análises químicas de diferentes tipos de solos no estado, fato que facilitou muito a compreensão dos achados nesta investigação. Considerando o exaustivo trabalho que deve ser desenvolvido para o estabelecimento de valores orientadores para a avaliação da contaminação do solo, consideramos que o relatório elaborado pela CETESB traz uma valiosa contribuição e avanço nessa área, pelo fato de conter valores baseados no conceito de limite de exposição para a saúde humana, sem exceder o Risco Máximo Tolerável (RMT) e adaptados à realidade nacional.

Com respeito à análise de metais pesados em amostras vegetais, foi evidenciada uma carência mundial de níveis de referência que possam ser utilizados como valores orientadores para avaliação de contaminação de metais em amostras vegetais. Como alternativa, foram considerados os resultados existentes na literatura, ficando evidenciado que esta temática representa uma área que precisa ser mais explorada, dada à variabilidade de absorção de metais entre diferentes espécies 
vegetais, bem como diferentes condições regionais que podem determinar a absorção de metais pelas plantas. Os vegetais constituem-se em matrizes ambientais muito importantes, pelo fato de serem, em muitos casos, integrantes importantes de cadeias tróficas, possibilitando a passagem de metais pesados até outros seres vivos, incluindo-se o ser humano.

Considera-se o chorume como um efluente líquido que deve ser previamente monitorado para o lançamento em corpos d'água. O estado de São Paulo possui como instrumento de controle deste tipo de rejeito o Decreto 8468/76 que dispõe sobre a Prevenção e o Controle da poluição do Meio Ambiente. Neste decreto apresentam-se detalhadamente os padrões de qualidade para o lançamento de efluentes em corpos d'água. Considerando que o chorume gerado no Aterro Sanitário apresentou níveis de $\mathrm{Cd}, \mathrm{Mn}, \mathrm{Pb}$ e $\mathrm{Cu}$ acima dos valores estipulados nesse Decreto, não seria recomendável o seu lançamento em sistema público de tratamento de esgoto, devendo ser buscado, portanto, um outro método de tratamento.

A potabilidade da água é um aspecto de relevante importância para a saúde pública, no mundo inteiro, pelo qual, existem muitas normas de qualidade da água que podem ser utilizadas como valores de referência. No Brasil, os critérios de qualidade da água estão em fase de transição normativa, passando da Portaria 36/90 para a Portaria 1469/2000, a qual entrará em vigência a partir de janeiro de 2003. Ambas as portarias apresentam semelhança nos criterios adotados; as únicas diferenças apresentadas nos parâmetros estabelecidos para os metais avaliados no presente estudo foram o nível máximo de $\mathrm{Pb}$ que foi reduzido de 0,05 para 0,01 $\mathrm{mg} / \mathrm{L}$, enquanto o nível de Cobre permitido foi aumentado de 1 para $2 \mathrm{mg} / \mathrm{L}$. 
Assim, considera-se que os valores orientadores para avaliação da qualidade do solo e águas subterrâneas, elaborados recentemente pela Companhia de Tecnologia de Saneamento Ambiental do Estado de SP - CETESB, trazem uma valiosa contribuição e avanço nessa área, pelo cuidado em se obter valores baseados no conceito de limite de exposição para a saúde humana, dando sustentação a programas que visen prevenir os problemas associados à exposição ambiental aos metais ao longo do tempo. 


\section{CONCLUSÕES}

Nesta investigação, através do caminho percorrido, foi possível alcançar os objetivos traçados inicialmente, sendo caracterizados os níveis de cádmio $(\mathrm{Cd})$, cromo $(\mathrm{Cr})$, chumbo $(\mathrm{Pb})$, manganês $(\mathrm{Mn})$, zinco $(\mathrm{Zn})$, cobre $(\mathrm{Cu})$ e mercúrio $(\mathrm{Hg})$, em diversas matrizes anbientais, tais como solo, vegetais, chorume e água, na área do entorno do Aterro Sanitário e Incinerador de Resíduos Sólidos de Ribeirão Preto.

A informação gerada traz novos conhecimentos sobre a situação ambiental da área estudada, no que se refere à presença de metais, trazendo subsíduos para ações político-administrativas municipais, num momento significativo, haja vista o término da primeira etapa de operação do Aterro Sanitário e o encerramento das atividades do Incinerador.

Especificamente, pode-se concluir que:

- As concentrações de metais nas amostras de solo e vegetais coletadas nos quatro sentidos de direção na área do Aterro Sanitário, em termos gerais, apresentaram-se significativamente superiores às encontradas nas amostras coletadas na mata Santa Teresa, consideradas amostras-controle. Os dados indicaram uma tendência de maiores concentrações dos metais analisados no sentido Norte.

- Destacam-se, nesta investigação, os valores detectados para $\mathrm{Cd}$ e $\mathrm{Cu}$ nas amostras de solo coletadas, que superaram os níveis de intervenção emitidos pela 
CETESB (2001), para o Estado de São Paulo. Também cabe mencionar, os níveis de Mn que apresentaram-se superiores aos valores referidos na literatura científica.

- O chorume foi outra matriz que evidenciou níveis de $\mathrm{Cd}, \mathrm{Pb}, \mathrm{Mn}$ e $\mathrm{Cu}$ que superaram os valores máximos estabelecidos legalmente, merecendo por tanto, uma avaliação mais acurada com a finalidade de se evitar a contaminação de corpos d'água no futuro, principalmente visando-se impedir que esses pontos de água se convertam em fator de risco para a saúde humana.

- Até o presente momento, a água subterrânea da área estudada, de acordo com o processo metodológico desta investigação, não representa risco para a saúde humana, no que se refere à presença de metais pois, segundo os achados, não foram encontrados teores de metais nessa matriz que superassem os níveis de intervenção definidos para o país, embora alguns deles estivessem próximos dos limites, indicando a necessidade de dar continuidade ao monitoramento de agentes químicos, de forma permanente, nesses corpos d'água.

- Considera-se, de vital importância a educação ambiental para o fortalecimento da participação da comunidade nos programas já existentes de coleta seletiva, tanto para materiais recicláveis quanto para resíduos tóxicos tais como: pilhas, baterias e similares, devido ao fato de que o encaminhamento de resíduos sólidos contendo metais para o Aterro Sanitário, por parte da comunidade, pode ser um dos fatores que esteja contribuindo para que alguns dos metais pesquisados se apresentem em concentrações não esperadas no solo.

O presente trabalho gera outros temas para o desenvolvimento de investigações visando um aprofundamento para a geração de novos conhecimentos nessa linha de pesquisa, dentre os quais podemos citar: 
1. Monitoramento de metais pesados considerando uma área de maior abrangência, baseado nas recomendações da OMS (2001), através do relatório "Métodos de avaliação de riscos para a saúde derivados da exposição a substâncias perigosas libeardas por aterros sanitários”, documento no qual é assinalada a necessidade de se realizar monitoramentos permanentes numa area de influência de até $2 \mathrm{~km}$ de distância de aterros sanitários. Considera-se que um estudo com essa abrangência permitiria uma estimativa mais apurada do risco que os metais pesados representam para a saúde nas comunidades estabelecidas nessa área, facilitando a compreensão das vias de propagação e transporte, bem como a caracterização de possíveis grupos vulneráveis.

2. Realização de um estudo experimental, utilizando espécies vegetais brasileiras fito-remediadoras, na área do Aterro Sanitário e Incinerador de resíduos sólidos de Ribeirão Preto, que ofereça a posibilidade de obter uma restauração biológica do solo.

3. Monitoramento de outros contaminantes químicos presentes no solo e vegetais, dentre os quais destacam-se: dioxinas e furanos, considerados poluentes altamente tóxicos, que podem causar agravos a saúde em áreas circunvizinhas a Incineradores e/ou Aterros Sanitários.

4. Avaliação dos níveis de metais pesados no Córrego Monte Alegre, desde sua nascente até a confluência com o córrego Ribeirão Preto, avaliando se as características microbiológicas e físico-químicas de suas águas estão sendo afetadas pelo lançamento de efluentes de diversas atividades locais, talém da disposição de resíduos sólidos, tais como a atividade açucareira 
e a existência de um hospital de grande porte em suas margens, como o HCFMRP/USP, que não possui sistema de tratamento de seus efluentes.

5. Estudo da caracterização dos RSM e dos RSS gerados no município, avaliando as fontes de metais pesados.

Muito há, ainda, que se investir em recursos humanos e materiais para o aprimoramento de metodologias e investigações específicas para a avaliação e monitoramento ambiental, no que se refere a poluentes químicos. Com esta pesquisa foi possível a geração de importantes conhecimentos relativos à questão do gerenciamento de resíduos sólidos, não apeans no âmbito municipal, mas também, para o próprio país, pela possibilidade de se conhecer parte de uma realidade ainda pouco explorada em nosso meio. Espera-se contribuir, também, para a tomada de decisões político-administrativas no gerenciamento de resíduos sólidos no Brasil. 


\section{CONSIDERAÇÃOES FINAIS}

Dentre os problemas ambientais que entraram no cenário público internacional, a partir da década de 70 , um dos que mais vem sendo destacado é a crescente poluição química e seus impactos sobre a qualidade da água, ar, solo e alimentos em várias regiões do planeta e o reconhecimento científico dos chamados riscos ecológicos globais a ela associados, que formam parte determinante e condicionante do processo saúde-doença.

No âmbito do gerenciamento dos resíduos sólidos, a Organização Mundial da Saúde (OMS, 2001), assinala a necessidade de se identificar os contaminantes potencialmente adversos, dentre os quais, os metais pesados que foram definidos como contaminantes prioritários pela sua toxicidade, permanência ambiental, mobilidade e grau de bioacumulação. Ações integrais, além de caraterizar estes contaminantes no meio ambiente, devem servir de instrumentos, através dos quais, seja avaliado o risco que estes contaminantes representam para a saúde pública.

A questão dos resíduos sólidos gerados pela sociedade atual encontra-se num limiar que tem obrigado, não apenas as autoridades sanitárias e ambientais, mas também a população, a buscar soluções alternativas para um gerenciamento que 
atenda às recomendações técnicas e legais, em função dos riscos à saúde pública e ao meio ambiente.

Considerando-se que a concepção atual dos principais determinantes do processo saúde-doença dá ênfase aos fatores ligados ao ambiente físico e social, não privilegiando os de ordem biológica e, ainda, que o modelo de assistência à saúde é regido por princípios que buscam, dentre outros, um equilíbrio entre os diferentes fatores e ações que interferem nesse processo, há que se buscar, também, uma melhor organização do sistema de informação para instrumentalizar as políticas ligadas ao meio ambiente e à saúde.

Nesse sentido, as informações geradas com esta investigação têm um relevante significado, não apenas no âmbito das informações alcançadas, mas também, no direcinamento para a necessidade de se articular ações interdisciplinares e intersetoriais para o equacionamento de problemas ambientais que, por sua vez, guardam estreita relação com a saúde humana e conseqüentemente com a qualidade de vida.

A intersetorialidade é considerada um conceito-chave, significando a integração entre vários setores do governo envolvidos, direta ou indiretamente, em torno de problemas de saúde e ambiente.

Assim, considera-se que o presente trabalho através do qual interagiram diferentes setores guvernamentais, é resultado do processo de interdisciplinaridade que o setor saúde vem vivenciando ao longo dos últimos anos, mediante a otimização dos mecanismos de articulação e integração setorial, permitindo a geração de novos conhecimentos que possam instrumentalizar as ações da vigilância 
das políticas públicas, em particular aquelas relacionadas ao meio ambiente, dentro do contexto da saúde coletiva. 


\section{REFERÊNCIAS BIBLIOGRÁFICAS}

ABNT. ASSOCIAÇÃO BRASILEIRA DE NORMAS TÉCNICAS. NBR 10.004. Resíduos sólidos: Classificação. Rio de Janeiro, 1987.

AITA, L. Florística e fitossociologia de uma floresta mesófila semi-caducifolia, Estação ecológica de Ribeirão Preto-Mata Santa Teresa, SP. Etapa II. Ribeirão Preto, 1997. 65p. Monografia. Faculdade de Filosofia Ciências e Letras de Ribeirão Preto, Universidade de São Paulo.

ALLERMANN, L.; POULSEN, O. M. Inflammatory potential of dust from waste handling facilities measured as IL-8 secretion from lung epithelial cells in vitro. The Annals of Ocupational Hygiene. v. 44, n. 4, p. 259-269, 2000.

ALVARENGA, E.C; SOUZA, A.; GRECO, P.A.P.; ZUQUETE, L.V. Estudo de impacto ambiental e relatório de impacto ambiental do Aterro Sanitário e Incinerador (EIA-RIMA). Ribeirão Preto, São Paulo, DURSARP, 1986.

ALVEZ, Z.C. Qualidade da água. Meio ambiente por inteiro. Jornal da Secretaria Municipal do Meio Ambiente de Ribeirão Preto, v.1, n. 1, p. 7, 1995.

APHA. American Public Health Association. Standard Methods for the Examination of Water and Wastewater. 20. ed. Washington DC: APHA INC. 1015, 1998. 1085 p. 
BANKS, E.; FERRETI, L.; SCHUCARD, D. Effects of low level lead exposure on cognitive function in children: a review of behavioral, neuropsycological and biological evidence. NeuroToxicology, v. 18, n. 1, p. 237-282, 1997.

BARCElOUX, D.G. Chromium. Journal Toxicol. Clin. Toxicology, v. 37, n.2, p.173-194, 1999.

Zinc. Journal Toxicol. Clin. Toxicology, v. 37, n.2, p. 279-292, 1999.

BAXTER, J.; EYLES, J.; ELLIOT, S. "Something Happened": The relevance of the risk society for describing the siting process for a municipal landfill. Geografiska Annaler. v. 81B, n.2, p. 91-109, 1999.

BECKER, N. Cancer mortality among welders exposed to fumes containing chromium and nickel. Results of a third follow-up: 1989-1995. Journal Occupational Environmental Medicine, v.41, n.4, p.294-303, 1999

BEUTER, A.; EDWARDS, R.; GEOFFROY, A.; MERGLER, D.; HUNDNELL, K. Quantification of neuromotor function for detection of the effects of manganese. NeuroToxicology, v.20, n.2-3, p.355-366, 1999.

BLENKHARN, J.I. The disposal of clinical wastes. J. Hosp. Infect., v.30, p.514520, 1995.Supplement.

BOISCHIO, A.; HENSHEL, D. Risk assessment of mercury exposure through fish consumption by the riverside people in the Madeira Basin, Amazon, 1991. NeuroToxicology, v.17, n.1, p.169-176, 1996.

BRASIL. Portaria n. 36/GM do Ministério da Saúde. Dispõe os critérios de potabilidade da água. Diário Oficial da União, Brasília, 23 de janeiro de 1990.

BRASIL. Lei $\mathrm{N}^{\circ}$ 8080, de 19 de setembro de 1990. Dispõe sobre as condições para a promoção, proteção e recuperação da saúde, a organização e funcionamento dos serviços correspondentes e dá outras providências. Diário Oficial da União. Disponível em: http://www.saude.gov.br/doc/lei8080.htm. Acesso em: 24/04/2000. 
BRASIL. Resolução n.6, de 19 de setembro de 1991. Desobriga a incineração como única alternativa para o tratamento de resíduos sólidos oriundos de serviços de saúde, Diário Oficial da União, Brasília, 30 de outubro de 1991.

BRASIL. Resolução n.5, de 5 de agosto de 1993. Define normas mínimas para o tratamento de resíduos sólidos oriundos de serviços de saúde, portos e aeroportos bem como a necessidade de estender tais exigências aos terminais rodoviários e ferroviários. Diário Oficial da União, Brasília, 31 agosto de 1993.

BRASIL. Portaria n. 1469, do Ministério da Saúde. Estabelece os procedimentos e responsabilidades relativos ao controle e vigilância da qualidade da água para consumo humano e seu padrão de potabilidade. Diário Oficial da União, Brasília, 02 de janeiro de 2001.

BRASIL. Resolução n.283, de 12 de julho de 2001. Dispõe sobre o tratamento e destinação final dos RSS. Diário Oficial da União, Brasília, 01 de outubro de 2001.

BROWN, S.L.; CHANEY, R.L.; ANGLE, J.S.; BAKER, A.J.M. Phitoremediation potential of Thalspi caerulescens and bladder campion for zinc and cadmium contaminated soil. J. Environ. Qual, v. 23, p. 1151-1157, 1994

BRUNNER, C.; BROWN, C. Hospital waste disposal by incineration. JAPCA, v.38, n.10, p. 1297-1309, 1988.

BUCHEIM, K.; STOLTENBURG-DIDINGER, G.; LILIENTHAL, H.; WINNIKE, G. Miopathy: A possible effect of chronic low level lead exposure. NeuroToxicology, v.19, n.4-5, p. 539-546, 1998.

CARVALHO V.S.; TELLA M.A. Sociedade de consumo e sustentabilidade planetária. Debates Sócio-Ambientais. Centro de Estudos da Cultura Contemporânea, SP-Brasil. Ano 11 - n. 5, p 2-4, 1997.

CAI, S.; YUE, L.; SHANG, Q.; NORDBERG, G. Cadmium exposure among residents in an area contaminated by irrigation water in China. Bulletin World Health Organization, v.73, n.3, p. 359-367,1995. 
CATALDO D.A.; GARLAND, T.R.; WILDUNG, R.E. Cadmium uptake kinetics in intact soybean plants. Plant. Physiol., v. 73, 0. 844-848, 1983.

CAUSON, R. Validation of chromatographic methods in biomedical analysis. Viewpoint and discussion. Journal of Chromatography B, v. 689, p. 175-180, 1997.

CDC. Division of healthcare Quality Promotion. Issues in Healthcare Settings. Infectious Waste. Disponível em: http://www.cdc.gov/rcidod/hip/Blood/waste.htm. Acesso em: 04/07/2002.

CEHN. Children's Environmental Health Network. Training Manual on Pediatric Environmental Health: Putting it into Practice. National Multidisciplinary Project. 1999. Disponível em: http://www.cehn.org/trainningmanual/manualform.html. Acesso em: 28/10/2000.

CETESB. Companhia de Tecnologia de Saneamento Ambiental. Resíduos sólidos. São Paulo. CETESB,1990.

CETESB. Companhia de Tecnologia de Saneamento Ambiental. Relatório de estabelecimento de valores orientadores para solos e águas subterrâneas. São Paulo. CETESB, 2001.

CERQUEIRA L. ALVES F. Incineração e Co-processamento: Alternativas para a gestão de resíduos perigosos. Saneamento Ambiental, n.59, p.18-23, 1999.

CHARNOCK, D.; WELLS, C. The challenge of waste disposal. Journal of the Royal Society of Health, v.105, n.5, p. 171-178, 1985.

CHEREMISIHOFF, P.N.; SHAH, M. K. Hospital waste management. Pollut. Eng., n. 4, p. 61-66, 1990.

COLE, D. Risk assessment- some frameworks. McMaster University. Environmental Health Program. Working Papers. Series 3. Risk Assesment Workshop. Waterloo, Canada. 1995. 
CONSEMA. Secretaria do Meio Ambiente, Secretaria da Agricultura e Abastecimento, Secretaria de Economia e Planejamento. Macrozonamento das Bacias do Rio Mogi - Guaçu, Pardo e Médio Grande: Questões sócioambientais regionais. São Paulo. 1995.

CORONA, J. Intoxicação por metais pesados: O chumbo. Sociedade de Medicina Ortomolecular do Estado de Rio de Janeiro. Disponível em: www.vitamins.com.br. Acesso em: 11/11/98.

CORY-SLECHTA, D. Postnatal lead exposure and MK-801 sensitivity. NeuroToxicology, v.18, n.1, p. 209-20, 1997.

COSTA, M. Carcinogenic metals. Science Progress, vol.81, n.4, p. 329-339, 1998.

CRANMER, M.; GILBERT, S.; CRANMER J. Neurotoxicity of mercury indicators and effects of low-level exposure: Overview. Neurotoxicity, v.17, n.1, p. 9-14, 1996.

CSA. Canadian Standards Association. Risk analysis requeriments and guidelines. National Standard of Canada. Toronto. CAN/CSA- Q634-91, 19991

DAVER, V. Plasma Térmico: solução ecológica para o lixo. Rev. Ciência HojeTecnologia. SEBRAE. P. 2-3, 1997

D’ALMEIDA M.L.; VILHENA A. Lixo municipal: manual de gerenciamento integrado. 2 ed. São Paulo. IPT/CEMPRE, 2000. (Publicação IPT 2622).

DENISON, R.; SILBERGELD, E. Risk of municipal solid waste incineration an environmental perspective. Risk Analysis. v. 8, n.3, p.343-355, 1988.

DIXIT V.; PANDEY V.; SHYAN R. Differential antioxidative responses to cadmium in root and leaces of pea (Pisum sativum L. c.v. Azad). Journal of Experimental Botany. v. 52, n. 358, p. 1101-1109, 2001. 
ELLIOT, S.J.; TAYLOR, S.M.; HAMPSON, C.; DUNN, J.; EYLES, J.; WALTER, S.; STREINER, D. "It's not because you like it any better...": Residents' reappraisal of landfill site. Journal of Environmental Psycology, v.17, p. 229-41,1997.

ELLIOT, S.J. A comparative analysis of public concern over solid waste incinerators. Waste Management Research. v.16, n.4, p.351-364,1998.

EYER, C. Qualidade Ambiental. O desafio de ser competitivo protegendo o meio ambiente. 1.ed. Brasil, Pionera-ABIMAQ/SINDIMAQ. 1995.

EYLES, J.; TAYLOR, S.M.; JOHNSON, N.; BAXTER, J. Worring about waste: living close to solid waste disposal facilities in Ontario. Social Science and Medicine, v. 37, n.6, 805 - 812, 1993.

FECHTER, L. Distribution of manganese in development. NeuroToxicology, v.20, n.2-3, p.197-202, 1999.

FLEMING, G. ; PARLE,P. Heavy metals in soil, herbage and vegetables from a industrialized area west of Dublin City. Irish Journal of Agricultural Research. v.16, p. 35-48, 1977.

FLORA, S. Thershold mechanisms and site specificity in chromium (VI) carcinogenesis. Carcinogenesis, v.21, n.4, p.533-41, 2000.

FORATINI, O. P. Ecologia, Epidemiologia e Sociedade. São Paulo. Editora da Universidade de São Paulo, 1992.

FREITAS, A. L. S. Caracterização do aqüífero Botucatu na região do Lixão de São Carlos - SP. São Carlos, 1996. 98 p. Dissertação (Mestrado). Escola de Engenharia de São Carlos, Universidade de São Paulo.

FU, J.; HUANG, X.; ZHU, X. Study on peripheral blood lymphocytes chromosome abnormality of people exposed to cadmium in environment. Biomed. Environ. Sci, v.12, n.1, p.15-9, 1999. 
GARCIA I.; DORRONSORO C. Contaminación del suelo. Curso: Tecnologia de Suelos. Tema 15. Disponível em: http://edafologia.ugr.es/conta/Tema15. Acesso em: 04/01/2002.

GENTILE, R. São Paulo despeja nas ruas um terço do seu lixo. Folha de São Paulo, São Paulo, 04 out. 1998. Cad. 3, p. 1.

GERHARD, I.; WAIBEL, S.; DANIEL, V.; RUNNEBAUM, B. Impact of heavy metals on hormonal and inmunological factors in women with repeated miscarriages. Hum. Reprod. Update, v.4, n.3, p. 301-309, 1998.

GLASSER, H.; CHANG, D. An analysis of biochemical waste incineration. J. Air Waste Management Assoc, n.41, p. 1180-1188, 1991.

GOLBERG, M.S.; AL-HOMSI, N.; GOULLET, L.; RIBERDY, M. Incidence of cancer among persons living near a municipal solid waste landfill site in Montreal, Quebec. Archives of Environmental Health, v. 50, n.6, 1995.

GORELL, J.; JOHNSON, C.; RYBICKI, B.; PETERSON, E.; KORTSHA, G.; BROWN, G.; RICHARDSON R. Occupational exposure to $\mathrm{Mn}, \mathrm{Cu}, \mathrm{Pb}, \mathrm{Fe}, \mathrm{Hg}$ and $\mathrm{Zn}$ and the risk of Parkinson's disease. NeuroToxicology, v.20, n.2-3, p.239-248, 1999.

GOYER, R.A. Toxic effects of metals: mercury. In: CASARETT, D. Doull's Toxicology: The Basic Science of Poisons, 5.ed. New York, Klaassen CD, 1996, p. 709-712.

GRANDJEAN, P.; WEIHE, P.; NIELSEN, J.B. Methylmercury: Significance of intrauterine and postnatal exposures. Clinical Chemistry, v. 40, p.1395-1400, 1994.

HAIGHT, M.E. Municipal solid waste management. Making decisions in the face of uncertainly. Waterloo Press. Ontario, 1991.

HAISHIMA, Y. Alternatives technologies on infectious waste treatment, and guidelines for evaluation on safety and efficacy of the alternative technologies. Rinsho Byori. v. 112, p. 64-75, 2000. 
HASSELRIIS, F.; LICATA, A. Analysis of heavy metal emission data from municipal solid waste combustion. J Hazard Mater, v. 47, p. 77-102, 1996.

HAMILTON, E.I. Environmental variables in a holistic evaluation of land contaminated by historic mine wastes: a study of multi-element mine waste in West Devon, England, using arsenic as an element of potential concern to human health. The Science of the Total Environment, v. 249, p.171-221, 2000.

HARADA, M.; NAKANISHI, J.; KONUMA, S.; OHNO, K.; KIMURA, T.; YAMAGUCHI, H.; TSURUTA, K.; KIZAKI, T.; OOKAWARA, T., OHNO, H. The present mercury contents of scalp hair and clinical symptons in inhabitants of the Minamata area. Environmetal Research, v.77, n.2, p.160-164,1998.

HESSE, P. A texbook of soil chemical analysis. London: Murray, 1971.

HOFFMAN, B.H.; TUOMANEN, B.; PRICE, R., BEAULIEU, H.J. Biological monitoring of employees with potential exposures to inorganic lead and cadmium at municipal solid waste resource recovery, or trash- to-energy, Facilities. Applied Occupational Environmental Hygiene, v.12, n. 7, p. 471-479, 1997.

HU, H. Bone lead as a new biologic marker of lead dose: recent findings and implications for public health. Environmental Health Perspectives, v.106, n.4, p.961-967, 1998.

HUANG, C.; CHU, N.; LU, C.; WANG, J.; TSAI, J.; TZENG, J.; WOLTERS, E.; CALNE, D. Progression after chronic manganese exposure. Neurology, v. 43, p.1479-1483, 1993.

HUDNELL, H. Effects from environmental Mn exposure: A Review of the evidence from non-ocupational exposure studies. NeuroToxicology, v. 20, n.2-3, p.379-398, 1999.

IBGE. Instituto Brasileiro de Geografia e Estatística. Pesquisa Nacional de Saneamento Básico de 2000. São Paulo. Disponível em: www.ibge.gov.br. Acesso em: 03/02/2002. 
IREGREN, A. Manganese neurotoxicity in industrial exposure. Proof of effects, critical exposure level and sensitive test. Neurotoxicity, v.20, n.2-3, p.315$323,1999$.

JARDIM N.S. (Coord.). Lixo municipal: manual de gerenciamento integrado. 1. ed. Edição. São Paulo: Instituto de Pesquisas Tecnológicas: CEMPRE, 1995. (Publicação IPT 2163)

KEEN, C.; ENSUNSA, J.; WATSON, M; BALY, D.; DONOVAN, SH.; MONACO, M.; CLEGG, M. Nutritional aspects of Mn from experimental studies. NeuroToxicology, v.20, n.2-3, p.213-224, 1999.

KELlEY, C. Cadmium therapeutic agents. Curr. Pharm. Des, v.5, n.4. p. 229-240, 1999.

KOSATSKY, T.; FORAN, P. Do historic studies of fish consumers support the widely accepted LOEL for methylmercury in adults. NeuroToxicology , v.17, n.1, p.177-186, 1996.

KOSSON, D.S.; VAN-DER SLOOT, H.A.; EIGHMY, T.T. An approach for estimation of contamination release during utilization and disposal of municipal waste combustion residues. J. Hazard Mater, v.47, p.43-75, 1996.

KREISS, I. Cadmium contamination of the countryside, a case study on health effects. Toxicology Ind. Health, v.6, n.5, p.181-188, 1990.

LAGUNA, V.G. Estrutura e diversidade do remanescente de floresta estacional semidecidual do Parque Municipal Morro de São Bento, Ribeirão Preto-SP. Ribeirão Preto, 2000. 100 p. Dissertação (Mestrado) - Faculdade de Filosofia, Ciências e Letras, Universidade de São Paulo.

LAI, JC.; MINSKI, MJ.; CHAN, AW.; LEUNG, TK.; LIM, L. Manganese mineral interactions in brain. NeuroToxicology, v.20, n.2-3, p. 433-444,1999. 
LAUWERYS, R.R.; BERNARD, A.M.; ROELS H.A., BUCHET J.P. Cadmium: Exposure markers as predictors of nephrotoxic effects. Clinical Chemistry, v.40, p.1391-4,1994.

LINDENBERG, R.G. Incineração e pirólise. In: CETESB. Curso Básico para Gerenciamento de sistemas de Resíduos Sólidos. São Paulo, 1982. cap. 20, p. 119.

LISK, D.J. Environmental implications of incineration of municipal solid waste and ash disposal. Sci. Total Environment. V.74, n. 1, p. 39-66, 1988.

LLOBET, J.M.; SCHUHMACHER, M.; DOMINGO J.L. Spatial distribution and temporal variation of metals in the vicinity of a municipal solid waste incinerator after a modernization of the flue gas cleaning system of the facility. Sci. Total Environment. v. 284, p. 205-214, 2002.

MAGOSSI, L.; BONACELlA, P. Poluição das águas. 2.ed. São Paulo, Editora Moderna. 1991.

MALAVAUD, S.; MARTY, N. Infectious risk in medical offices: a reality to be fought. Press. Med, v. 21, n.26, p.1008-12, 1997.

MANN, P. Introductory Statistics. 3.ed. United States of America. Ed. John Wiley \& Sons, INC., 1998. 789 p.

MENESES, M.; LLOBET, J.M.; GRANERO, S.; SCHUMACHER, M.; DOMINGO, J.L. Monitoring metals in the vicinity of a Municipal waste incinerator: temporal variation in soils and vegetation. Sci. Total Environment. v.226, p. 157164, 1999.

MERGLER, D.; BALDWIN, M.; BELANGER, S.; LARRIBE, F.; BEUTER, A.; BOWLER, R.; PANISSET, M.; EDWARDS, R.; DE GEOFFROY, A.; SASSINE, M.P.; HUDNELL, K. Manganese neurotoxicity, a continuum of disfunction: results from a community based study. NeuroToxicology, v.20, n.2-3, p.327-42, 1999. 
MORITZ, J.M. Current Legislation Governing Clinical Waste Disposal. J. Hosp. Infect, v.30, p.521-30, 1995.

MORSELLI, L.; PASSARINI, F.; ZAMAGNI, E.; BRUSORI, B. Methodological approach for an integrated environmental monitoring system relative to heavy metals from an incineration plant. Ann Chim-Rome, v. 90, p. 723-32, 2000.

MORSELLI, L.; BARTOLI, M.; BRUSORI, B.; PASSARINI, F. Application of an integrated environmetal monitoring system to an incineration plant. Sci. Total Environment. v.289, p. 177-188, 2002.

OMS. Métodos de evaluación de riesgos para la salud generados por la exposición a sustancias peligrosas liberadas por rellenos sanitários. Oficina regional para Europa. Division Bilthoven. 2001. Disponível em: www.cepis.org.pe/bvsea/e/fulltext/metodos/metodos/pdf. Acesso em 20/12/2001.

OPS. Oficina Regional de la Organización Mundial de la salud. Guía para la calidad del agua potable. Vol. I. Pub. Científica, 481,1985.

OSHA. Occupational safety and Health Administration. General Industry Standard, Federal Register. Bloodborne pathogens. Part 1910.10130. n.56, p.64175$64182,1991$.

PADHYE, A.A.; BENNET, J.E.; McGINNIS, M.R.; SIGLE, L.; FLISS, A.; SALKIN, I.F. Bio-safety considerations in handling medically important fungi. Med. Mycol., vol. 36, Sup. 1, p. 258-265, 1998.

PAL, P.; SAMII, A.; CALNE, D. Manganese Neurotoxicity: A review of clinical features, imaging and pathology. NeuroToxicology, v.20, n.2-3, p. 227-238,1999.

PEÑA, C., CARTER, D., AYALA-FIERRO, F. Toxicologia Ambiental: Evaluación de Riesgos y Restauración Ambiental. Southwest Hazardous Waste Program. College of Pharmacy. University of Arizona.2001. Disponível em: Http://superfund.pharmacy.arizona.edu/toxamb. Acesso em 02/01/2002. 
PEREIRA, M.G. Epidemiologia: Teoria e Prática. Rio de Janeiro. Editora Guanabara Koogan S.A., 1995.

PIRKLE, J.; KAUFMANN, R.; BRODY, D.; HICKMAN, T.; GUNTER, E.; PASCHAL, D. Exposure of the United States population to lead, 1991-1994. Environmental Health Perspectives, vol.106, n.11, p. 745-750, 1998.

PITCHEL, J.; SAWYER, H.; CZARNOWSKA, K. Spatial and temporal distribution of metals in soils in Warsaw, Poland. Environmental Pollution, v.98, n.2, p.169$174,1997$.

PIZARRO F., OLIVARES M., GIDI V., ARAYA M. The gastrointestinal tract and acute effects of copper in drinking water and beverages. Ver. Environ Health, 14(4):231-8. 1999.

PRODAM. Limpeza Urbana da Prefeitura de São Paulo. Disponível em:www.prodam. sp. gov. br. Acesso em: 15/ 05/ 2002.

REIF, J.; TSONGAS, T.; MITCHELL, J.; KEEFE, T.; TESSARI, J.; METZGER, L.; AMLER, R. Risk factors for exposure to arsenic at a hazardous waste site. Journal Expo Anal. Environ. Epidemiology, v.3, n.1, p.73-86,1993.

RIBEIRO FILHO, V.O. Tratamento e destinação final de RSS. In: ABIP. Curso de Resíduos Sólidos de Serviços de Saúde. São Paulo, 1997. p.47

RISSO, W. M. Gerenciamento de resíduos de serviços de saúde: a caracterização como instrumento básico para abordagem do problema. São Paulo, 1993. 162p. Tese (Doutorado) - Departamento de Saúde Ambiental da Faculdade de Saúde Pública da Universidade de São Paulo.

SÃO PAULO. Decreto Estadual N. 8468. Aprova o regulamento da Lei n. 997, de 31 de maio de 1976, que dispõe sobre a prevenção e o controle da poluição do meio ambiente. Diário Oficial da União. 8 de setembro de 1976.

SÃO PAULO. Portaria n. 53/SE do 1 de março de 1979. Diário Oficial da União. Publicada no dia 08 de março de 1979. 
SCHALCH, V., REZENDE, M. O processo de compostagem do lixo e sua relação com a qualidade do adubo formado. Bio., v.3, n.4, p. 44-47, 1991.

SCHUHMACHER, M.; MENESES, M.; GRANERO, S.; LLOBET, J.M.; DOMINGO, J.L. Trace element Pollution of soils collected near a Municipal Solid waste Incinerator: Human Health Risk. Bull Environ Contam Toxicol, v. 59, p. 861-67, 1997.

SERRA, V.; GROSSI, M.; PIMENTEL, V. Lixão, aterro Controlado e aterro sanitário. Dpto. De Química e Bioquímica. UNESP. Botucatu. S.P., Brasil. Disponível em: www.laser.com.br/IBB/lixo/aterro/html . Acesso em: 22/10/98. 1998.

SHALLARI, S., SCHWARTZ, C., HASKO, A., MOREL, J.L. Heavy metals in soil and plants of serpentine and industrial sites of Albania. The Science of the Total Environment, 209:133-142, 1998.

SHIMA, E.; BECCARI, A. Os perigos do lixo hospitalar. Rev. Globo Ciência, agosto, p. 66-67, 1996.

SILVANY-NETO, A.; CARVALHO, F.; TAVARES, T.; GUIMARÃES, G.; AMORIN, C.; PERES, M.; LOPES, R.; ROCHA, C.; RAÑA, M. Evolução da Intoxicação por chumbo em crianças de Santo Amaro, Bahia - 1980, 1985 e 1992. Bol. Oficina Sanitária Panamericana, v.120, n.1, p. 11-19, 1996.

SISINNO, C.; MOREIRA, J. Avaliação da contaminação e poluição ambiental na área de influência do aterro controlado do Morro do Céu, Niterói, Brasil. Cad. Saúde Públ., v. 12, n. 4, p. 515-23, 1996.

SNYDER, C.; SELLAKUMAR, A.; WATERMAN, S. An assessment of the tumorgenic properties of a Hudson County soil samole heavily contaminated with hexavalent chromium. Arch. Environmental Health, v.52, n.3, p.220-226, 1997.

SODRÉ, M.G. Meio Ambiente: Consumo e globalização. Debates SocioAmbientais, Centro de Estudos de Cultura Contemporânea- SP-Brasil. Ano 11, n. 5, p. 4-6, 1997. 
STAESSEN, J.; ROELS, H.; EMELIANOV, D.; KUZNETSOVA, T.; THIJS, L.; VANGRONSVELD, J.; FAGARD, R. Environmental exposure to cadmium, forearm bone density, and risk of fractures: prospective population study. Public Health and Environmental Exposure to Cadmium (PheeCad) Study Group. Lancet, v.3; n. 353(9159), p.1140-1144, 1999.

STERN, A.H., MUNSHI, A.A.; GOODMAN, A.K. Potential exposure levels and health effects of neighborhood exposure to a municipal incinerator bottom ash landfill. Arch. Environ. Health. v. 44, n. 1, p. 40-8, 1989.

STEINBÖRN, M.; BREEN, J. Heavy metals in soil and vegetation at Shallee Mine, Silvermines, CO. Tipperary. Biology and Environment: Proceedings of the Royal Irish Academy. v. 99B, n.1, p. 37-42, 1999.

STOEWSAND, G.; ANDERSON, J.; BACHE, C.; LISK D. Cadmium deposition and hepatic microsomal activity in mice fed Swiss chard grown on municipal incinerator refuse ash. Science Total Environment, v. 94, n.3, p.253-259, 1990.

TACK,F.; SINGH, S.; VERLOO, M. Heavy metals concentrations in consecutive saturation extracts of dredged sediment derived surface soils. Environmental Pollution, v.103, p.109-115, 1998.

TAKAYANAGUI, A.M. Trabalhadores de saúde e meio ambiente: Ação educativa do enfermeiro na conscientização para o gerenciamento de resíduos sólidos. Ribeirão Preto, 1993. 180p. Tese (Doutorado). Programa Interunidades. Escola de Enfermagem, Universidade de São Paulo/Escola de Enfermagem de Ribeirão Preto, Universidade de São Paulo.

TAKAYANAGUI, A.M. Avaliação de risco ambiental no gerenciamento de resíduos de serviços de saúde. Ribeirão Preto, Escola de Enfermagem de Ribeirão Preto/USP-S.P., 2000 (Relatório Científico de Pós-Doutoramento junto a McMaster University -MIEH-Canadá).

TASCHNER, S.P.; BOGUS, L.M.M. Mobilidade espacial da população brasileira: aspectos e tendências. Rev. Bras. Est. Pop, n.3, p.87-132, 1986. 
TOPPI L.S.; GABBRIELLI, R. Response to cadmium in higher plants. Environmental and Experimental Botany, vol. 41, p. 105-130, 1999.

TÜRKAN, I.; HENDEN, E.; CELIK, Ü.; KIVILCIM, S. Comparison of moss and bark samples as biomonitors of heavy metals in a highly industrialized area in Izmir, Turkey. Science Total Environment, v. 166, p.61-7, 1995.

URBAN, P.; LUKAS, E.; BENICKY, L.; MOSCOVICOVÁ, E. Neurological and electrophysiological examination on workers exposed to mercury vapors. NeuroToxicology, v.17, n.1, p.191-196,1996.

URBANOWICS, G.R. Medical waste autoclaves: not just a lot of hot air. Prof. Dev. Ser (Chic III). p. 4-24, 1998.

VALLE, C.E. Qualidade Ambiental. O desafio de ser competitvo protegendo o meio ambiente. São Paulo, Livraria Pioneira Editora, 1995.

VAN-LEEUWEN, F.X.R. Safe drinking water: toxicologist's approach. Food Chem. Toxicol. Suppl. v. 38, p. 51-58, 2000.

VARIAN. Analytical methods for graphite tube atomizers. Varian Australia Pty Ltd, Victória, Australia. 1988.

VAZOLLER, R.F. Microbiologia de lodos ativados. São Paulo. CETESB. Série Manuais. 1989.

VIANA, E. Resíduos alimentícios de lixo domiciliar: coleta, processamento, caraterização e avaliação da viabilidade como um ingrediente para ração de frangos de corte. São Carlos, 1999. 164 p. Tese (Doutorado) - Escola de Engenharia de São Carlos- Universidade de São Paulo.

VIAENE, M.; ROELS, H.; LEENDERS, J.; GOORF, M.; SWERTS, L.; LISON, D.; MASSCHELEIN, R. Cadmium: A possible etiological factor in peripheral polyneuropathy. NeuroToxicology, v. 20, n.1, p.7-16,1999.

VIARTI P. Água escassa. Revista Revide, n. 11, p. 13-16, 1999. 
VOEGBORLO, R.B., EL-METHNANI, A.M., ABEDIN, M.Z. Mercury, cadmium and lead content of canned tuna fish. Food Chemistry, v.67, p. 341-345,1999.

VRIJHEID, M. Health effects of residence near hazardous waste landfill sites: a review of epidemiologic literature. Environmental Health perspectives., v.108, suppl. 1, p. 101-112, 2000.

WAKEFIELDS, S.; ELLIOT, S.J. Environment risk perception and well-being: effects of the landfill siting process in two southern Ontario Communities. Social Science and Medicine. v. 50, p. 1139-1154, 2000.

WASSERMAN, D. A decade of change in clinical waste treatment and disposal in Scotland. Health State. v. 53, n. 10, p. 6-12, 1999.

WEIR, E. Hospitals and the environment. JAMC. v. 166, n. 3, p. 354.

WEISS, B. Long ago and far away: Retrospective on the implications of Minamata. NeuroToxicology, v. 17, n.1, p.257-264,1996.

WHO. World Health Organization. Manganese. Environmental Health Criteria 17. International Programme on Chemical Safety. Geneva, 1981. Disponível em: http://inchem.org/documents/ehc. Acesso em 20/04/2002.

Lead: Environmental aspects. Environmental Health Criteria 85. International Programme on Chemical Safety. Geneva, 1989. Disponível em: http://inchem.org/documents/ehc. Acesso em 20/04/2002.

Cadmium: Environmental Aspects. Environmental Health Criteria 135. International Programme on Chemical Safety. Geneva, 1992. Disponível em: http://inchem.org/documents/ehc. Acesso em 20/04/2002.

Inorganic Lead. Environmental Health Criteria 165. International Programme on Chemical Safety. Geneva, 1995. Disponível em: http://inchem.org/documents/ehc. Acesso em 20/04/2002. 
Chromium. Environmental Health Criteria 61. International Programme on Chemical Safety. Geneva, 1998. Disponível em: http://inchem.org/documents/ehc. Acesso em 20/04/2002.

Copper. Environmental Health Criteria 200. International Programme on Chemical Safety. Geneva, 2001. Disponível em: http://inchem.org/documents/ehc. Acesso em 20/04/2002.

Zinc. Environmental Health Criteria 221. International Programme on Chemical Safety. Geneva, 2001. Disponível em: http://inchem.org/documents/ehc. Acesso em 20/04/2002.

YOURTEE, R. Pills, pollution and power; Japan's Soiled Past. World Paper. Disponível em: http://www.uest.gu.se/ bosse/Mercury/Culture/Events/minamata.html Acesso em 28/10/1998.

ZAR, J.H. Biostatistical Analysis. 4. ed. Prentice Hall, Upper Saddle River, New Jersey, USA. 1999. 580 p. 